
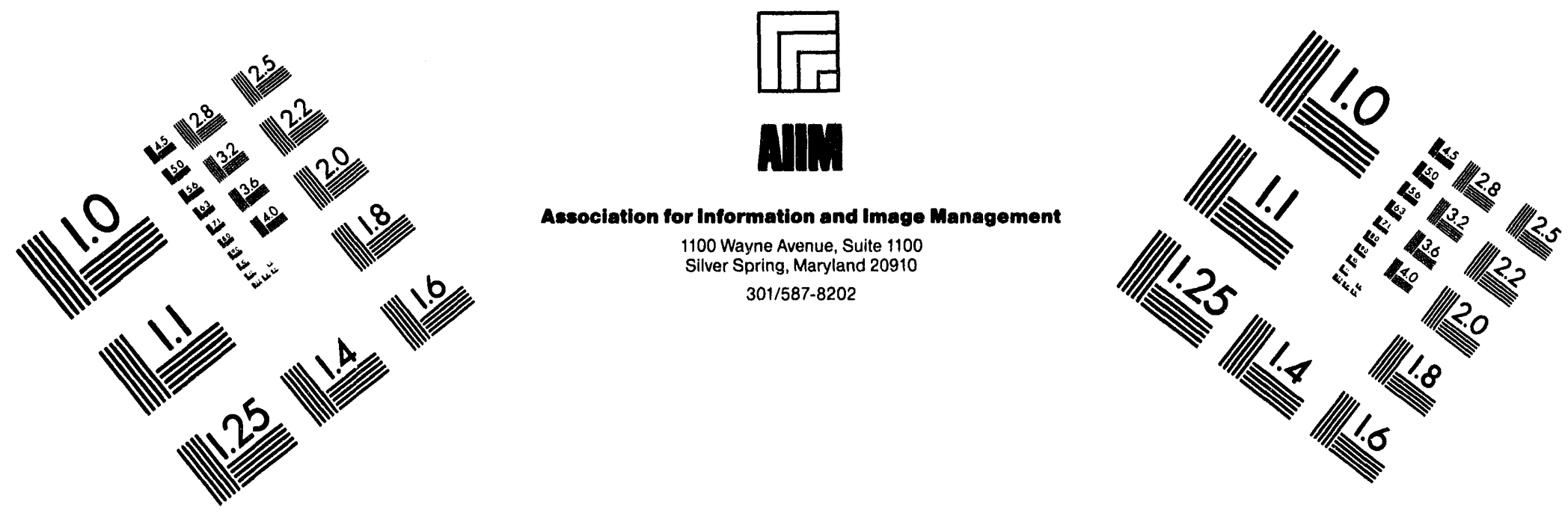

\title{
Centimeter
}

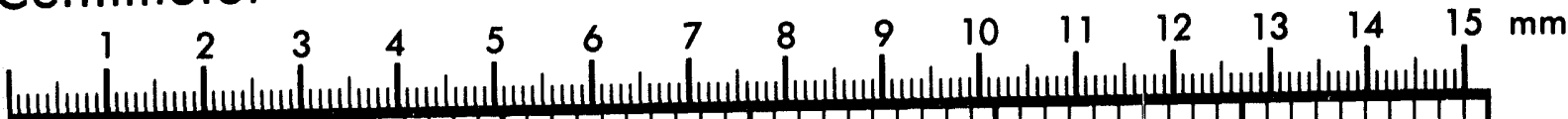
mindum Inches

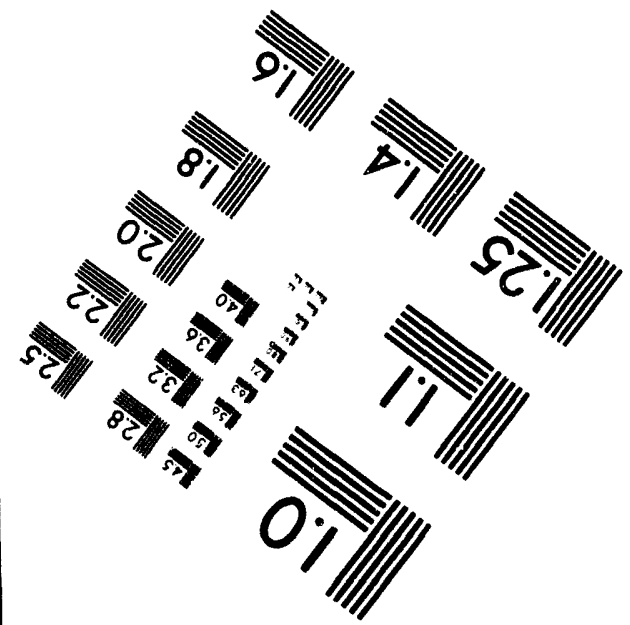

MANUFACTURED TO AIIM STANDARDS

BY APPLIED IMAGE, INC.

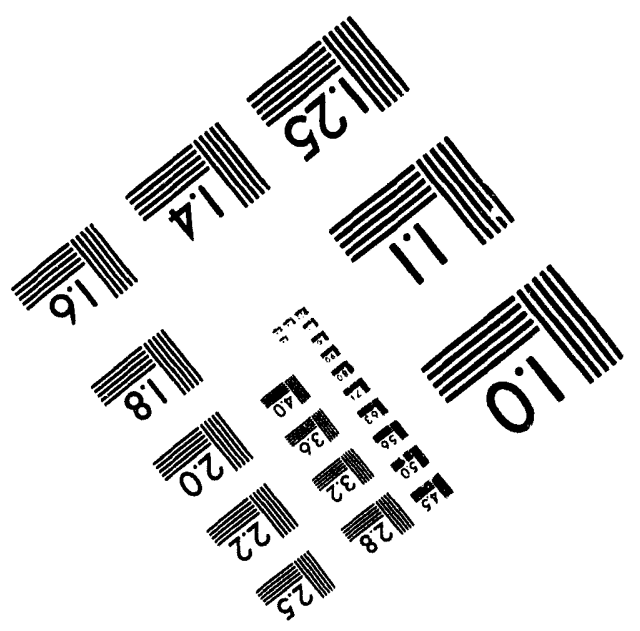



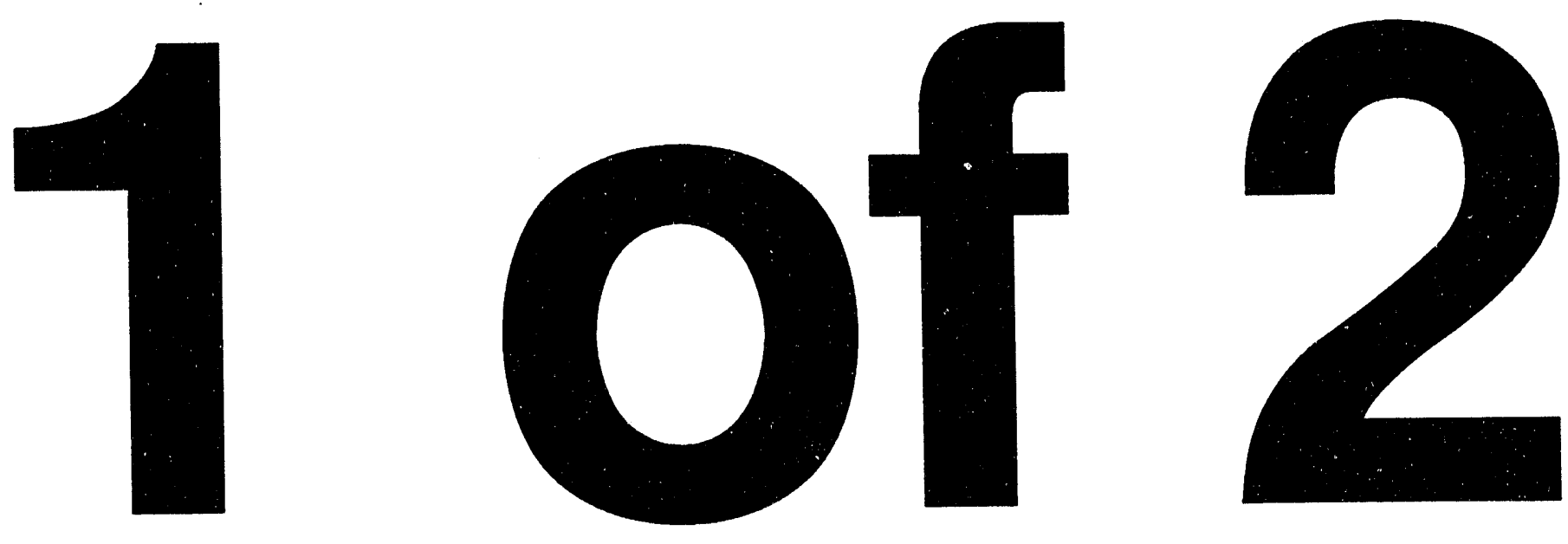


\section{High Pressure Humidification Columns: Design Equations, Algorithm, And Computer Code}

\section{Technical Report}

By

Dr. Robert M. Enick

ORISE Faculty Participant

Department of Chemical and Petroleum Engineering

University of Pittsburgh

1249 Benedum Hall

Pittsburgh, Pennsylvania. 15261

Scott M. Klara

U.S. Department of Energy

Pittsburgh Energy Technology Center

P.O. Box 10940

Pittsburgh, Pennsylvania 15236-0940

John J. Marano

Burns \& Roe Services Corporation

Pittsburgh Energy Technology Center

P.O. Box 18288

Pittsburgh, Pennsylvania $15236-8288$

July 1994 


\section{TABLE OF CONTENTS}

Page

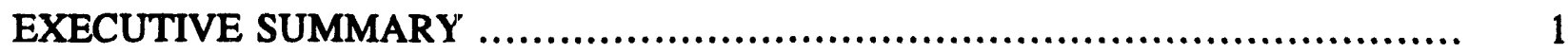

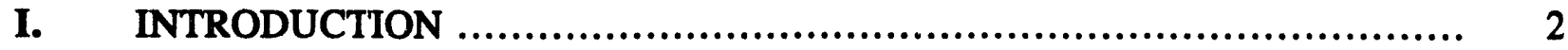

I.A. Example Application of High Pressure Humidification .................. 2

I.B. Need for a High Pressure Humidification Model ......................... 2

I.C. Previous Models for Humidification Columns ........................... 2

I.D. Need for a New Model ................................................ 5

I. HUMIDIFICATION PROCESSES ........................................ 5

II.A. Adiabatic Gas Cooling and Humidification .......................... 5

II.B. Liquid Cooling, Gas Humidification and Heating ..................... 8

II.C. Liquid Cooling, Gas Humidification and Cooling ....................... 8

III. SIMPLE MODEL OF A HUMIDIFICATION COLUMN $\ldots \ldots \ldots \ldots \ldots \ldots \ldots \ldots \ldots . . . \ldots$

IV. RIGOROUS MODEL OF A HUMIDIFICATION COLUMN .................. 18

IV.A. Adiabatic Humidification ........................................... 22

IV.B. Countercurrent Flow Columns ......................................... 23

V. DETAILS OF COMPUTER ALGORJ $\quad$ A ..................................... 29

V.A. Logic Used to Solve the Entire Jolumn ................................ 29

V.B. Solution for a Section of the Column ................................. 33

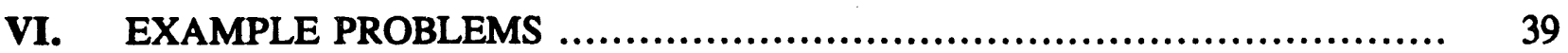




\section{TABLE OF CONTENTS}

(Continued)

Page

VI.A. Effect of Air Temperature on Column Performance .................... 43

VI.B. Effect of Energy Distribution on Column Performance ................... 44

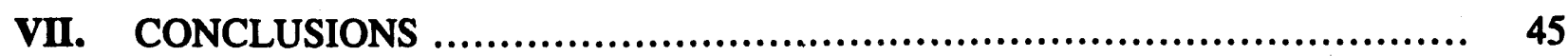

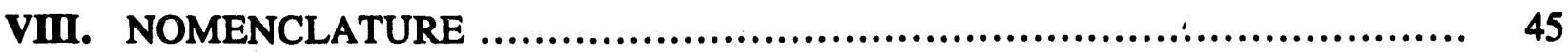

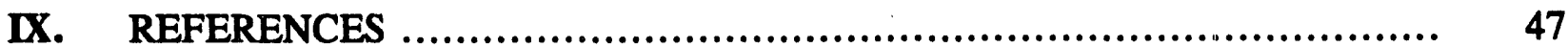

X. APPENDIX A: COMPUTER PROGRAM ................................... 48 


\section{LIST OF FIGURES}

Figure

Page

1 Simplified Gas Turbine Power Cycle ...................................... 3

2 Humidity Chart for Various Humidification Operations $\ldots \ldots \ldots \ldots \ldots \ldots \ldots \ldots \ldots \ldots .6$

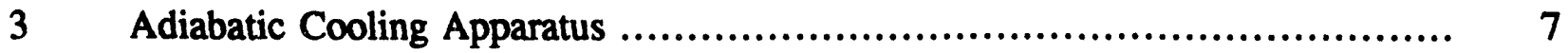

4 Profiles at Several Positions within an Adiabatic Humidification Column ........ 9

5 Liquid Cooling, Gas Humidification, and Gas Heating (or Cooling) Apparatus . 10

6 Profiles at One Position (Height) in a Countercurrent Column ................. 11

7 Column Representation Used in Mass and Energy Balance Model ............... 13

8 Differential Element for Rate-Limited Model .................................. 19

9 Discrete Section Model of a Counter Current Column ......................... 24

10 Equilibrium and Operating Lines for Humidification on the Enthalpy-Temperature Diagram ............................................. 28

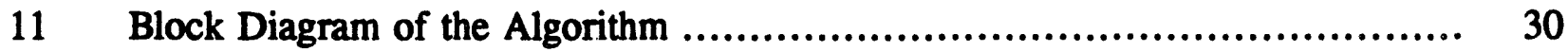

12 Humidity and Temperature Profiles for a Gas Cooling Problem ................. 40

13 Humidity and Temperature Profiles for a Gas Heating Problem ................ 41 


\section{LIST OF TABLES}

Table

Page

1 Input and Output Data for Humidification Examples

42

2 Effect of Entering Air Temperature on Column Performance

43

3 Effect of Energy Distribution of Entering Streams on Column Performance ....

44 


\section{EXECUTIVE SUMMARY}

This report describes the detailed development of a computer model used to simulate the humidification of an air stream in contact with a water stream in a countercurrent, packed tower, humidification column. The computer model is written in a FORTRAN programming language and has been developed as a user-model for the Advanced System for Process Engineering (ASPEN) simulator. This was done to utilize the powerful ASPEN flash algorithms as well as to provide ease of use when using ASPEN to model systems containing humidification columns. The model can easily be modified for stand-alone use by incorporating any standard algorithm for performing flash calculations. The model was primarily developed to analyze Humid Air Turbine (HAT) power cycles; however, it can be used for any application that involves a humidifier or saturator. The solution is based on a multiple stage model of a packed column which incorporates mass and energy balances, mass transfer and heat transfer rate expressions, the Lewis relation, and a thermodynamic equilibrium model for the air-water system.

The inlet air properties, inlet water properties and a measure of the mass transfer and heat transfer which occur in the column are the only required input parameters to the model. Several example problems are provided to illustrate the algorithm's ability to generate the temperature of the water, flow rate of the water, temperature of the air, flow rate of the air and humidity of the air as a function of height in the column. The algorithm can be used to model any highpressure air humidification column operating at pressures up to $50 \mathrm{~atm}$.

This report also provides a fundamental review of the principles involved with humidification for readers not familiar with these concepts. This discussion includes descriptions of various humidification processes, detailed derivations of the relevant expressions, and methods of incorporating these equations into a computer model for a humidification column. 


\section{INTRODUCTION.}

\section{A. Example Application of High-Pressure Humidification}

Consider a simple gas turbine power cycle as shown in Figure 1. Ambient air is compressed and then introduced into a combustion chamber along with a fuel such as natural gas or coalderived gas. The hot, high pressure gas products from the combustion chamber enter a gas turbine, where power is generated via expansion. The amount of power produced from the gas turbine is a function of the temperature and mass flowrate of the entering gas. For example, a higher temperature and/or mass flowrate of the entering gas will result in more power being generated by the gas turbine. The exhaust stream from the gas turbine is typically very hot, with temperatures exceeding $700 \mathrm{~K}$. In practice, the energy contained in this exhaust stream would be utilized to generate additional power. Several options exist for utilizing the energy contained in the gas turbine exhaust stream, such as the generation of steam which would then be expanded in a steam turbine. A relatively new option, however, is to use this energy to humidify air and generate power with a Humid Air Turbine (HAT).

Patent rights on the HAT power cycle are held by Fluor Daniel (Morton and Rao, 1989). High pressure gas humidification shows promise as a viable means of enhancing the efficiency of gas turbine power cycles using the HAT concept. In this cycle, the dry, high pressure air exiting the gas turbine compressor is contacted with high temperature water in a humidification column. This humidified air is then introduced into the gas turbine combustor. The energy required for humidification is supplied by the gas turbine exhaust stream. In comparison to the simple gas turbine cycle shown in Figure 1, the HAT cycle provides additional power by increasing the mass flowrate (added water vapor) through the gas turbine and improved efficiency by using the energy contained in the gas turbine exhaust stream for humidification.

\section{I.B. Need for a High Pressure Humidification Model}

To assess the technical and economic performance of processes that utilize humidifiers or saturators, accurately modelling the high pressure humidification column is important. This model must be capable of predicting the conditions, at pressures up to $50 \mathrm{~atm}\left(5 \mathrm{MN} / \mathrm{m}^{2}\right)$, of the air and water streams exiting the humidifier, as well as basic performance information about the column. In addition, the model must be capable of predicting temperature and humidity profiles as a function of height throughout the column.

\section{I.C. Previous Models for Humidification Columns}

Parsons, Dotson, and Bechtel (1991) modelled the high pressure humidification of air in their study of regenerative, indirect-fired, coal-fueled gas turbines. Their humidification column was a single stage adiabatic flash drum. The gas cooled and became more humid in this column. The temperature/humidity path of the air followed an adiabatic saturation curve, therefore the effluent air stream exited at the wet bulb temperature of the incoming air, if it was saturated. Although simple to model, this approach cannot enhance the humidity of a high pressure air 


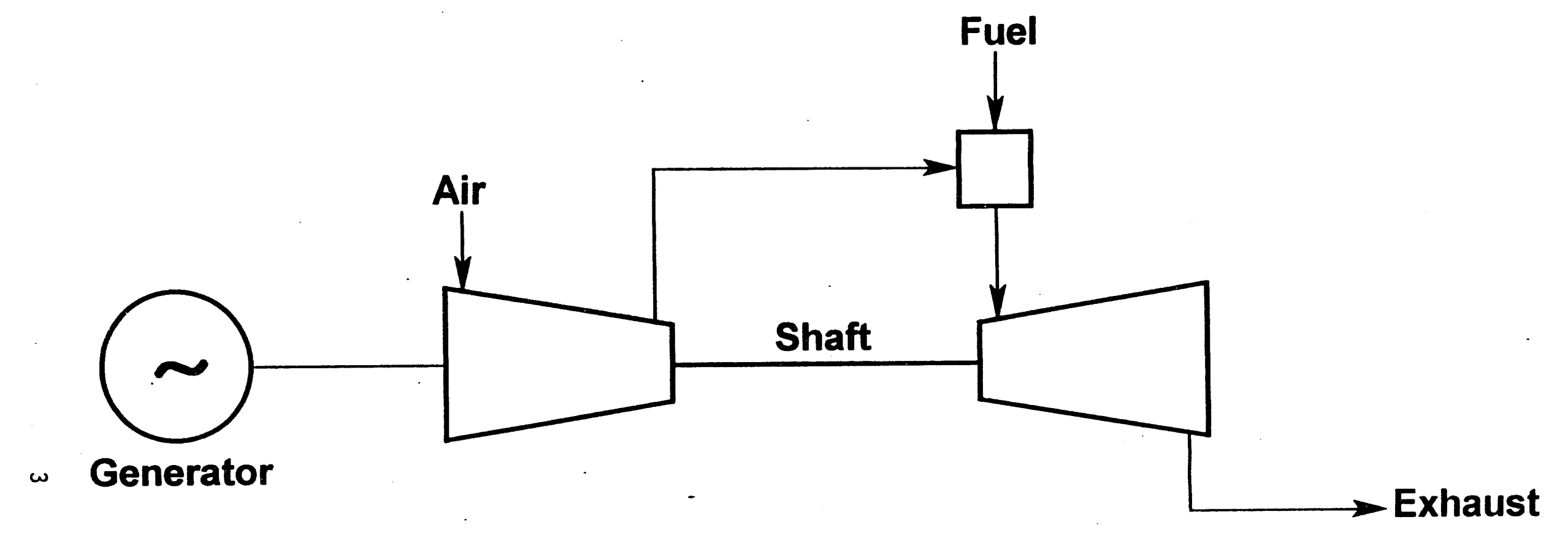

Figure 1. Simplified Gas Turbine Power Cycle 
stream to the degree possible in a countercurrent column (Morton and Rao, 1989). Furthermore, this model cannot be used for a countercurrent humidification column.

The governing expressions for the simultaneous mass and heat transfer processes occurring within a countercurrent humidification column have been presented by many authors, such as McCabe and Smith (1976), Kern (1950), Foust et al. (1980), and Mickley (1949). The nomenclature used in this report is based on that of McCabe and Smith (1976).

The model of McCabe and Smith (1976) is insufficient for our application because it only provides a solution for the effluent gas enthalpy, and not the temperature or humidity. Kern (1950) determined the properties of the exiting air stream by dividing the column into increments and solving the energy balance equations and the discrete form of the mass transfer and heat transfer equations. Foust et al. (1980) and Mickley (1949) presented a graphical solution which utilized the discrete form of the mass and heat transfer equations, the overall energy balance, the air-water saturation curve, and the Lewis Relation. Although these methods can be used to estimate the properties of the gas stream throughout an atmospheric humidification column, they would require significant modifications for high pressure countercurrent humidification columns such as that used in a HAT power cycle. For example, they would have to be presented in an efficient computer code rather than graphical form, the air-water equilibrium relationships would have to be predicted at various pressures rather than referring to a humidity chart, a technique for solving problems in which either the approach to wet bulb or the column characteristic was specified needs to be developed, modifications for columns in which equilibrium conditions are limiting rather than mass and heat transfer need to be incorporated, corrections for problems in which unrealistic approaches to wet bulb are specified need to be inclided, and methods for accounting for the change in the liquid flowrate must be made rather than assuming such changes are insignificant.

This need to develop a computer code to model the high pressure humidification column for analyzing the HAT power cycle was previously recognized by Morton and Rao (1989). In their proprietary model, based on the procedure similar to that described by Kern (1950), the column was divided into small sections. The governing mass and heat transfer equations and mass and energy balances were then solved for each column section. Rather than using the Lewis Relation, empirical correlations for mass and heat transfer coefficients were employed. The exiting air stream and entering water stream for each section were assigned as the entering air stream and exiting water stream for the section above. This procedure was continued from the bottom section to the top section of the column. The air exiting the top section corresponded to the air leaving the humidification column. This technique appears to be appropriate for the humidification model. In fact, several published predictions using this technique were matched using our technique.

Sivasubramanian and Boston (1990) also developed a proprietary mass and heat transfer-based approach that is applicable to high pressure staged separations. Their model is used in the RATEFRAC ASPEN model. 


\section{I.D. Need for a New Model}

Process simulators typically require the inclusion of a separate program for processes that are governed by simultaneous mass and heat transfer. The only two models that are apparently capable of accomplishing this task are the proprietary algorithms of (1) Morton and Rao and (2) Sivasubramanian and Boston. The goal of this report, therefore, is to develop a high pressure countercurrent humidification column model which can be used as a stand-alone model or as a FORTRAN block in an ASPEN simulation of a power plant. This model will require a minimal amount of input data from the user, including the specification of the incoming water and air stream properties and a single measure of the size of the column (the approach to wet bulb or the column characteristic). The model will incorporate each of the modifications detailed in the previous section (I.C), thereby enabling it to be used for a wide variety of humidification problems.

\section{HUMIDIFICATION PROCESSES}

Many humidification processes can be illustrated on a humidity chart to show the temperaturehumidity path of the air as it passes through the humidification column, See Figure 2. Point " $A$ " is the entering gas at $T_{1}, H_{1}$. Points $E, P, Q, R$ and $S$ represent the temperature and humidity of the air as it exits various types of humidifiers. The processes which correspond to the paths shown in Figure 2 are the following:

AE adiabatic cooling and humidification.

$\boldsymbol{A P}$ cooling and dehumidification of gas.

AQ liquid cooling, gas humidification, and heating.

$\boldsymbol{A R}$ liquid cooling, gas humidification, and cooling.

AS liquid cooling, gas humidification, and cooling, but less humidification than adiabatic cooling

Although all processes increase relative or percent humidity, not all increase absolute humidity. This report considers only the following processes, $A E, A Q$, and $A R$ because the power cycles to be analyzed are concerned with increasing air humidity. Although the $A S$ process increases humidity, it was not considered in this study because the humidity enhancement is less than that attained in adiabatic humidification.

\section{II.A. Adiabatic Gas Cooling and Humidification}

In this simple process, curve $\boldsymbol{A E}$ of Figure 2, the water stream is not required for another column or process, therefore the column's function is primarily air humidification, not water cooling. The water can be recirculated without being heated or cooled and without makeup water being added to compensate for water lost to the effluent air. The makeup liquid enters at $T_{s}$, the steady state water temperature. This aperation is illustrated in Figure 3. 


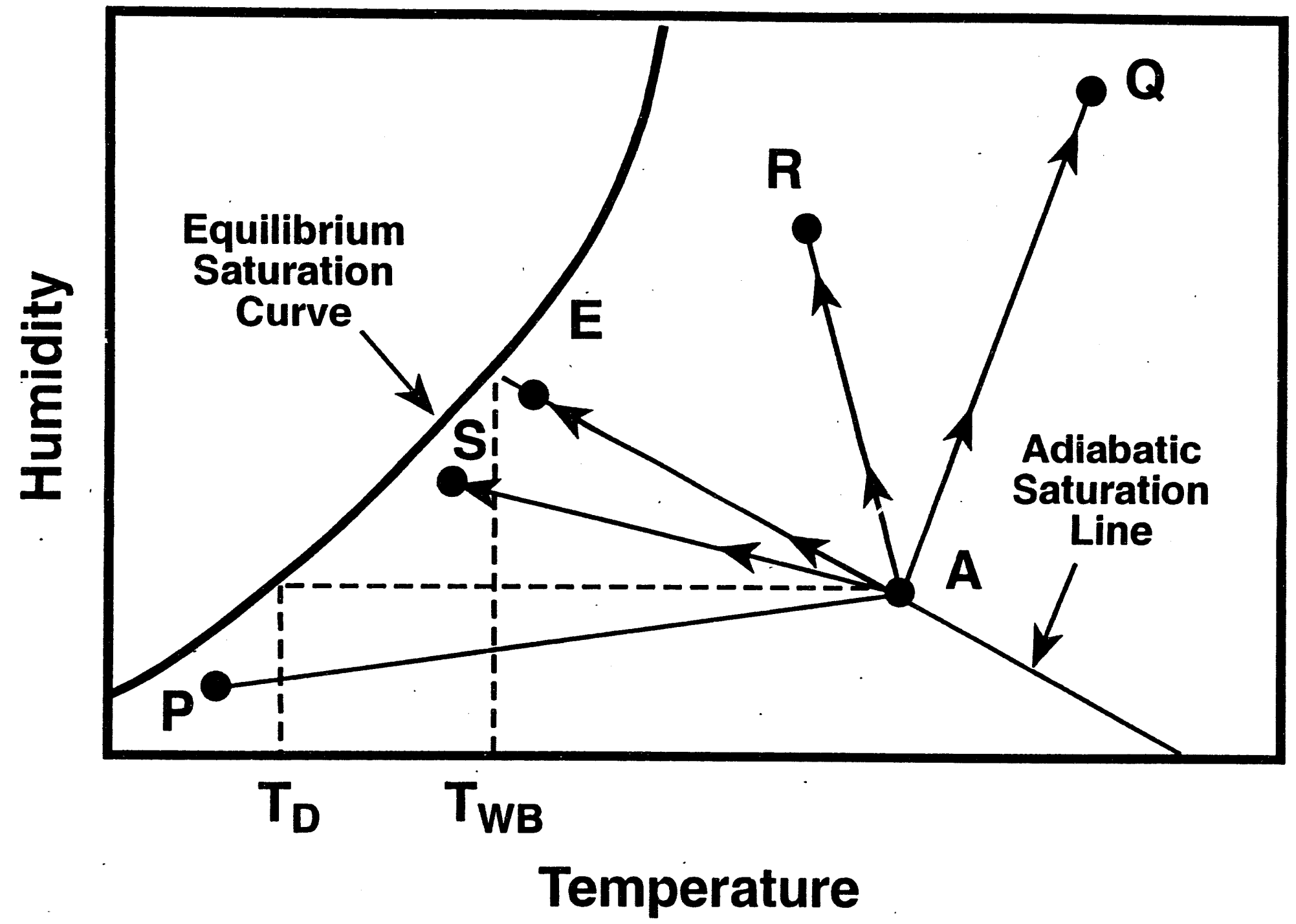

Figure 2. Humidity Chart for Various Humidification Operations 


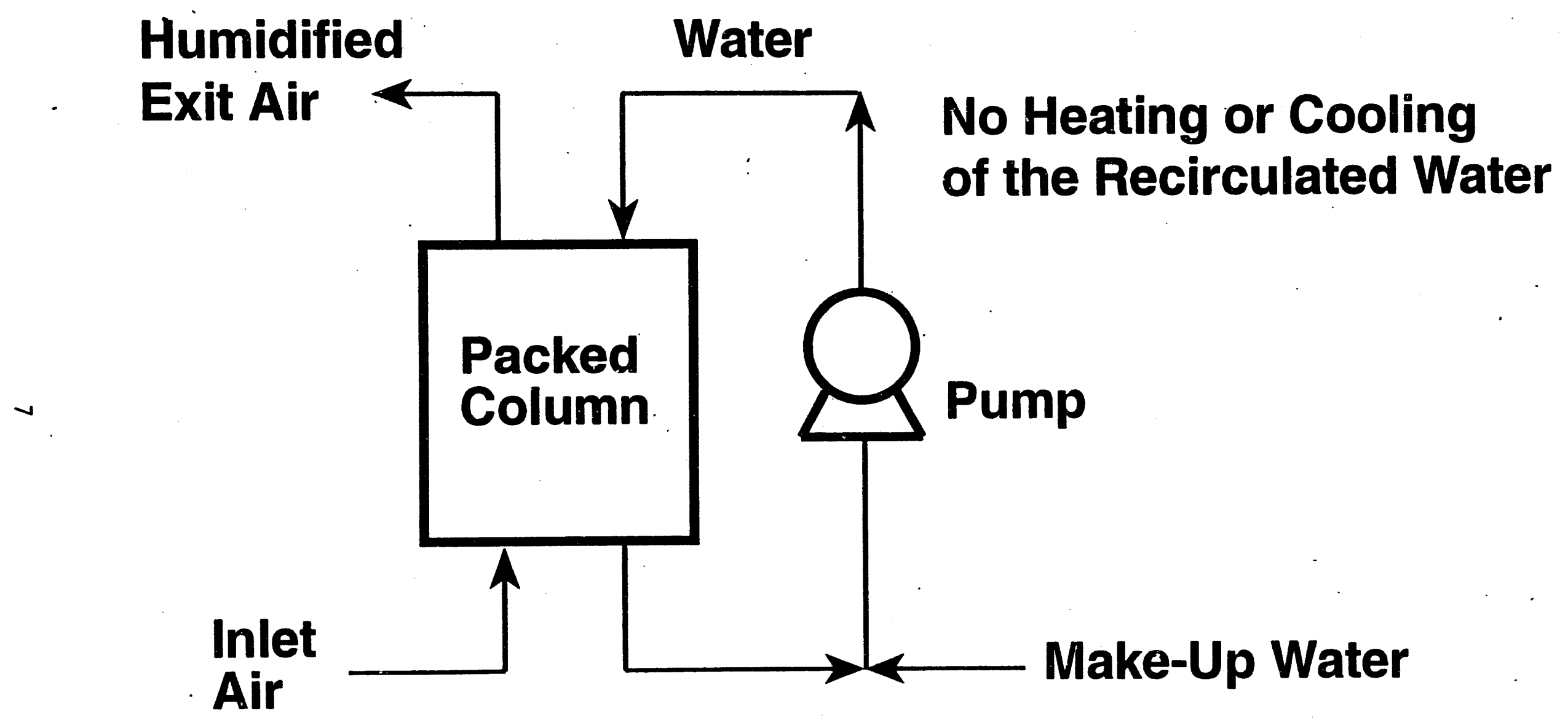

Figure 3. Adiabatic Cooling Apparatus 
If enough contact occurs between vapor and liquid, the exiting gas and liquid will be in phase equilibrium. The temperature of the liquid reaches a steady state temperature $T_{s}$, which is also the adiabatic saturation temperature. The adiabatic saturation temperature is lower than the temperature of the incoming gas (unless the entering gas is saturated, in which case $T=T_{s}$; but there would be no useful purpose for such a "humidification" column since the air is already saturated). Therefore, the air is cooled and humidified in this process.

Figure 4 shows the temperature and humidity conditions in an adiabatic humidifier. Note that there is no temperature gradient in the liquid. The modelling section of this report will show that the effluent air approaches the saturation humidity only as the column becomes infinitely tall.

\section{II.B. Liquid Cooling, Gas Humidification and Heating}

In this column, a water stream is counter-currently contacted by air. The entering, warm liquid exits the column at a lower temperature. The liquid flow rate also decreases due to evaporation, although, in some cases, this change may be $1 \%$ or less. The air exits the column at a higher temperature and humidity, as shown by line $A Q$ in Figure 2. The exiting water will be colder than the water entering the column. Therefore, the effluent water would require heating if it was to be recirculated as shown in Figure 5.

Liquid cooling, gas heating and humidification, $\boldsymbol{A Q}$, has the potential to provide the air stream with the highest humidity of all processes shown in Figure 2. In this case, the temperature of the entering liquid, $T_{x a}$, is higher than the entering gas temperature, $T_{y b}$. The temperature requirements of the process are $T_{x a}>T_{y b}>T_{s b}>T_{\omega b}$. Gas humidification and heating ( $A Q$ of Figure 2) always occur under these conditions.

\section{II.C. Liquid Cooling, Gas Humidification and Cooling}

The effluent air can exit a column at an elevated humidity and a lower temperature if: $T_{y b}>T_{x a}$ $>T_{s b}>T_{c b}$. The gas humidification and cooling occurs ( $A R$ of Figure 2) as the water cools in this column. Therefore the water would be heated if it were to be recirculated as shown in Figure 5.

Figure 6 illustrates the temperature profile at one point (with respect to column height) within a countercurrent column. Unlike the adiabatic humidification process, the gas at the interface can be much hotter than the bulk gas. Therefore the exiting gas can become saturated at $T_{y}$. Mass-transfer equations are no longer valid if this occurs since the mass transport is equilibrium limited. An overall energy balance must be satisfied with the assumption that the exiting gas is saturated. 


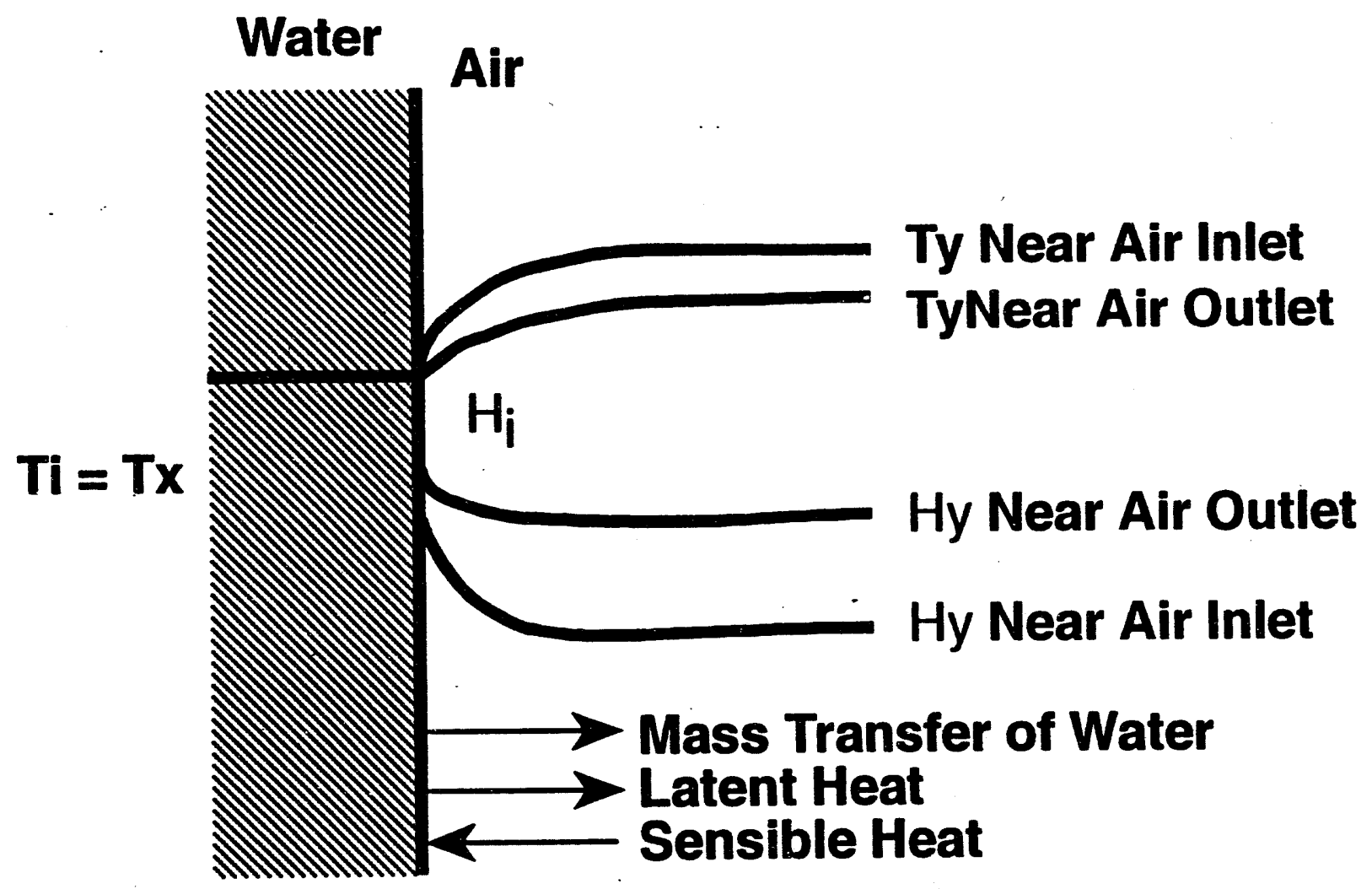

Figure 4. Profiles at Several Positions Within an Adiabatic Humidification Column 


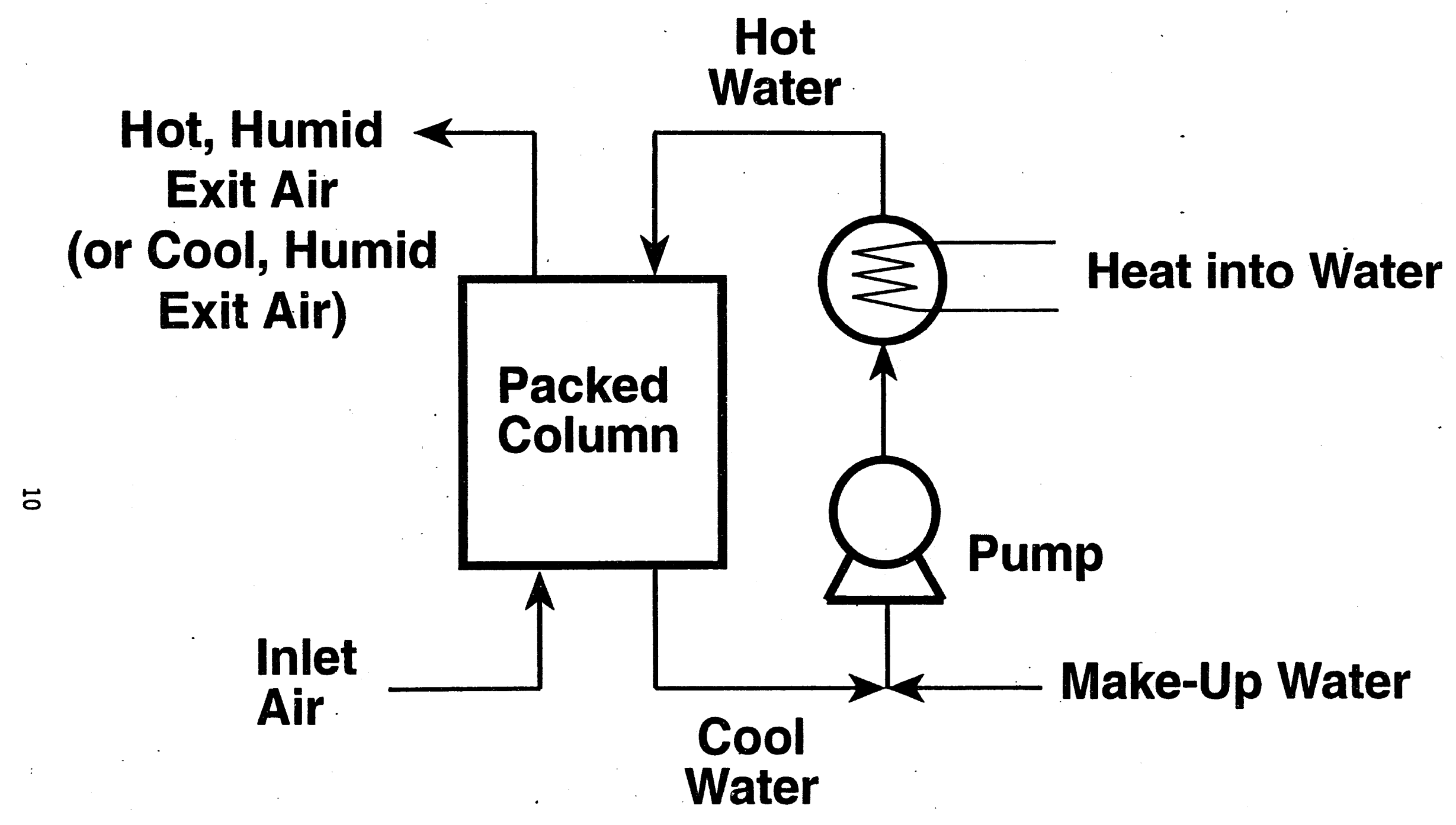

Figure 5. Liquid Cooling, Gas Humidification, and Gas Heating (or Cooling) Âpparatus 


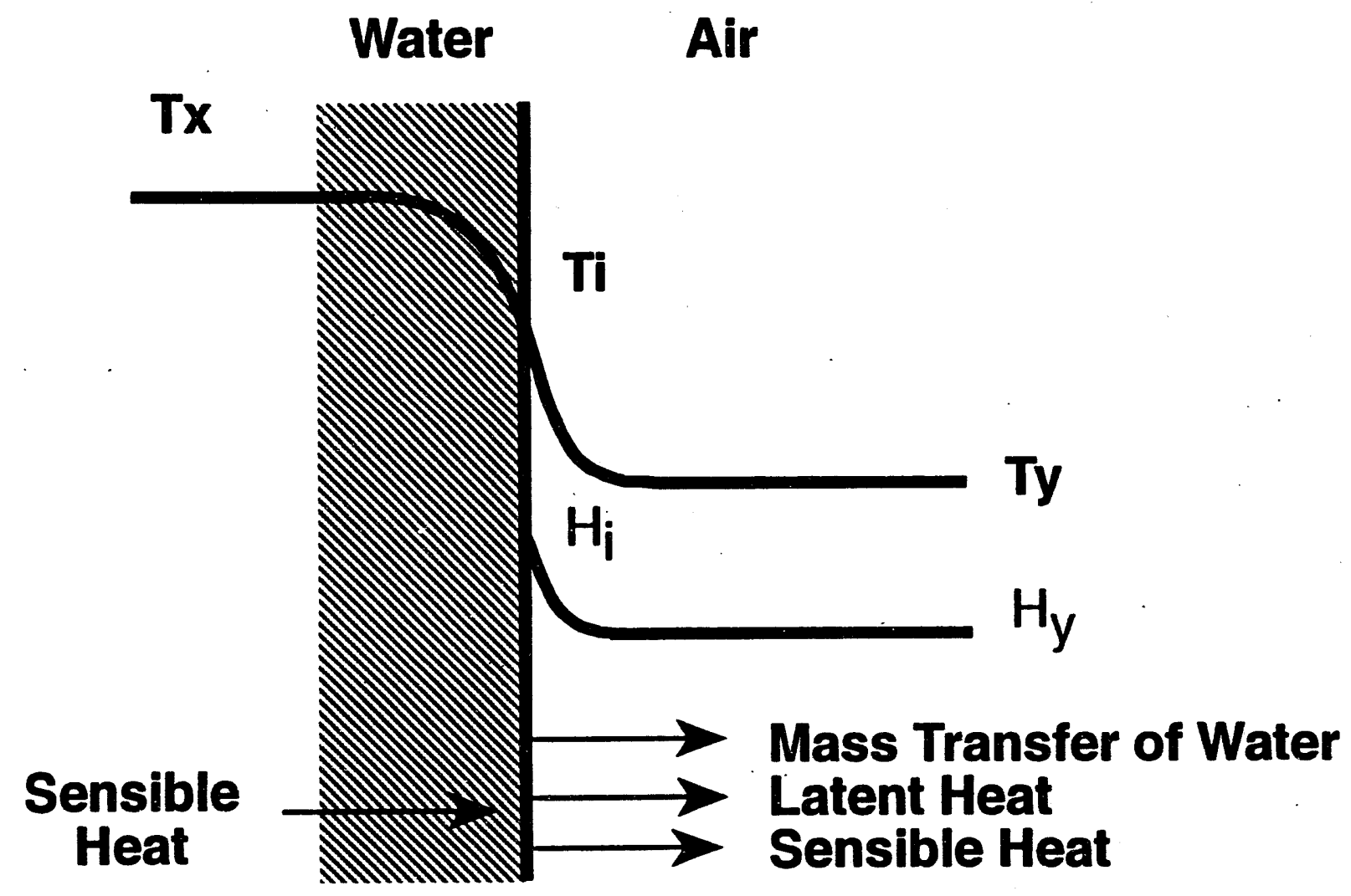

Figure 6. Profiles at One Position (Height) in a Countercurrent Column 


\section{SIMPLE MODEL OF A HUMIDIFICATION COLUMN ·}

The simplest model for determining the effluent gas temperature and humidity for any of the processes described above involves only mass and energy balances over the entire column, See Figure 7. The details regarding this model are presented below to provide the reader with a thorough understanding of humidification theory. The computer model described in this report is based on the rigorous model described in Section IV. The main features of the simple humidification model are the following:

- Tower packing, diameter and height of the tower are not considered,

- Mass and heat transfer concepts are not considered, and

- The column can operate at elevated pressures.

The tower performance must be specified in terms of both of the following.

- The approach to wet $r \quad$ the exiting water stream must be specified. In the limit the approach is $0^{\circ}$, and $\quad T_{w b}$ of the entering air.

- The exiting gas humidity or relative humidity must be specified. In the limit, the humid air exiting is completely saturated with water.

The danger associated with the use of such a simple model, which ignores the mass and heat rates of transfer between the water and air, include the following.

- The specified approach temperature to wet bulb $(A T W B), 10^{\circ} \mathrm{C}$ for example, may be well below the realistic limit, $50^{\circ} \mathrm{C}$ for example, of the system. This realistic limit can only be determined using a rigorous model of the column.

- The specified relative or percent humidity will correspond to a unique $A T W B$, which is unlikely to coincide with the specified ATWB. The appropriate value of effluent humidity that corresponds to the specified $A T W B$ can only be determined using a rigorous model.

The determination of the 6 unknowns for this problem requires the solution of six independent equations. The unknowns include: $T_{y a}, H_{a}, H_{y a}, G_{x b}, T_{x b}, H_{x b}$.

The three steps required to determine these values are described below.

Step 1. Solve for $T_{x b}$

$$
T_{x b}=T_{w} \text { Entering Air }+ \text { Approach to Wet Bulb }
$$


Inlet Water

Exiting Humid Air

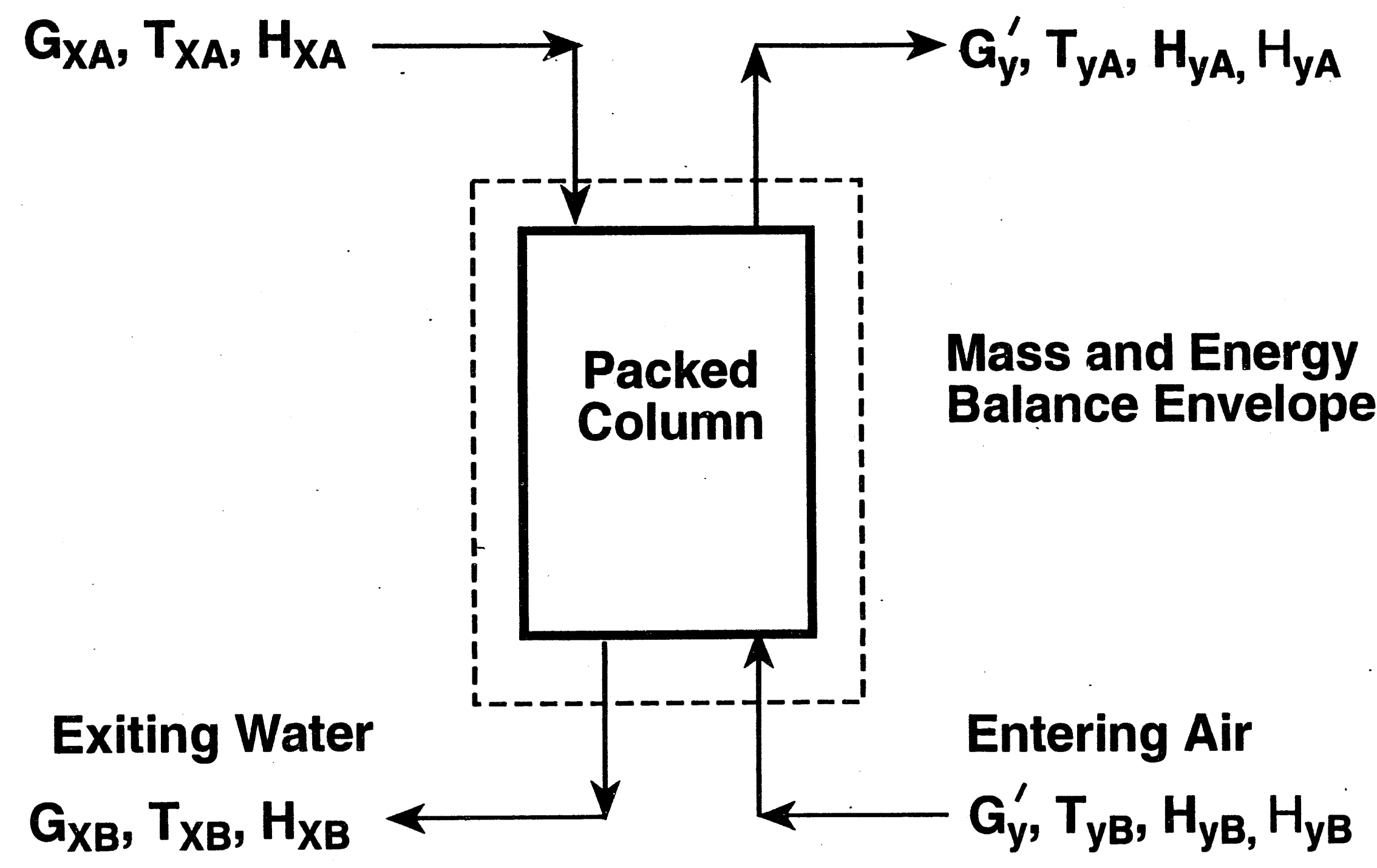

Figure 7. Column Representation Used in Mass and Energy Balance Model 
- $A T W B$ is given

- Solve for $T_{w}$ (a seventh unknown)

The equations needed to solve for the wet-bulb temperature are as follows:

$$
T_{w}=T_{y b}+\left(H_{b}-H_{w}\right)\left(\frac{k_{y}}{h_{y}}\right) M_{b} \lambda_{w}
$$

where

$$
\frac{h_{y}}{M_{b} K_{y}}=C_{s}\left[\frac{k}{\rho_{a i r} D_{v} C_{s}}\right]^{2 / 3}
$$

The procedure to solve for the wet bulb temperature is detailed below.

A. $\quad P, H_{b}, H_{y b}$, and $T_{y b}$ are all specified.

B. Guess $T_{w}$. An adequate first guess is (Dew Point $T$ of incoming gas at pressure. $P+$ the incoming gas temperature $) / 2$

C. Solve for $D_{v}$ at $T_{y b}$ and $P$ using correlations.

D. Solve for $K_{\text {airr }}, \mathbf{Q}_{\text {atr }}, C_{p \text { Hso vaporr }} C_{p \text { atr }}$ at $\mathrm{T}_{\mathrm{yb}}$ and $\mathrm{P}$ using correlations.

E. Solve

$$
\left(\frac{h_{y}}{M_{b} k_{y}}\right)=C_{s}\left[\frac{k}{\rho D_{v} C_{s}}\right]^{2 / 3}
$$

F. Determine $\lambda_{w}$ at $T_{s}$ from tabular listings or correlations.

G. Solve for $H_{w}$, the dew point composition in terms of humidity at $P, T_{w}$ H. Solve for $T_{w}$

$$
T_{w}=T_{y b}+\left(H_{b}-H_{w}\right)\left(\frac{M_{b} k_{y}}{h_{y}}\right) \lambda_{w}
$$

I. Does $T_{w}$ (determined in step $\left.H\right)=T_{w}$ (determined in step B)? If not, change 
guess on $T_{w}$ and repeat.

If the Lewis Relation is used, one iterates on $T_{w}$ as described above. If an energy balance is done, with $T_{s}$ as the reference temperature,

$$
\begin{aligned}
& G_{y}^{\prime} \boldsymbol{E}_{\text {gas vap in }}=G_{y}^{\prime} \boldsymbol{E}_{\text {gas vap out }} \boldsymbol{B}_{11 \mathrm{q} \text { in }} G_{\mathrm{x} \text { 11q in }} \\
& C_{s}\left(T-T_{s}\right)+H \lambda_{s}=H_{s} \lambda_{s}+C_{s}\left(T_{s}-T_{s}\right)+\left(\frac{G_{x}}{G_{y}^{\prime}}\right) C_{p 11 Q H_{2} O}\left(T_{s}-T_{s}\right) \text {, III-7 } \\
& C_{s}=C_{p \text { gas }}+C_{p_{2} \mathrm{HVap} H}
\end{aligned}
$$

where $H_{2}=$ saturated humidity at $T_{2}$, and $\lambda_{1}=$ latent heat at $T_{s}$.

This expression can also be written as:

$$
\frac{H-H_{s}}{T-T_{s}}=-\frac{C_{s}}{\lambda_{s}}=\frac{-\left(C_{p \text { air }}+C_{p \text { water vapor }} H\right)}{\lambda_{s}}
$$

The value of the steady-state water temperature, $T_{s}$, can be determined from this equation. The steps followed in the solution are similar to those above, except that one solves for $H_{s}$ rather than $T_{w}$ in step $H$.

$$
H_{s}=\frac{\left(C_{p \text { atx }}+C_{p \text { water vapor }} H\right)\left(T-T_{s}\right)+H \lambda_{s}}{\lambda_{s}}
$$

If the guess for $T_{s}$ is correct, the values of $T_{s}$ and $H_{s}$ will correspond to water at $T_{s}$ and saturated humidity, $H_{s}$, at the same temperature. Therefore, determine if these parameters correspond to equilibrium conditions by performing a dew point calculation at $T_{s}$ and $P$ for the air/water system. The conversion between the molar dew point composition for the equilibrium vapor into a humidity is given by,

where $\mathrm{H}_{200}$ is calculated from an equation of state. 


$$
H_{s-\text { eos }}=\frac{M_{H_{2} \mathrm{O}} Y_{\mathrm{H}_{2} \mathrm{O}}}{M_{\text {air }}\left(1-Y_{\mathrm{H}_{2} \mathrm{O}}\right)}
$$

Does $\mathrm{H}_{s-\infty}$ correspond to $\mathrm{H}_{2}$ determined from the energy balance? If so, $T_{s}, H_{s}$ is the solution. If not, guess a new $T_{s}$ until

$$
\begin{gathered}
e=\frac{H_{\text {eos }}-H_{s_{\text {mexgy }}}}{H_{s_{\text {maxgy }}}}<0.0001 \\
T_{w}=T_{y b}+\left(H_{b}-H_{w}\right) \frac{\lambda_{s}}{C_{s}}
\end{gathered}
$$

Where $H_{w}$ is the saturated gas humidity at $T_{w}$ and $\lambda_{s}$ is the latent heat at $T_{w}$. One can now solve for $T_{x b}$ using Equation III-1.

The Lewis Relation greatly simplifies the mathematics of this problem. Because the systems of interest are at pressures up to $\mathbf{5 0}$ atmospheres, the validity of the relation at these conditions must be established. The following expression

$$
\frac{h_{y}}{M_{b} K_{y}}=C_{s}\left[\frac{k}{\rho D_{v} C_{s}}\right]^{\frac{2}{3}}
$$

can be simplified to the following form for the air/water system, based on empirical results.

$$
\frac{h_{y}}{C_{s} M_{b} K_{y}}=\left[\frac{k}{\rho D_{v} C_{s}}\right]^{\frac{2}{3}}=1
$$

This relation, known as the Lewis Relation, should be valid in the pressure range of interest because at pressures between 1-50 atmospheres, $k$ is pressure independent, $\rho D_{v}$ is pressure independent, and $C_{s}$ is a weak function of pressure.

Step 2. Solve for $\boldsymbol{H}_{x b}$ 
Definition of $\boldsymbol{H}_{\boldsymbol{x} b}$ :

$$
H_{x b}=C_{l}\left(T_{x b}-T_{a}\right) \quad\left(H_{x b}, T_{x b}\right)
$$

Step 3. Now, there are four unknowns remaining

$$
G_{x b}, H_{a}, T_{y a}, H_{y a}
$$

The following four equations can be used to solve for these unknowns.

Water mass balance:

$$
G_{x a}+G_{y}^{\prime} H_{b}-G_{x b}-G_{y}^{\prime} H_{a}=0 \quad\left(G_{x b}, H_{a}\right)
$$

Total energy balance:

$$
G_{x a} H_{x a t}+G_{y}^{\prime} H_{y b}-G_{x b} H_{x b}-G_{y}^{\prime} H_{x a}=0 \quad\left(G_{x b}, H_{x b}, H_{y o}\right)
$$

Definition of $\boldsymbol{H}_{\mathbf{m}}$ :

$$
\left.H_{y a}=H_{a} \lambda_{0}+C_{p H 2 O}\left(T_{y a}-T_{\alpha}\right)\right)+C_{p, \text { adr }}\left(T_{y a}-T_{\alpha}\right) \quad\left(H_{y a}, H_{a}, T_{y a}\right)
$$

Saturated gas exits if $H_{a}$ from gas composition is saturated at $T_{y a}, P$. One may incorporate an "approach to saturation" in terms of percent humidity, for example:

$$
H_{a}=90 \% H_{a}^{:}
$$

The algorithm for solving these equations is provided below.
$\rightarrow$ A. Guess $G_{x b}\left(=99 \% G_{x a}\right)\left(=98 \% G_{x b} \ldots\right)$ or set $G_{x b}=G_{x a}$
$\uparrow \quad$ B. Solve for $H_{a}$, water balance
$\uparrow \quad$ C. Solve for $\boldsymbol{H}_{\mathrm{m}}$, ènergy balance
$\uparrow \quad$ D. Solve for $T_{y a}$, definition of $H_{y a}$
$\uparrow \quad$ E. Solve for $H_{a}$, saturation specification
$\uparrow \quad$ F. Does $H_{a}($ step $B)=H_{a}$ (step $\left.E\right) \rightarrow$ yes, solution reached

$\leftarrow$ no $G$. Iterate

If $G_{y b} \leq 0$, the problem cannot be solved; $G_{x a}$ must be higher or the specified outlet air humidity must be lower. 


\section{RIGOROUS MODEL OF A HUMIDIFICATION · COLUMN}

A more rigorous model of this process requires the derivation of governing equations for simultaneous mass transfer and heat transfer in a gas/liquid contact. Consider a small element of a gas warming and humidification and liquid cooling column as shown in Figure 8. Performing an energy balance on the volume of this element, $s$ (cross sectional area)* $d Z$ (change in height), yields

$$
G_{y}^{\prime} d H_{y}=d\left(G_{x} H_{x}\right) .
$$

The rate of heat transfer from liquid to interface is

$$
d\left(G_{x} H_{x}\right)=h_{x}\left(T_{x}-T_{\nu}\right) A_{h} d Z
$$

where $\quad T_{x}=$ Bulk liquid temperature,

$A_{h}=$ Heat transfer area/unit volume,

$h_{x}=$ Liquid side convective heat transfer coefficient, and

$T_{i}=$ Interfacial temperature.

The rate of heat transfer from interface to gas is

$$
G_{y}^{\prime} C_{s} d T_{y}=h_{y}\left(T_{i}-T_{y}\right) A_{h} d Z
$$

where $\quad C_{s}=$ Gas heat capacity,

$h_{y}=$ Gas-side convective heat transfer coefficient, and

$T_{y}=$ Bulk gas temperature.

The rate of mass transfer that occurs from the interface to the gas is

$$
G_{y}^{\prime} d H=k_{y} M_{b}\left(H_{i}-H\right) A_{m} d Z
$$

where

$$
\begin{aligned}
& M_{b}=\text { gas molecular weight, } \\
& H=\text { Humidity, and } \\
& A_{m}=\text { "wetted" area for mass transfer. }
\end{aligned}
$$

Because $G_{x}$ does not change much along the height of the element (this assumption will be relaxed in a later section to provide more precise results).

$$
d\left(G_{x} H_{x}\right)=G_{x} d H_{x}=G_{x} C d T_{x}
$$

This expression can be substituted into Equation IV-1 to obtain 


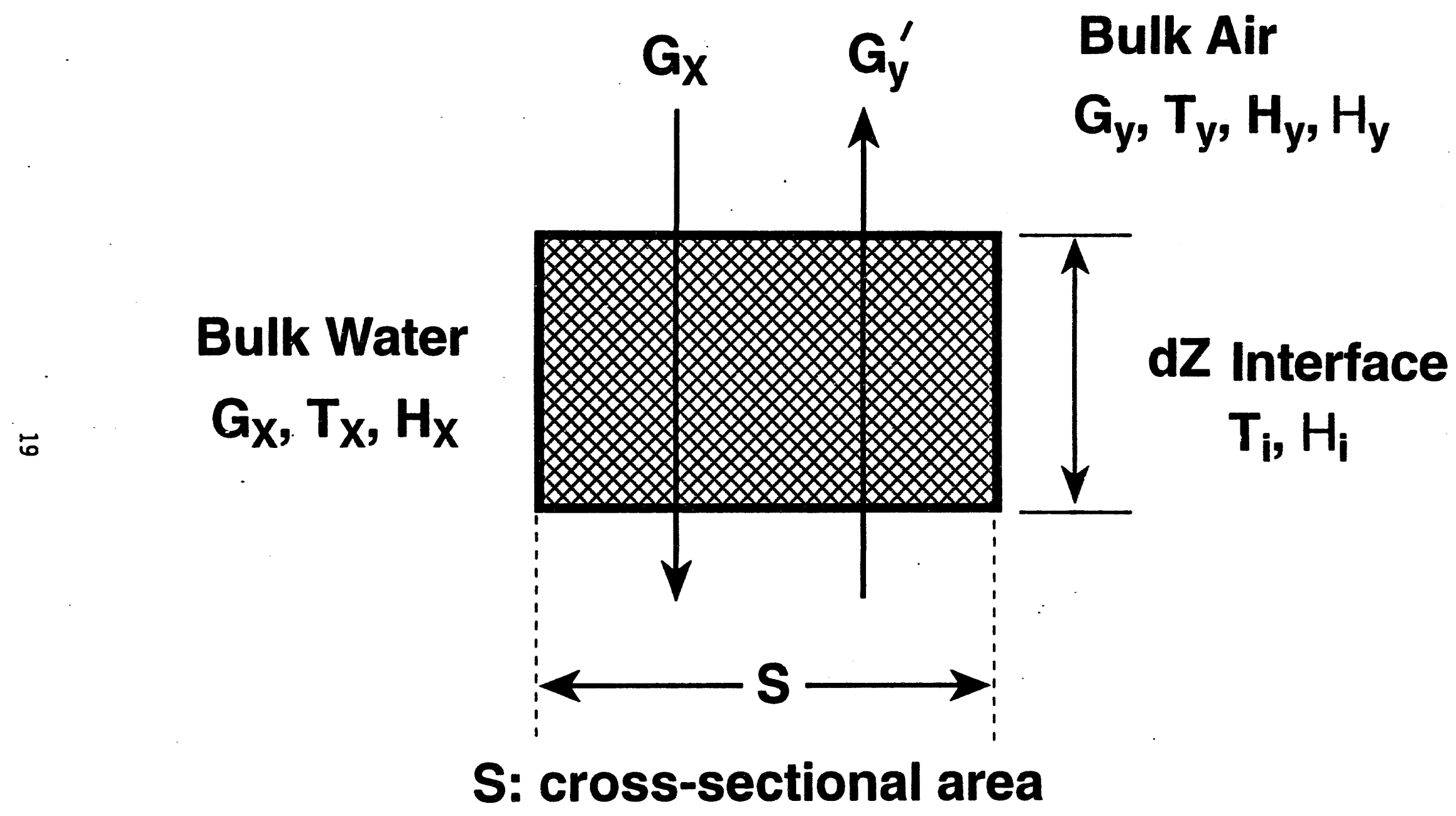

Figure 8. Differential Element for Rate-Limited Model 


$$
G_{x} C d T_{x}=h_{x}\left(T_{x}-T_{j}\right) A_{h} d Z
$$

The rate of heat transfer from the liquid to the interface is

$$
\frac{d T_{x}}{\left(T_{x}-T_{1}\right)}=\frac{h_{x} A_{h}}{G_{x} C_{1}} d z
$$

Equation IV-3 can be rearranged to yield heat transfer from interface to gas as

$$
\frac{d T_{y}}{\left(T_{1}-T_{y}\right)}=\frac{h_{y} A_{h}}{C_{s} G_{y}^{\prime}} d z
$$

and equation IV-4 can be rearranged to yield mass transfer from interface to gas.

$$
\frac{d H}{H_{1}-H}=\frac{k_{y} M_{b} A_{m}}{G_{y}^{\prime}} d z
$$

Since $G_{y} d H_{y}=d\left(G_{x} H_{x}\right)=G_{x} C d T_{x}$, Equation IV-9 can be rearianged as follows.

$$
\frac{d B_{y}}{d T_{x}}=\frac{G_{x} C_{1}}{G_{y}^{\prime}}
$$

A more accurate derivation of $d H_{y} / d T_{x}$ is presented later. Other expressions which will be used in the computer algorithm for the simulation of the humidification unit are presented below.

Combination of the mass transfer Equation IV-3 and the heat transfer interface to the Gas (Equation IV-2) yields:

$$
G_{y}^{\prime}\left(C_{s} d T_{y}+\lambda_{0} d H\right)=\left[\lambda_{0} k_{y} M_{b}\left(H_{1}-H\right) A_{m}+h_{y}\left(T_{1}-T_{y}\right) A_{h}\right] d Z
$$

where usually $A_{m}=A_{h}=A$.

Since $H_{y}=C_{s}\left(T-T_{\partial}\right)+H \lambda_{o}$ then: 


$$
d H_{y} \cong C_{s} d T_{y}+\lambda d H \quad\left(C_{s} \cong \text { constant }\right) .
$$

Making this substitution yields an expression by combining mass transfer and gas-side heat transfer.

$$
\mathrm{G}_{\mathrm{y}} \mathrm{ddH}_{\mathrm{y}}=\left[\lambda_{\mathrm{o}} K_{\mathrm{y}} M_{\mathrm{b}}\left(H_{i}-H\right) A+h_{y}\left(T_{i}-T_{y}\right) A\right] d Z
$$

If the following Lewis relation is valid for air/ $\mathrm{H}_{2} \mathrm{O}$ systems,

$$
\frac{h_{y}}{M_{b} k_{y}}=C_{s}
$$

then hy can be eliminated from Equation IV-13 and the equation can be simplified using the definition of gas enthalpy,

$$
\begin{aligned}
& H_{i}=\lambda_{d} H_{i}+C_{s}\left(T_{i}-T_{d}\right) \\
& H_{y}=\lambda_{d} H_{y}+C_{s}\left(T_{y}-T_{\partial}\right)
\end{aligned}
$$

yielding for combined mass transfer and gas-side heat:

$$
\frac{d B_{y}}{\left(H_{y}-H_{y}\right)}=\left[\frac{k_{y} M_{b} A}{G_{y}^{\prime}}\right] d z .
$$

Now, the liquid-side heat transfer and enthalpy balance yields:

$$
G_{y}^{\prime} d E_{y}-h_{x}\left(T_{x}-T_{1}\right) A d z
$$

These two expressions can be rearranged to yield:

$$
\frac{\left(B_{1}-B_{y}\right)}{\left(T_{1}-T_{y}\right)}=-\frac{h_{x}}{k_{y} M_{b}}=-\frac{h_{x} C_{g}}{h_{y}} .
$$


Now, dividing Equation IV-4 by Equation IV-17 yields

$$
\begin{gathered}
\frac{d T_{y} /\left(T_{i}-T_{y}\right)}{d E_{y} /\left(H_{y}-B_{1}\right)}=\frac{h_{y}}{k_{y} M_{b} C_{s}}=1 \text { (Lewis Relation) } \\
\frac{d T_{y}}{d E_{y}}=\frac{T_{1}-T_{y}}{B_{1}-E_{y}}
\end{gathered}
$$

\section{IV.A. Adiabatic Humidification}

For this case only, the following temperature constraints are required: $T_{x a}=T_{x b}=T_{i}=T_{x}=$ $T_{s}$. The expression for heat transfer from the interface to gas is:

$$
\frac{d T_{y}}{T_{s}-T_{y}}=\frac{H_{y a}}{C_{s} G_{s}^{\prime}} d z
$$

Using an average $C_{s}$, integrate to obtain:

$$
L N \frac{T_{y B}-T_{s}}{T_{y A}-T_{s}}=\frac{h_{y} A Z_{t}}{C_{s} G_{y}^{\prime}}\left(\frac{s}{s}\right)=\frac{h_{y} A Z_{t}}{C_{s} M^{1}} \quad, \quad V_{t}=S Z_{t} \quad, \quad M^{\prime}=S G_{y}^{\prime}
$$

The expression for rnass transfer from interface to gas can be used to obtain an equivalent expressior.

$$
L N \frac{H_{s}-H_{b}}{H_{s}-H_{a}}=\frac{K_{y} M_{b} A Z_{t}}{G_{y}^{1}}=\frac{K_{y} M_{b} A V_{t}}{M^{1}}
$$

Now, by definition, the number of transfer units is

$$
N_{t}=L N \frac{H_{s}-H_{b}}{H_{s}-H_{a}}
$$


therefore, the height of a transfer unit becomes

$$
\frac{Z_{t}}{N_{t}}=H_{t}=\frac{\frac{Z_{t}}{K_{y} M_{b} A Z_{t}}}{G_{y}^{\prime}}=\frac{G_{y}^{\prime}}{K_{y} M_{s} A}=H_{t}
$$

or

$$
N_{t}=L N \frac{T_{y b}-T_{s}}{T_{y a}-T_{s}}
$$

where,

$$
H_{t}=\frac{G_{y}^{1} C_{s}}{H_{y} A}
$$

\section{IV.B. Countercurrent Flow Columns for Gas Heating or Cooling}

Now consider a countercurrent cooling tower in which a hot dry air stream and warm water enter the column. Gas cooling or heating and humidification can occur along with liquid cooling. Figure 9 illustrates that this column will be modelled as a series of small, discrete sections where mass and heat transfer occur. The air exiting a lower section will enter the section above it as the water which exits the higher section flows into the one below.

The following set of equations represent the governing equations for each section of the column. The equations for heat transfer from the liquid to the interface are,

$$
\begin{aligned}
& d\left(G_{x} H_{x}\right)=h_{x}\left(T_{x}-T\right) A d Z \\
& G_{x} C_{Y} d T_{x}=h_{x}\left(T_{x}-T_{\nu}\right) A d Z
\end{aligned}
$$

The rate of heat transfer from interface to gas is governed by

$$
G_{y} C_{s} d T_{y}=h_{y}\left(T_{i}-T_{y}\right) A d Z \text {. }
$$

Mass transfer is governed by

$$
G_{y} d H=k_{y} M_{b}\left(H_{i}-H\right) A d Z \text {. }
$$


Top of Column

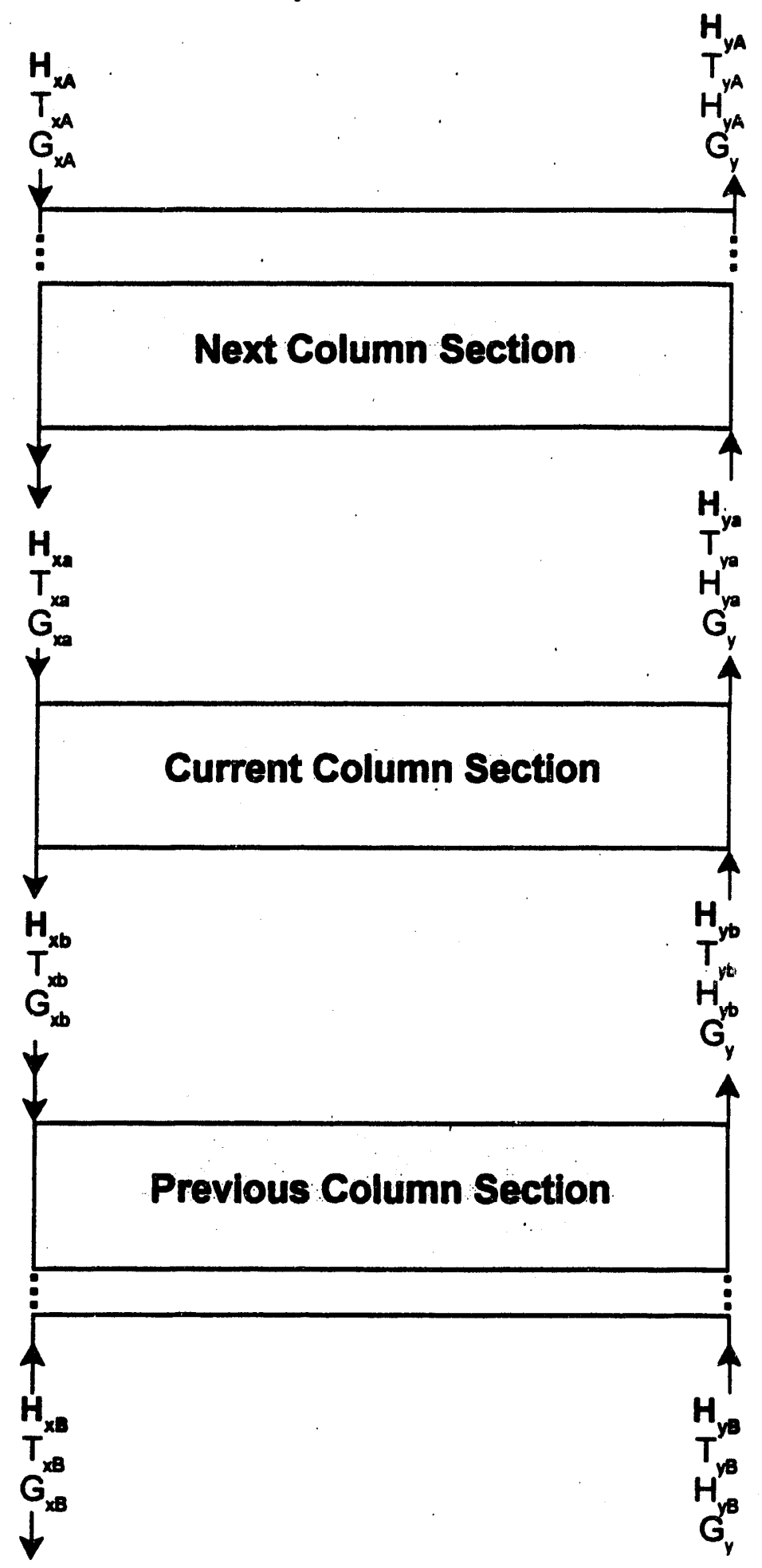

Bottom of Column

Figure 9. Discrete Section Model of a Countercurrent Column 
These expressions can be combined to yield,

$$
\begin{aligned}
& \frac{d T_{x}}{T_{x}-T_{1}}=\frac{h_{x} A}{G_{x} C_{1}} d Z, \\
& \frac{d T_{y}}{T_{1}-T_{y}}=\frac{h_{y} A}{C_{s} G_{y}^{\prime}} d Z,
\end{aligned}
$$

and

$$
\frac{d H}{H_{1}-H}=\frac{k_{y} M_{b} A}{G_{y}^{\prime}} d z
$$

The total enthalpy balance for the section is

$$
d \mathrm{H}_{\mathrm{y}}=\frac{G_{x}}{G_{y}^{\prime}} C_{1} d T_{x}
$$

The definition of gas enthalpy is

$$
d H_{y}=C_{s} d T_{y}+\lambda d H
$$

These expressions can be further simplified if the following assumptions are made.

- Air/Water System

- Lewis Relation is valid

- $A_{h}=A_{m}$

- $d G_{x} \cong 0$

Expressions for countercurrent column design can now be derived which include:

$$
\frac{d B_{y}}{B_{1}-B_{y}}=\frac{k_{y} M_{b} A}{G_{y}^{\prime}} d Z
$$




$$
\begin{gathered}
G_{y}^{\prime} d H_{y}=h_{z}\left(T_{x}-T_{1}\right) A d Z, \\
\frac{B_{1}-H_{y}}{T_{1}-T_{x}}=\frac{H_{x}}{k_{y} M_{b}}=-\frac{h_{x} C_{g}}{H_{y}}, \\
\frac{d T_{y}}{T_{1}-T_{y}}=\frac{d B_{y}}{B_{1}-B_{y}},
\end{gathered}
$$

and

$$
S z_{t}=V_{t} \text {. }
$$

IV -44

Expressions for the design of the cooling tower can also be derived as follows:

$$
\begin{aligned}
& \int_{z_{s 0}}^{z_{y_{0}}} \frac{d E_{y}}{B_{1}-B_{y}}=\frac{K_{y} M_{b} A}{G_{y}^{\prime}} \int_{0}^{Z_{t}} d z=\frac{K_{y} M_{b} A}{G_{y}^{\prime}}=\frac{K_{y} M_{b} A V_{t}}{M_{y}}, \\
& \int_{T_{x b}}^{T x a} \frac{d H_{y}}{E_{1}-E_{y}}=\frac{G_{y}^{\prime}}{G_{x} C_{1}} \frac{K_{y} M_{b} A V_{t}}{C_{1} M_{x}}=\frac{G_{y}^{\prime}}{G_{x} C_{1}} \int_{M_{s b}}^{Z_{y 0}} \frac{d B_{y}}{H_{1}-H_{y}}, \\
& \int_{z_{y b}}^{x_{x}} \frac{d B_{y}}{B_{1}-B_{y}}=\frac{K_{y} M_{b} A V_{t}}{M_{y}}=\frac{G_{x} C_{1}}{G_{y}^{\prime}} \int_{T_{x b}}^{T_{x x}} \frac{d T_{x}}{H_{i}-H_{y}} \\
& \int_{z_{y b}}^{Z_{y b}} \frac{d E_{y}}{B_{1}-B_{y}}=C_{z} \int_{T_{y b}}^{T_{y a}} \frac{d T_{y}}{H_{1}-H_{y}}+\lambda_{0} \int_{H_{b}}^{H_{a}} \frac{d H}{H_{i}-H_{y}},
\end{aligned}
$$


and

$$
\int_{Z_{y b}}^{E_{y a}} \frac{d F_{y}}{B_{1}-H_{y}}=\int_{T_{y b}}^{T_{y a}} \frac{d T_{y}}{T_{1}-T_{y}}=\int_{H_{a}}^{H_{b}} \frac{d H}{H_{1}-H_{y}} .
$$

The logic for solving these equations is presented below.

1. Assume that $G_{x b} \cong G_{x a}$.

2. Calculate $\boldsymbol{H}_{x \boldsymbol{~}}$.

3. Determine the value of the remaining unknowns, $T_{x b}, H_{a}, T_{y a}, H_{y a}$.

4. The following gas enthalpy-temperature diagram, Figure 10 , illustrates the equilibrium (interface) conditions and operating line (energy balance) for the column.

There will be two general methods for specifying countercurrent problems. Either method requires the inlet water and air properties and flow rates. The column's capability to provide mass and heat transfer must then be specified as either (1) the Approach to Wet Bulb or (2) the column characteristic. Method (1) will require the computation of the characteristic, and method (2) will require the computation of the $A T W B$. If $A T W B$ is specified, then $T_{x b}$ can be calculated by adding $A T W B$ to the wet bulb temperature of the entering air. Figure 10 can then be constructed for the specific column, thereby, yielding $\boldsymbol{H}_{\mathrm{j} \text {. }}$. If the characteristic is specified, one guesses on $A T W B$, constructs the diagram, and calculates the column characteristic as shown below.

$$
C H^{\prime}=\frac{k_{y} M_{b} a Z_{t}}{G_{x} C L}=\frac{k_{y} M_{b} a V_{t}}{M_{x} C L}=\int_{T_{x \downarrow}}^{T_{x a}} \frac{d T_{x}}{B_{1}-B_{y}}
$$

Iteration on $A T W B$, and thereby $T_{x a}$, continues until the specified column characteristic is attained.

Now, $H_{a} T_{y a}$ remain as unknowns. The following expression is valid for the air/water system,

$$
\int_{z_{y b}}^{x_{y 0}} \frac{d E_{y}}{B_{1}-E_{y}}=\int_{T_{y b}}^{T_{y e}} \frac{d T_{y}}{T_{i}-T_{y}}=\int_{T_{y b}}^{T_{y b}} \frac{d T_{y}}{T_{y}-T_{i}} .
$$

5. One can now solve for $T_{y a}$. Assuming that the change in $T_{y}$ is linear with respect to $T_{i}$ (an assumption that can be verified in step 7), one can numerically integrate the enthalpy integral and integrate on $T_{y a}$ until the temperature integral is equivalent to the enthalpy integral. This yields the exiting air temperature. 


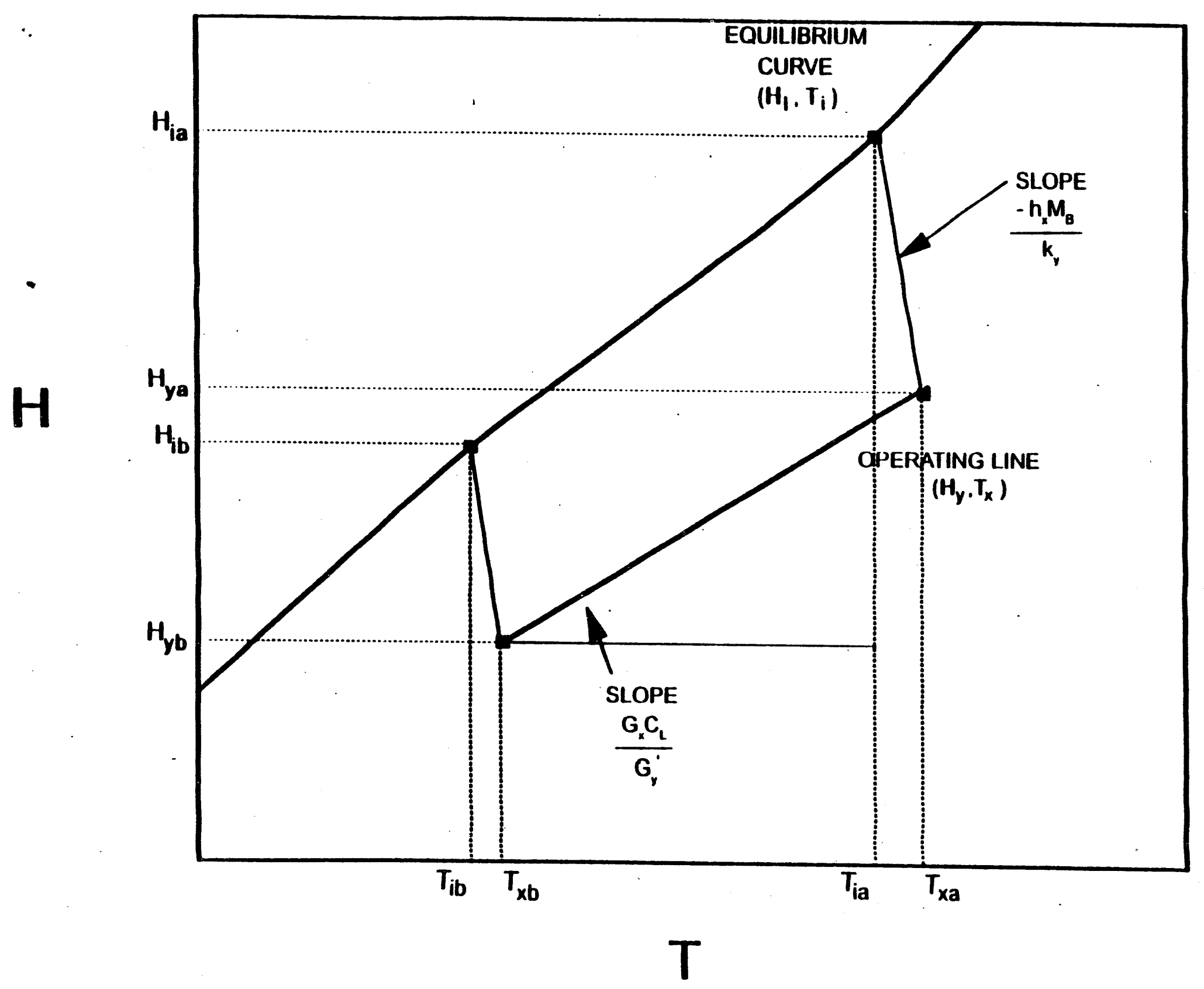

Figure 10. Equilibrium and Operating Lines for Humidification on the Enthalpy-Temperature Diagram 
6. The definition of $\boldsymbol{H}_{\mathrm{s}}$ can now be used to solve for the last unknown, the effluent air humidity.

$$
B_{y a}=C_{s}\left(T_{y a}-T_{0}\right)+H_{a} \lambda_{0}
$$

7. The following expression can be used to verify whether the size of the column; or this section of the column, was too large to justify the assumption used in Step 5.

$$
\int_{T_{y b}}^{T_{y a}} \frac{d T_{y}}{T_{1}-T_{y}}=\int_{H_{a}}^{H_{b}} \frac{d H}{H_{1}-H}
$$

If these do not agree, the size of the column must be reduced in the manner prescribed in the next section of this report.

8. Finally, one must determine if the mass transfer of water into the air was equilibrium limited.

NOTE: In step 6, $\mathbf{H}_{90}$ may be greater than the saturation humidity at the column pressure and the effluent gas temperature. If this occurs, the effluent properties must be solved by (1) guessing in effluent temperature, $T_{y a}$, (2) using an equation of state to solve for the saturated humidity $H$ and (3) determining if $T_{y e}$ and $H$ satisfy the overall mass and energy balance.

\section{DETAILS OF THE COMPUTER ALGORITHM}

A large number of equations are associated with the humidification algorithm. Specific details for the algorithm are provided in this section. A block diagram outlining the step-wise calculational sequence for the algorithm is provided in Figure 11. Figure 8 provides a schematic showing all variables associated with a typical humidification column.

\section{V.A. Logic Used to Solve the Entire Column}

\section{Specification of input data}

The following stream data must be provided to the model: $P, G_{x A}, T_{x A}, G_{y}{ }^{\prime}, T_{y B}$, and $H_{y B}$. An equation of state is used to verify that the inlet water stream is a single liquid phase and the inlet air stream is a single gas phase. Similarly, the effluent streams are checked to verify that the exiting water is a single phase liquid and that the humidified air stream is either undersaturated or saturated, but not supersaturated. If these input streams are nqt in the correct phase, the 


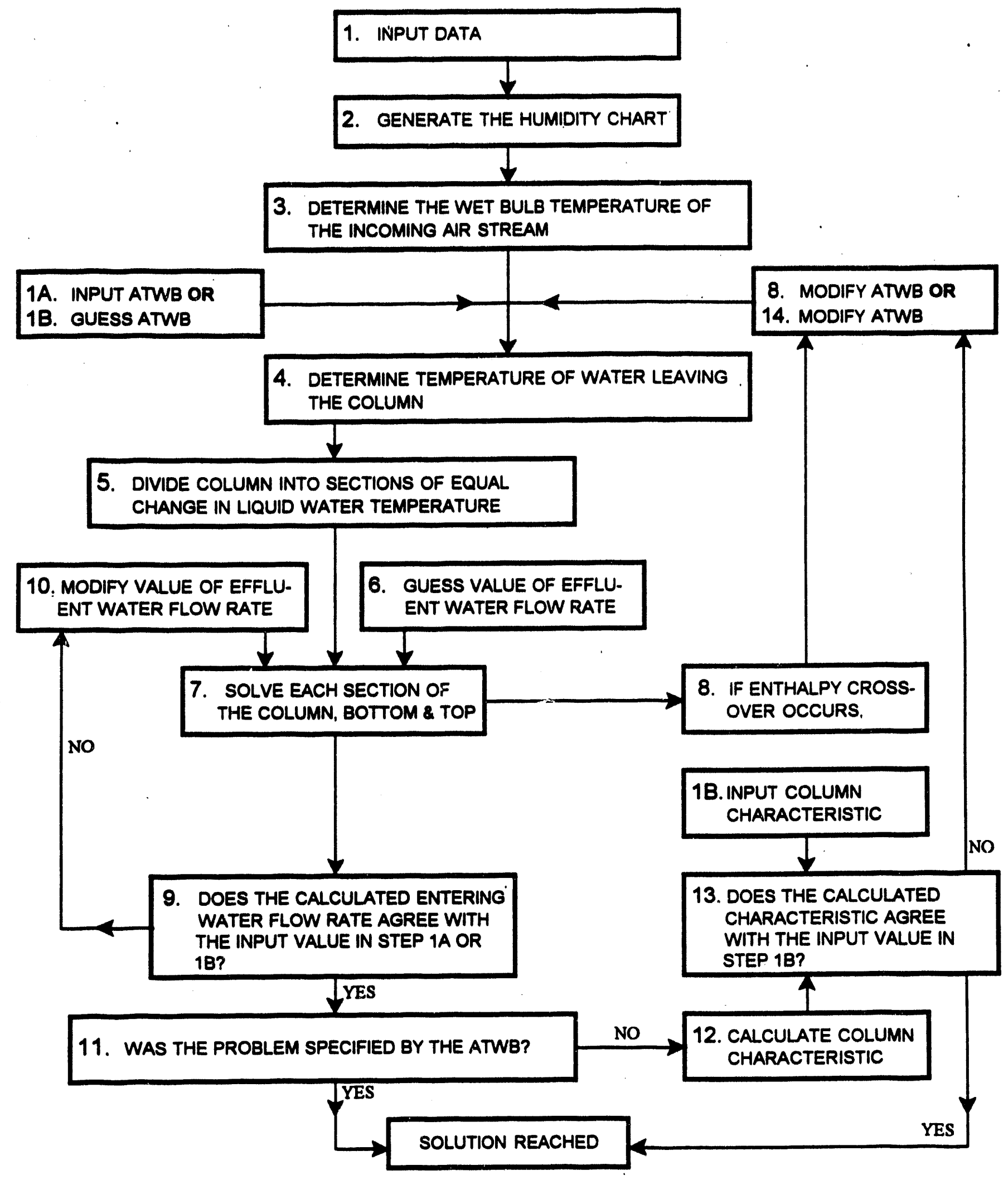

Figure 11. Block Diagram of the Algorithm 
program is stopped and an error message is printed.

The column itself must be characterized in one of two ways: the approach temperature to wet bulb (ATWB) or approach to saturation temperature must be specified (the rating mode) or a value of the column characteristic must be specified (the design mode). The ATWB for the rating mode need not be input unless the user wishes to override the default value of $5.5 \mathrm{~K}$. The column characteristic for the design mode is calculated according to the following equation.

$$
C H=h_{y} a Z /\left(\dot{G}_{y}{ }^{\prime} c_{s}\right)=k_{y} M_{b} a Z / G_{y}{ }^{\prime} \text {. }
$$

A more commonly used column characteristic (Perry and Chilton, 1973), CH', can alternatively be specified if desired.

$$
C H^{\prime}=k_{y} M_{b} a Z / G_{x}=\left(G_{y}{ }^{\prime} / G_{x}\right) C H=c_{1} \int d T_{x} /\left(H_{1}-H_{y}\right)
$$

\section{Generation of a high pressure humidity chart}

Since the humidification column is operated at high pressures and humidity charts are valid only at atmospheric pressure, the model generates a tabular humidity diagram for the specified pressure. An equation of state is used to generate this table over a wide range of temperatures most likely to be encountered. These humidity values are determined at $1 \mathrm{~K}$ temperature increments. Interpolations from the table are performed using an exponential interpolation routine (rather than linear) to ensure a better representation of the saturation curve.

\section{Determination of wet-bulb temperature of the entering air}

The wet-bulb temperature, $T_{w b}$, of the entering air (temperature $T_{y B}$, humidity $H_{y B}$ ) is determined using the following expression:

$$
T_{w b}=T_{y B}-\lambda_{T w b}\left(H_{w b}-H_{y B}\right) / c_{i}
$$

where $c_{3}$ is evaluated at the average temperature $\left(T_{w b}+T_{y B}\right) / 2$. Values of the latent heat of vaporization are interpolated from a tabular steam table listing. Saturated wet bulb humidities are determined from the table generated in Step 2.

\section{Determination of $T_{x B}$}

The temperature of the water exiting the column is determined by summing the approach to wet bulb and the wet bulb temperature of the air entering the column as follows.

$$
T_{x B}=T_{w b}+A T W B
$$

ATWB is either (a) the default value or specified by the user in the rating mode (it is increased only if it leads to an unrealistic solution), or (b) it is an adjustable parameter which is modified 
until the specified column characteristic is attained in the design mode.

\section{Division of the column into sections}

The column is divided into segments with equivalent change in liquid temperature (not equal size or height). The temperatures at the top and bottom of the entire column are $T_{x A}$ and $T_{x B}$, respectively. The temperatures at the top and bottom of each section are designated $T_{x w}$ and $T_{x b}$, respectively. Therefore, for a column divided into $\mathbf{N}$ sections,

$$
T_{x b}-T_{x b}=\left(T_{x A}-T_{x B}\right) / N
$$

\section{Guess value of $G_{x B}$}

The column must be solved from the bottom to the top. The exiting liquid flowrate, which is less than the entering water flowrate due to evaporation in the column, is initially estimated as a relatively high fraction of $\mathrm{G}_{\mathrm{xA}}$, such as $0.98 \mathrm{G}_{\mathrm{xA}}$.

\section{Solve each section of the column}

Using the procedure detailed in the next section of this report, the gas and liquid properties throughout the entire column are determined. If an enthalpy crossover occurs, Step 8 is implemented. If a crossover does not occur, the incoming water and exiting air from the last (top) section are used to determine, $G_{x \Lambda}, T_{y B}$, and $H_{y B}$, and Step 8 is skipped.

\section{Enthalpy Crossover Occurs}

For any section of the column, if the equilibrium and operating lines intersect, section-by-section computations are ceased and the ATWB is increased. If the ATWB was specified by the user, a message is printed indicating that the ATWB was unrealistic and had to be modified. The ATWB is then increased in $5.5 \mathrm{~K}$ increments until the enthalpy crossover disappears. If the column characteristic was specified, the ATWB guess is increased until the crossover disappears.

\section{Comparison of calculated $G_{x \wedge}$ with input}

$G_{x \wedge}$, as calculated in either Step 7 or Step 8, must agrce with the input value of $G_{x \wedge}$.

\section{0. $G_{x B}$ modification}

If the $G_{x A}$ 's compared in Step 9 are not equal, $G_{x B}$ is modified according to the following equation.

$$
G_{x B}^{i+1}=G_{x B}^{i}+\left(G_{x A}-G_{x A}^{i}\right)
$$




\section{Problem specified by ATWB}

If the model is being run in the rating mode and water flowrate convergence has been attained, the problem is solved. No more steps are performed.

\section{Calculate Column Characteristic}

If the water flowrate has converged and the model is being run in the design mode, the characteristic of the simulated column is calculated using either Equation V-1 or V-2.

\section{Column Characteristic Convergence}

The input column characteristic is compared with the calculated characteristic.

\section{Column Characteristic Agreement}

If agreement is attained between the actual and calculated column characteristics, the problem is solved. No more steps are performed.

\section{Column Characteristic Disagreement}

If agreement is not attained, the value of ATWB is modified using Newton's method with a fixed slope until convergence of the column characteristic is attained.

\section{V.B. Solution for a Section of the Column}

Consider a discrete section of a humidification column, such as that shown in Figure 8. The properties of the incoming air and exiting water are known. The temperature of the incoming water is known, but its flowrate is not. Due to the lack of high pressure, high temperature, air/water mass and heat transfer coefficient correlations for packed towers, the Lewis Relation (McCabe and Smith, 1976) must be used.

$$
h_{y} /\left(M_{B} k_{y} c_{\imath}\right)=N_{L e}=1
$$

This expression is commonly used for atmospheric pressure humidification problems because the actual value of $N_{L c}$ varies from 0.85 to 1.1 as temperature increases from $300 \mathrm{~K}$ to $800 \mathrm{~K}$. The effect of pressure on the Lewis number can be estimated from the following expression (McCabe and Smith, 1976).

$$
h_{y} /\left(M_{B} k_{y} c_{z}\right)=\left(N_{s c} / N_{P r}\right)^{2 / 3}=\left(k / \rho D_{v} c_{2}\right)^{2 / 3}
$$

In the 1 to 50 atm. pressure range, the thermal conductivity and heat capacity of the humid air are very weak functions of pressure, density is proportional to pressure, and the diffusion coefficient is inversely proportional to pressure. Therefore, the pressure effect on the Lewis 
number should be small, and the Lewis relation should be valid in the pressure range of interest. The use of the Lewis relation greatly simplifies the solution to the governing equations. More accurate solutions may be obtained if the actual values of the mass and heat transfer coefficients are experimentally determined and then the mass and heat transfer differential equations are solved numerically in a finite difference simulator.

The following step-wise procedure is used to determine the enthalpy, temperature and humidity of the exiting air and the flowrate of the entering water.

1. Determine the specific enthalpy of each inlet stream and the exiting water stream. Since the temperature of the water stream as it enters and exits each column section and the temperature and humidity of the incoming air stream are known, the specific enthalpy of each of these streams can be directly calculated.

2. Determine the humidity and enthalpy of saturated air as a function of temperature at the column pressure, represented by the equilibrium curve shown in Figure 10. This is accomplished by calling the table generated in Step 2 in Section V.A. of this report.

3. Establish the location of the operating line, illustrated in Figure 10. The change in liquid flowrate with respect to height for any section of a column can normally be ignored when determining this slope. A more accurate determination of the slope, which accounted for the change in liquid flowrate in each column section, can be obtained from the following energy balance.

$$
G_{y}^{\prime} d H_{y}=d\left(G_{x} H_{x}\right)
$$

The resultant slope of the operating line becomes

$$
d H_{y} / d T_{x}=c_{1}\left(G_{x} / G_{y}{ }^{\prime}\right)\left(1+\left(H_{x b}\left(G_{x a}-G_{x b}\right)\right) /\left(G_{x b}\left(H_{x b}-H_{x b}\right)\right)\right.
$$

and can be reduced to the commonly used form

$$
d H_{y} / d T_{x}=c_{1}\left(G_{x} / G_{y}{ }^{\prime}\right)
$$

when the change in the liquid flowrate is ignored. The values for the parameters in the last term of Equation V-10 are established from the previous iteration. The operating line is then established because the coordinates of the point which corresponds to the bottom of the column, $T_{x b}, \mathbf{H}_{x b}$, and the slope of the operating line are known. The temperature of the incoming water, $T_{x n}$, is known, therefore the enthalpy of the exiting air stream, $\mathbf{H}_{\mathrm{xan}}$, can be determined. Equation $\mathrm{V}-10$ yields energy balance errors of 0.01 $-0.05 \%$, while Equation $\mathrm{V}-11$ results in errors at least an order of magnitude larger.

4. Determine the temperature of the interface, where the air is saturated. The slope of the tie line connecting a point on the operating line $\left(T_{x}, H_{y}\right)$ to the conditions at the interface 
at the same position in the column $\left(T_{i}, H_{i}\right)$ is obtained by equating the heat flux on the liquid and gas sides of the interface and rearranging the result to yield

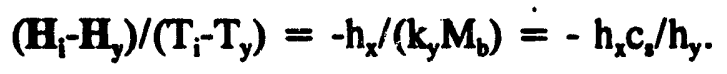

Often, specific values of $h_{x}$ and $h_{y}$ are not known. In these cases, it is assumed that $h_{x}$ is much greater than $h_{y}$, therefore the slope of the tie line is nearly vertical and

$$
\mathbf{T}_{\mathbf{x}}=\mathbf{T}_{\mathbf{i}}
$$

5. Determine the value of the driving force integral and the characteristic of this section of the column. The equality of the following integrals (valid for the air/water system when the Lewis relation is used (McCabe and Smith, 1976)) is used to complete the problem.

$$
\begin{aligned}
& \left(c_{1} G_{x} / G_{y}{ }^{\prime}\right) \int d T_{x} /\left(H_{i}-H_{y}\right)=\int d H_{y} /\left(H_{i}-H_{y}\right)= \\
& \int d T_{y} /\left(T_{y}-T_{i}\right)=\int d H_{y} /\left(H_{i}-H_{y}\right)
\end{aligned}
$$

Either of the first two integrals of Equation V-14 is then determined numerically. When the column section is small enough to assume that the enthalpy profiles of the bulk gas and interfacial gas are linear with respect to each other, an analytical integration yields the following expression.

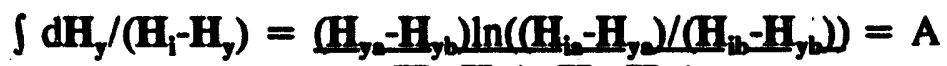

$$
\begin{aligned}
& \left(\mathbf{H}_{\mathrm{ib}}-\mathbf{H}_{\mathbf{j}}\right)-\left(\mathbf{H}_{\mathrm{mb}}-\mathbf{H}_{\mathrm{jb}}\right)
\end{aligned}
$$

The enthalpy of the saturated vapor at the interface is compared to the enthalpy of the bulk vapor at the same position in the column. If at any time the enthalpy of the bulk gas is greater than or equal to the enthalpy of the saturated vapor, the computations are stopped and the ATWB is increased. This corresponds to the specification of an unreasonably small ATWB, resulting in a crossover or intersection of the equilibrium and operating lines.

6. Determine the 'characteristic' of this section of the column. CH is a dimensionless group which is equated to both of the following products (Perry and Chilton, 1973)

$$
C H=h_{y} a Z /\left(G_{y}{ }^{\prime} c_{z}\right)=k_{y} M_{b} a Z / G_{y}{ }^{\prime} \text {. }
$$

A more commonly used column characteristic (McCabe and Smith, 1976), CH', can also be calculated

$$
\mathrm{CH}^{\prime}=\mathrm{k}_{\mathrm{y}} \mathrm{M}_{\mathrm{b}} \mathrm{aZ} / \mathrm{G}_{\mathrm{x}}=\left(\mathrm{G}_{\mathrm{y}}{ }^{\prime} / \mathrm{G}_{\mathrm{x}}\right) \mathrm{CH}=\mathrm{c}_{\mathrm{y}} \int \mathrm{dT} \mathrm{T}_{\mathrm{x}} /\left(\mathrm{H}_{\mathrm{i}}-\mathrm{H}_{\mathrm{y}}\right)
$$

7. Determine the temperature of the exiting, air. By definition, the enthalpy driving force integral has to be equal to the temperature driving force integral. Having established the 
definite enthalpy integral, $A$, the upper bound, $T_{y a}$, of the temperature integral which . satisfies Equation V-14 is determined. Analytical expressions result when the temperature of the bulk gas and the interfacial gas in this section of the column are assumed to be linear with respect to one another.

a. Gas Cooling

If the incoming water is colder than the incoming air, $T_{x a}<T_{y b}$, then

$$
\begin{aligned}
& T_{y a}=T_{x a}+\left(T_{y b}-T_{x b}\right) \exp -f B \\
& B=(1 / f) \ln \left(\left(T_{y a}-T_{x b}\right) /\left(T_{y a}-T_{x b}\right)\right. \\
& f=1-m \\
& m=\left(T_{x a}-T_{x b}\right) /\left(T_{y a}-T_{y b}\right) .
\end{aligned}
$$

b. Isothermal Gas

If the incoming water is at the same temperature as the incoming air, $T_{x a}=T_{y b}$, then

$$
T_{y_{a}}=T_{x a}
$$

c. Gas Heating

If the incoming water is warmer than the incoming air, $T_{x w}>T_{y b}$, it is determined whether a temperature crossover occurs in the stage. This corresponds to a position in the stage where $T_{x}=T_{y}=T^{*}$. This occurs whenever the incoming water is warmer than the incoming air, but the effluent water is cooler than the incoming air.

\section{c.1 Gas Heating With Crossover, $T_{x a}>T_{y b}$ and $T_{x b}<T_{y b}$.}

Determine the Crossover Temperature, $T^{*}$, as follows

$$
T^{*}=\left(T_{x b}-m T_{y b}\right) /(1-m)
$$

$T^{*}$ must satisfy the following expression to enable the improper integral obtained when integrating Equation V-14 to have a positive value.

$$
\mathrm{T}^{*}<\left(\left(\mathrm{T}_{\mathrm{ya}}+\mathrm{T}_{\mathrm{yb}}\right) / 2\right)
$$

If this criterion is not satisfied, the range of liquid cooling which occurs 
in the section is increased by specifying that a colder liquid is entering the . stage. This corresponds to an increase in the actual size of this section of the column. The expression for the temperature of the effluent air under these conditions becomes

$$
T_{y a}=T_{x a}-\left(T_{y b}-T_{x b}\right) \exp -f B .
$$

c.2 Gas Heating Without Crossover, $T_{x a}>T_{y b}$ and $T_{x b}>T_{y b}$.

Under these conditions, the expression for the temperature of the effluent air is

$$
T_{y a}=T_{x a}+\left(T_{y b}-T_{x b}\right) \exp -f B
$$

8. Determine the humidity of the exiting air. The enthalpy and temperature of the effluent air are now known, therefore, the humidity is determined by rearranging the definition of gas phase enthalpy

$$
H_{y_{a}}=c_{s}\left(T_{y_{2}}-T_{0}\right)+H_{y_{a}}
$$

to obtain the following expression

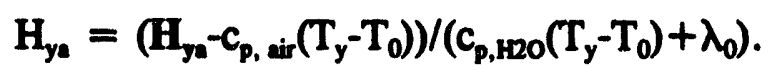

9. Verify that the integrated solution is accurate. It is then substantiated that the section of the column is small enough to justify the assumptions concerning the nature of the profiles stated in Steps 5 and 7. This is accomplished by determining the value of the humidity driving force integral and comparing it to the enthalpy integral and temperature integral, which were previously equated. Again, an analytical solution is available if the profiles of the interfacial and bulk gas humidity are assumed to be linear.

$$
\int d H_{y} /\left(H_{i}-H_{y}\right)=\frac{\left(H_{y y}-H_{y b}\right) \ln \left(\left(H_{i b}-H_{y y}\right) /\left(H_{i b}-H_{y b}\right)\right)=C}{\left(H_{i b}-H_{y_{1}}\right)-\left(H_{i b}-H_{y_{b}}\right)}=C
$$

If the integrals $C$ and $A$ agree to within 1 percent, the section of the column is considered to be small enough to enable the analytical expressions for the enthalpy, temperature, and humidity integrals to be used.

10. Determine if the air became supersaturated in this section of the column. Having established the humidity of the air, $H_{y_{a}}$, at the temperature of the effluent air, $T_{y a}$, it is necessary to determine if the humidity is less than or equal to the saturation humidity at $\mathrm{T}_{\mathbf{y a}}$. If

$$
\mathrm{H}_{\mathrm{ya}_{\mathrm{a}}} \leq \mathrm{H}_{\mathrm{Ty \mathbf {a }}}^{*}
$$


then the solution for humidity based on the assumption of mass and heat transfer limited . transport is correct, and proceed to Step 11. The solution for temperature and humidity is incorrect, however, if

$$
\mathbf{H}_{\text {ya }}>\mathbf{H}_{\text {Tya }}^{*}
$$

indicating that the transport of water into the air stream is equilibrium limited, not mass transfer limited. Under these conditions, the temperature and humidity of the effluent air stream are determined by assuming that the humidity, $\mathrm{H}_{\mathrm{ya}}$, corresponds to the saturation humidity at $\mathbf{T}_{\text {yus }}$

$$
\mathbf{H}_{\mathbf{y a}_{\mathbf{a}}}=\mathbf{H}_{\mathrm{Ty \mathbf {a }}}^{*}
$$

and that the temperature and humidity satisfy the mass and energy balances for this section of the column,

$$
\left(G_{x}+H^{*}{ }_{T y a} G_{y}^{\prime}\right) H_{x a}-G_{x} H_{x b}=G_{y}^{\prime}\left(H_{y a}-H_{y b}\right) \text {. }
$$

Then proceed to (a) guess a temperature $\mathrm{T}_{\mathrm{ya}}$ (or humidity $\mathrm{H}^{*}{ }_{\mathrm{Ty}}$ ), such as the incorrect result obtained in Steps 7 (or 8), (b) solve Equation V-32 by referring to the table of temperature versus saturated humidity referred to in step 2, (c) rearrange Equation V-33 to solve for $T_{y a}$ (or $H_{T y}^{*}$ ), and check for convergence. Having established the temperature and saturated humidity that satisfy Equations V-32 and V-33, the relative size of the section of the column is estimated with Equations V-15, V-29, or the following.

$$
\int d T_{y} /\left(T_{i}-T_{y}\right)=\frac{\left(T_{y b}-T_{y b}\right) \ln \left(\left(T_{i}-T_{y b}\right) /\left(T_{b b}-T_{y b}\right)\right)}{\left(T_{i n}-T_{y}\right)-\left(T_{y b}-T_{y b}\right)}=D
$$

These three integrals, A,C,D, typically agree to within 1 percent. Although Equations $V-15, V-29$, and V-34 are derived from Equation V-14, which is based on the mass and heat transfer expressions, they still provide an accurate result for the characteristic of this equilibrium-limited section of the column. Although the effluent air may be supersaturated due to round-off error, the degree of supersaturation is very small $(<<1 \%)$ when the column is divided into 50 sections or more.

If Equation V-31 was satisfied, Step 11 is skipped.

11. Determine the flowrate of the entering water. If the humidity of the effluent air is undersaturated, then a material balance on water is performed to determine the flowrate of the entering water stream.

$$
G_{x a}=G_{x b}+G_{y}^{\prime}\left(H_{y a}-H_{y b}\right)
$$


12. The entering water stream and the exiting air stream are then assigned as the exiting water stream and the entering air stream for the next section (above) of the column, respectively. Since the column is divided into equal increments of change in liquid temperature, the temperature of the incoming liquid stream of the next section is also known. This information enables the procedures listed in Steps 1-11 to be repeated for each section of the column, starting at the bottom and ending at the top.

\section{EXAMPLE PROBLEMS}

The input data and output results for two example air humidification problems are provided in Table 1. The first example illustrates a rating application where the exiting air is cooler and more humid than the entering air, i.e. gas cooling. The second example illustrates a design application where the specific column design parameters were used to calculate a column characteristic. This example illustrates an effluent air stream which is hotter and more humid than the incoming air stream, i.e. gas heating. Profiles of the gas temperature, gas humidity and liquid temperature throughout the column for these two examples are illustrated in Figures 12 and 13.

Note that the algorithm provides an exact material balance for the column. The error associated with the energy balance, $0.03 \%$, is representative of all simulations. This error is associated with the assumption that the operating line is linear in each section of the column, although a very slight curvature does occur. Section V.B, Step 3 details the method employed to estimate the slope of the operating line. Simply estimating the slope as $\mathrm{G}_{\mathbf{1}}\left(\mathrm{G}_{\mathbf{x}} / \mathrm{G}_{\mathbf{y}}{ }^{\prime}\right)$, which is commonly suggested, yields errors that are about an order of magnitude larger. 


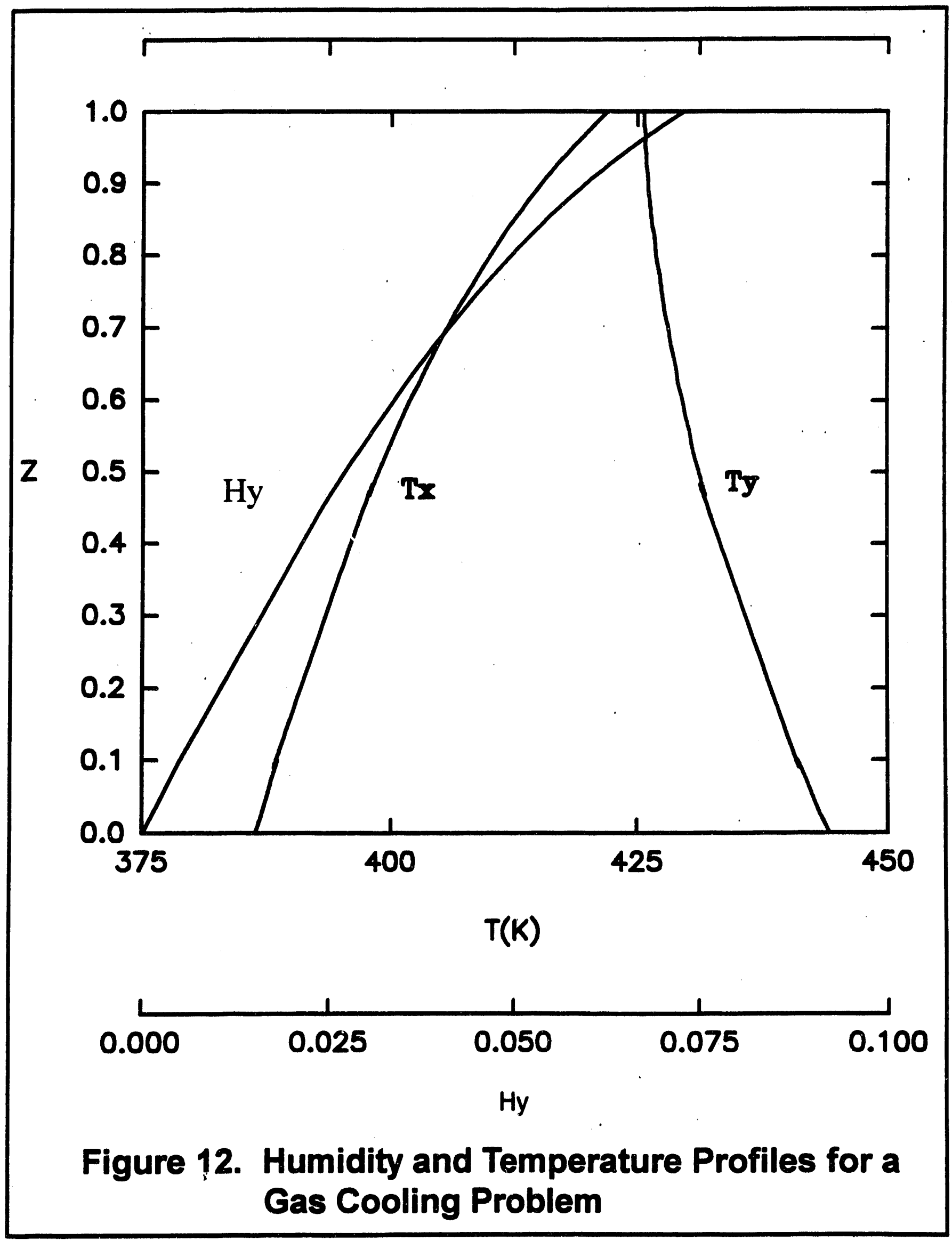




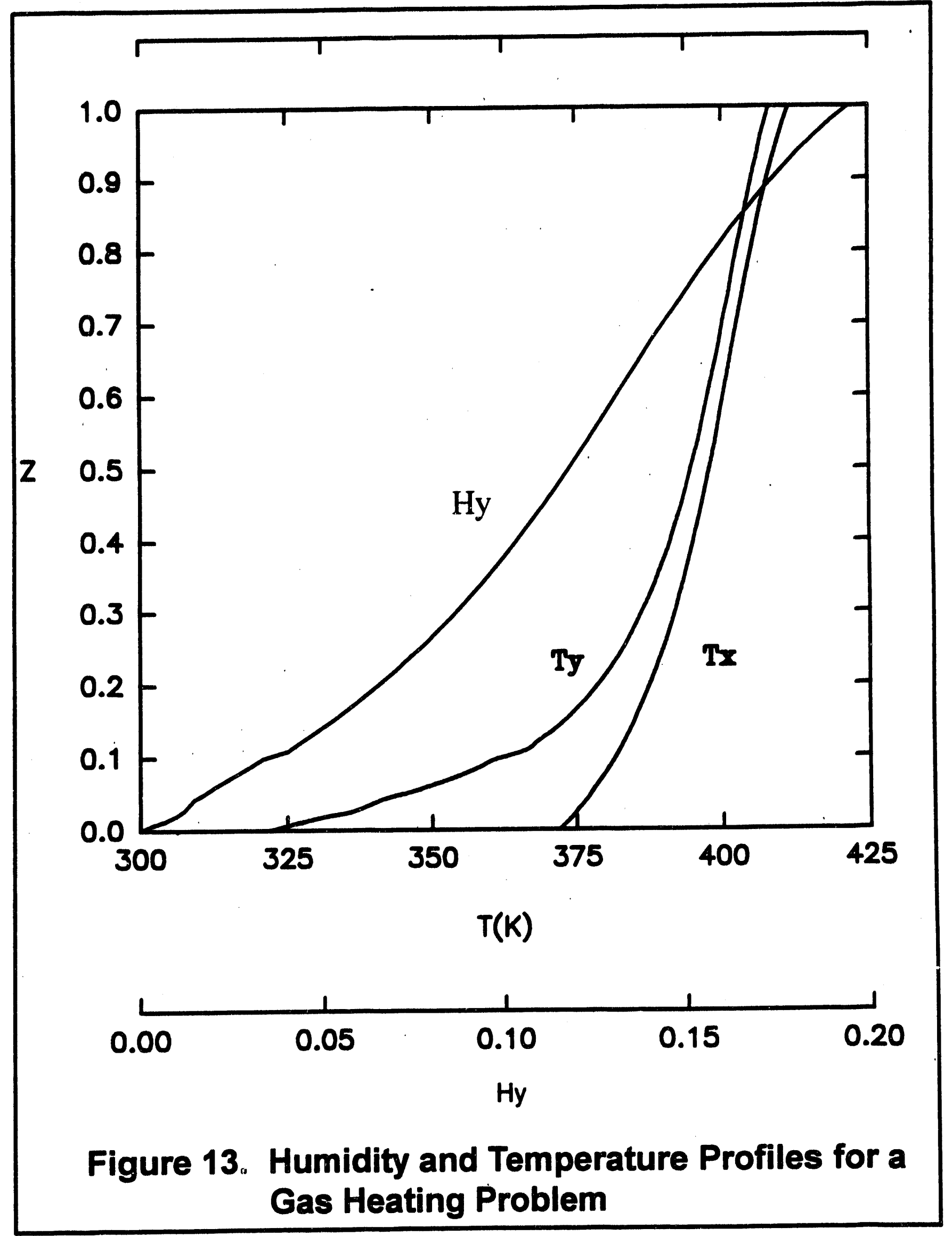


Table 1. Input and Output Data for Humidification Examples

\begin{tabular}{|c|c|c|}
\hline & $\begin{array}{l}\text { Gas Cooling } \\
\text { (See Figure 12) }\end{array}$ & $\begin{array}{c}\text { Gas Heating } \\
\text { (See Figure 13) }\end{array}$ \\
\hline \multicolumn{3}{|l|}{ Input Data } \\
\hline Column Pressure, $\mathrm{MN} / \mathrm{m}^{2}$ & 1.386 & 1.386 \\
\hline Approach to Wet Bulb, $\mathrm{K}$ & 22.2 & -- \\
\hline Column Characteristic, $\mathrm{CH}$ & -- & 9.596 \\
\hline Entering Liquid Flowrate, $\mathrm{kg} / \mathrm{hr}$ & 6803.9 & 4309.1 \\
\hline Entering Liquid Temperature, $\mathbf{K}$ & 422.0 & 411.5 \\
\hline Entering Dry Air Flowrate, $\mathrm{kg} / \mathrm{hr}$ & 6803.2 & 1308.2 \\
\hline Entering Air Temperature, $\mathrm{K}$ & 444.3 & 322.0 \\
\hline Entering Air Humidity & 0.0001 & 0.0 \\
\hline Column Sections & 50 & 50 \\
\hline \multicolumn{3}{|l|}{ Output Results } \\
\hline Approach to Wet Bulb, $\mathbf{K}$ & -- & 58.7 \\
\hline Column Characteristic, $\mathrm{CH}$ & 0.578 & -- \\
\hline Exiting Liquid Flowrate, $\mathrm{kg} / \mathrm{hr}$ & 6309.1 & 4054.7 \\
\hline Exiting Liquid Temperature, $\mathbf{K}$ & 386.3 & 372.0 \\
\hline Exiting Dry Air Flowrate, $\mathrm{kg} / \mathrm{hr}$ & 6803.2 & 1308.2 \\
\hline Exiting Air Temperature, $\mathbf{K}$ & 425.7 & 408.2 \\
\hline Exiting Air Humidity & 0.07283 & 0.19449 \\
\hline Material Balance Error, $\%$ of total & 0.0 & 0.0 \\
\hline Energy Balance Error, $\%$ of total & 0.027 & 0.032 \\
\hline
\end{tabular}




\section{VI.A. Effect of Air Temperature on Column Performance}

The effect of entering air temperature on column performance (i.e. exiting air humidity and temperature) was examined over a wide range of conditions. The column characteristic was kept constant in all runs, thereby, providing a comparison of results for the same column. The input data and results for these runs are provided in Table 2. The only input parameter that was varied from run to run was the entering air temperature to the column. As seen in Table 2, as the entering air temperature was varied from $294 \mathrm{~K}$ to $644 \mathrm{~K}$, the exiting air humidity varied from 0.320 to 0.359 , while the exiting air temperature remained relatively constant. Therefore, a doubling of the entering air temperature produced a $12 \%$ increase in exit air humidity, while having a negligible effect on the exiting air temperature. An enthalpy versus temperature diagram which illustrates the relationships of the humidity and temperature of the exiting air stream as a function of the temperature of the incoming air is presented in Figure 10.

\begin{tabular}{|c|c|c|c|c|c|c|c|c|}
\hline \multicolumn{9}{|c|}{ Input Data } \\
\hline \multicolumn{4}{|c|}{ Column Pressure, $\mathrm{MN} / \mathrm{m}^{2}$} & \multicolumn{5}{|c|}{1.386} \\
\hline \multicolumn{4}{|c|}{ Column Characteristic, $\mathrm{CH}$} & \multicolumn{5}{|c|}{2.0} \\
\hline \multicolumn{4}{|c|}{ Entering Water Flowrate, $\mathrm{kg} / \mathrm{hr}$} & \multicolumn{5}{|c|}{$6.803 * 10^{6}$} \\
\hline \multicolumn{4}{|c|}{ Entering Water Temperature, $\mathrm{K}$} & \multicolumn{5}{|c|}{460.9} \\
\hline \multicolumn{4}{|c|}{ Entering Dry Air Flowrate, $\mathrm{kg} / \mathrm{hr}$} & \multicolumn{5}{|c|}{$3.175 * 10^{6}$} \\
\hline \multicolumn{4}{|c|}{ Entering Air Humidity } & \multicolumn{5}{|c|}{0.001} \\
\hline $\begin{array}{l}\text { Entering } \\
\text { Air } \\
\text { Temp., K }\end{array}$ & 294.3 & 310.9 & 366.5 & 422.0 & 477.6 & 533.2 & 588.7 & 644.3 \\
\hline \multicolumn{9}{|c|}{ Output Data } \\
\hline $\begin{array}{l}\text { Exiting } \\
\text { Air } \\
\text { Temp., } \mathbf{K}\end{array}$ & 421.0 & 421.3 & 421.5 & 421.8 & 422.3 & 422.8 & 423.4 & 424.0 \\
\hline $\begin{array}{l}\text { Exiting } \\
\text { Air } \\
\text { Humidity }\end{array}$ & 0.320 & 0.323 & 0.326 & 0.330 & 0.336 & 0.342 & 0.351 & 0.359 \\
\hline
\end{tabular}




\section{VI.B. Effect of Energy Distribution on Column Performance}

Several simulations were performed in which the total enthalpy of the entering air stream and water stream was held constant, but the temperatures of the individual streams were varied. The input data and results for these runs are provided in Table 3. As the temperature of the water entering the column was decreased for a given run, the temperature of the air entering the column was increased such that the total enthalpy of the two streams remained constant from run to run. These calculations were performed external to the model. As the inlet water temperature and inlet air temperature were varied from $463 \mathrm{~K}$ to $444 \mathrm{~K}$ and $509 \mathrm{~K}$ to $674 \mathrm{~K}$, respectively, the exiting air humidity varied from 0.351 to 0.303 . The exiting air temperature remained relatively constant for all runs. For a fixed quantity of energy entering the column, these results clearly indicate that the hottest, most humid air was obtained when the temperature of the water entering the column was as high as possible.

\begin{tabular}{|c|c|c|c|c|c|}
\hline \multicolumn{6}{|l|}{ Input Data } \\
\hline Column Pressure, $\mathrm{MN} / \mathrm{m}^{2}$ & \multicolumn{5}{|c|}{1.386} \\
\hline Column Characteristic, $\mathbf{C H}$ & \multicolumn{5}{|c|}{2.0} \\
\hline Entering Water Flowrate, $\mathrm{kg} / \mathrm{hr}$ & \multicolumn{5}{|c|}{$6.803 * 10^{6}$} \\
\hline Entering Dry Air Flowrate, $\mathrm{kg} / \mathrm{hr}$ & \multicolumn{5}{|c|}{$3.175 * 10^{6}$} \\
\hline Entering Air Humidity & \multicolumn{5}{|c|}{0.001} \\
\hline Entering Water Temp.,K & 463.7 & 460.9 & 455.4 & 449.8 & 444.3 \\
\hline Entering Air Temp., $\mathbf{K}$ & 509.8 & 533.1 & 580.4 & 627.6 & 674.8 \\
\hline \multicolumn{6}{|l|}{ Output Data } \\
\hline Exiting Air Temp., $\mathbf{K}$ & 423.3 & 422.8 & 421.8 & 420.7 & 420.1 \\
\hline Exiting Air Humidity & 0.351 & 0.342 & 0.328 & 0.315 & 0.303 \\
\hline
\end{tabular}




\section{CONCLUSIONS}

A robust algorithm has been developed for modelling a high pressure, countercurrent air humidification column. This model can be easily implemented in the simulation of any process which includes a high pressure, humidification column. The model is easy to use since the only required input data are the properties of the entering streams and a single parameter which describes the column's mass and heat transfer capabilities. The model generates profiles of temperature and humidity and is capable of adjusting the user-specified or default ATWB if it is unrealistic. The model also determines if the humidification of air is mass transfer limited or equilibrium limited. The material balance for the column is exact, and the energy balance is typically about $0.03 \%$ due to the nonlinearity of the operating line.

From parametric studies conducted with the model, it has been shown that the exiting air humidity increases with increased entering air temperature. It has also been shown that by varying the inlet temperatures of the water and air streams to the column, while maintaining a fixed total inlet enthalpy, the temperature and humidity of the exiting air stream increased as the inlet water temperature was increased.

\section{NOMENCLATURE}

a area available for mass or heat transfer per volume packing

A definite integral defined in Equation V-15

$A$ equivalent mass and heat transfer area

$A_{h} \quad$ heat transfer area per volume packing

$A_{m} \quad$ mass transfer area per volume packing

ATWB approach to wet bulb

B constant defined in Equation V-19

C heat capacity of liquid water

$c_{p}$, air heat capacity of dry air

$c_{p, H 2 O}$ heat capacity of water vapor

$c_{a}$ heat capacity of humid air

C definite integral defined in Equation V-29

CH column characteristic

CH' column characteristic

D definite integral defined in Equation V-34

$D_{v}$ diffusivity

F constant defined in Equation V-20

$G_{x}$ mass flux of water

$G_{x}$ mass flux of water at top of section

$G_{x A}$ mass flux of water at top of column

$G_{x A}{ }^{i} \quad G_{x A}$ from previous iteration

$G_{x b}$ mass flux of water at bottom of section 
$G_{x B}$ mass flux of water at bottom of column

$G_{x B} \quad G_{x B}$ from previous iteration

$\mathbf{G}_{x B}{ }^{i+1} \quad G_{x B}$ of current iteration

$G_{y}$ ' mass flux of dry air in column

$h_{\mathrm{x}} \quad$ liquid-side heat trasssfer coefficient

$h_{y}$ gas-side heat transfer coefficient

$\mathrm{H}^{*}$ Tya saturated gas humidity at temperature $\mathrm{T}_{\mathbf{y a}}$

$\mathrm{H}_{\mathbf{i}} \quad$ humidity at the interface

$\mathbf{H}_{\mathbf{i}}$ humidity at the interface at the bottom of the section

$\mathbf{H}_{\mathrm{w}}$ humidity at the interface at the top of the section

$\mathrm{H}_{\mathrm{wb}}$ saturation humidity at the wet bulb temperature

$\mathbf{H}_{\mathrm{ya}} \quad$ bulk gas humidity at the top of the section

$\mathrm{H}_{\mathrm{yA}}$ bulk gas humidity at the top of the column

$\mathrm{H}_{\mathrm{yb}}$ bulk gas humidity at the bottom of the section

$\mathrm{H}_{\mathrm{yB}}$ bulk gas humidity at the bottom of the column

$\mathbf{H}_{1}$ enthalpy of gas at the interface

$\mathbf{H}_{\mathrm{w}}$ interfacial gas enthalpy at the top of the section

$\mathbf{H}_{\mathrm{b}}$ interfacial gas enthalpy at the bottom of the section

$\mathbf{H}_{\mathbf{x}} \quad$ liquid enthalpy

$\mathbf{H}_{\mathbf{x}}$ liquid enthalpy at the top of the section

$\mathbf{H}_{\mathbf{x}}$ liquid enthalpy at the bottom of the section

$\mathbf{H}_{\mathbf{y}}$ bulk gas enthalpy

$\mathbf{H}_{\mathbf{y}}$ bulk gas enthalpy at the top of the section

$\mathbf{H}_{\mathrm{yb}}$ bulk gas enthalpy at the bottom of the section

$\mathbf{k}$ thermal conductivity of the gas

k. gas-side mass transfer coefficient

$\mathbf{M}_{\mathbf{B}}$ molecular weight of air

m constant defined by Equation V-21

$\mathbf{N}$ number of sections in column

$\mathbf{N}_{\text {Lo }} \quad$ Lewis number

$\mathbf{N}_{\mathrm{Pr}} \quad$ Prandtl number

$\mathbf{N}_{\text {sc }} \quad$ Schmidt number

P column pressure

$T^{*} \quad$ crossover temperature

$T_{0}$ reference temperature

$T_{i} \quad$ interfacial temperature

$T_{\text {in }}$ interfacial temperature at the top of the section

$T_{i b} \quad$ interfacial temperature at the bottom of the section

$T_{w b} \quad$ wet bulb temperature

$T_{x} \quad$ liquid temperature

$T_{x x} \quad$ liquid temperature at the top of the section

$T_{x A}$ liquid temperature at the top of the column

$T_{x b} \quad$ liquid temperature at the bottom of the section

$T_{x B} \quad$ liquid temperature at the bottom of the column 
$T_{y} \quad$ bulk gas temperature

$T_{y a} \quad$ bulk gas temperature at the top of the section

$T_{y A} \quad$ bulk gas temperature at the top of the column

$T_{y b}$ bulk gas temperature at the bottom of the section

$T_{y B}$ bulk gas temperature at the bottom of the column

$\mathrm{Z}$ column height

p gas density

\section{REFERENCES}

Foust, A.S., Wenzel, L.A., Clump, C.W., Maus, L., and Anderson, L.B., Principles of Unit Operations, Second Edition, John Wiley \& Sons, New York, 1980, 428-449.

Kern, D.Q., Process Heat Transfer, McGraw Hill, New York, 1950, 563-621.

McCabe, W.L. and Smith, J.C., Unit Operations of Chemical Engineering, Third Edition, Chemical Engineering Series, McGraw Hill, New York, 1976, 744-770.

Mickley, H.S., "Design of Forced Draft Air Conditioning Equipment," Chemical Engineering Progress, Vol. 45, No. 12, Dec. 1949, 739-745.

Morton, T.R., and Rao, A.D., "Perspective for Advanced High Efficiency Cycles Using Gas Turbines, " Presentation by Fluor Daniel at the 1989 Joint $\mathrm{NO}_{\mathbf{x}} / \mathrm{SO}_{\mathbf{x}}$ Control Symposium.

Parsons, E.L., Dotson, R.A, and Bechtel, T.F., "Performance Gains Derived from Water Injection in Regenerative, Indirect-Fired, Coal-Fueled Gas Turbines," ASME paper 91-GT-233, a METC presentation at the International Gas Turbine and Aeroengine Congress and Exposition, Oriando FL, June 3-6, 1991.

Perry, R.H. and Chilton, C.H., Chemical Engineer's Handbook Edition, Chapter 12, McGraw Hill, New York, 1973.

Sivasubramanian, M. S. and Boston, J.F., "The Heat and Mass Transfer Rate-Based Approach for Modeling Multicomponent Separation Processes," presentation at the European Symposium on Computer Applications in Chemical Engineering, The Hague, The Netherlands, May 7-9, 1990. 


\section{APPENDIX A}

\section{COMPUTER CODE:}

\section{FORTRAN BLOCK FOR ASPEN SIMULATION}




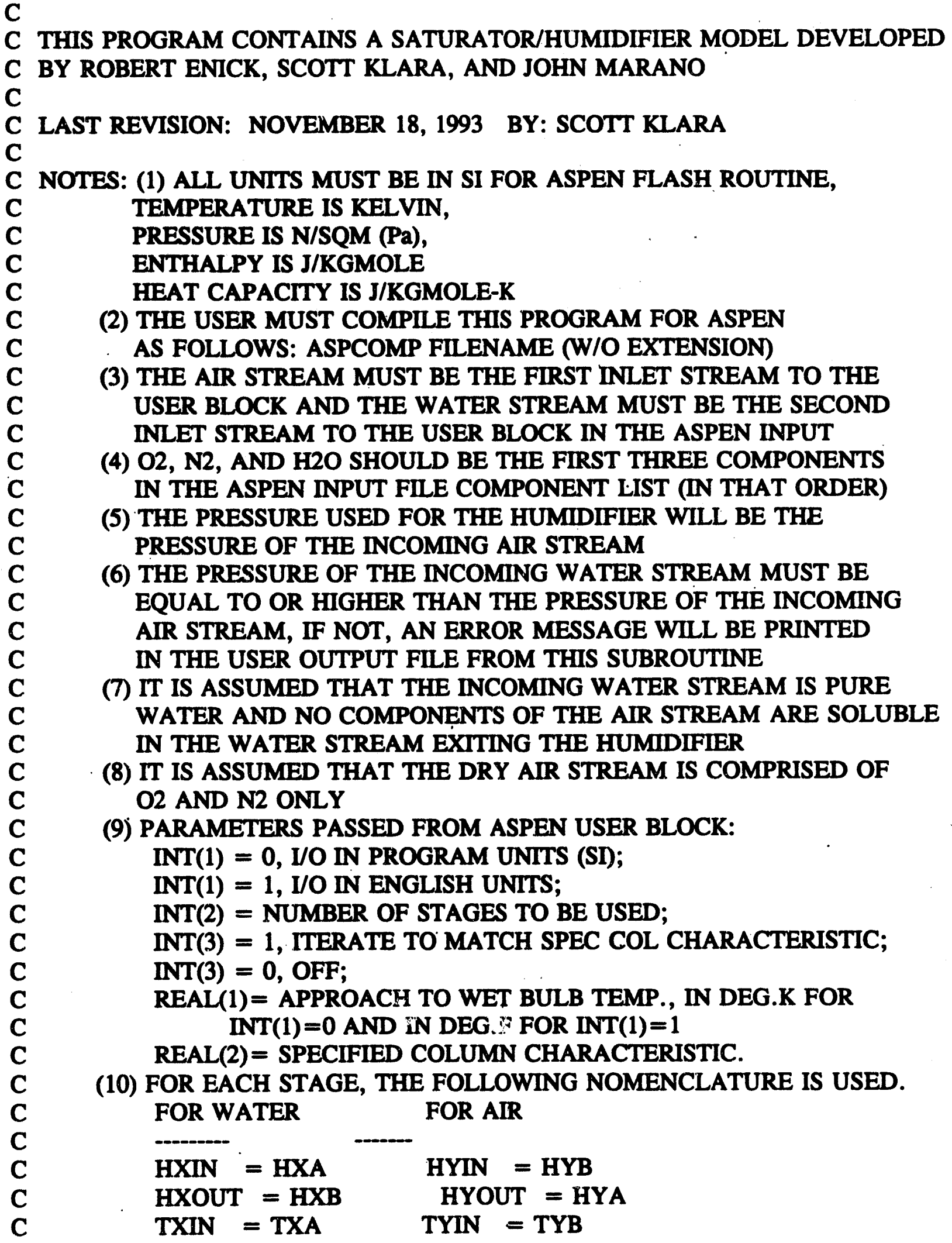




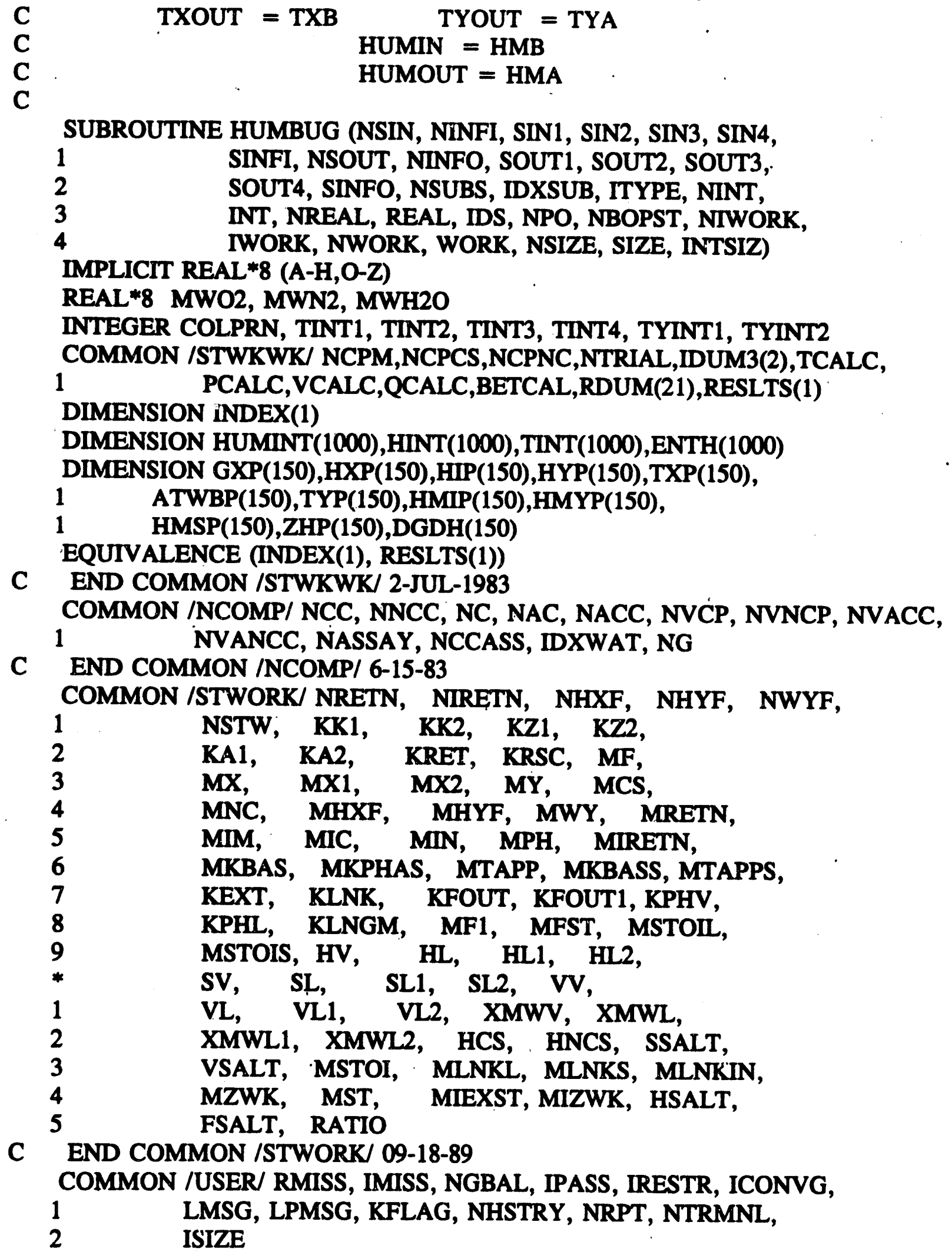

C END COMMON /STWORK/ 09-18-89

COMMON /USER/ RMISS, IMISS, NGBAL, IPASS, IRESTR, ICONVG,

LMSG, LPMSG, KFLAG, NHSTRY, NRPT, NTRMNL, ISIZE 


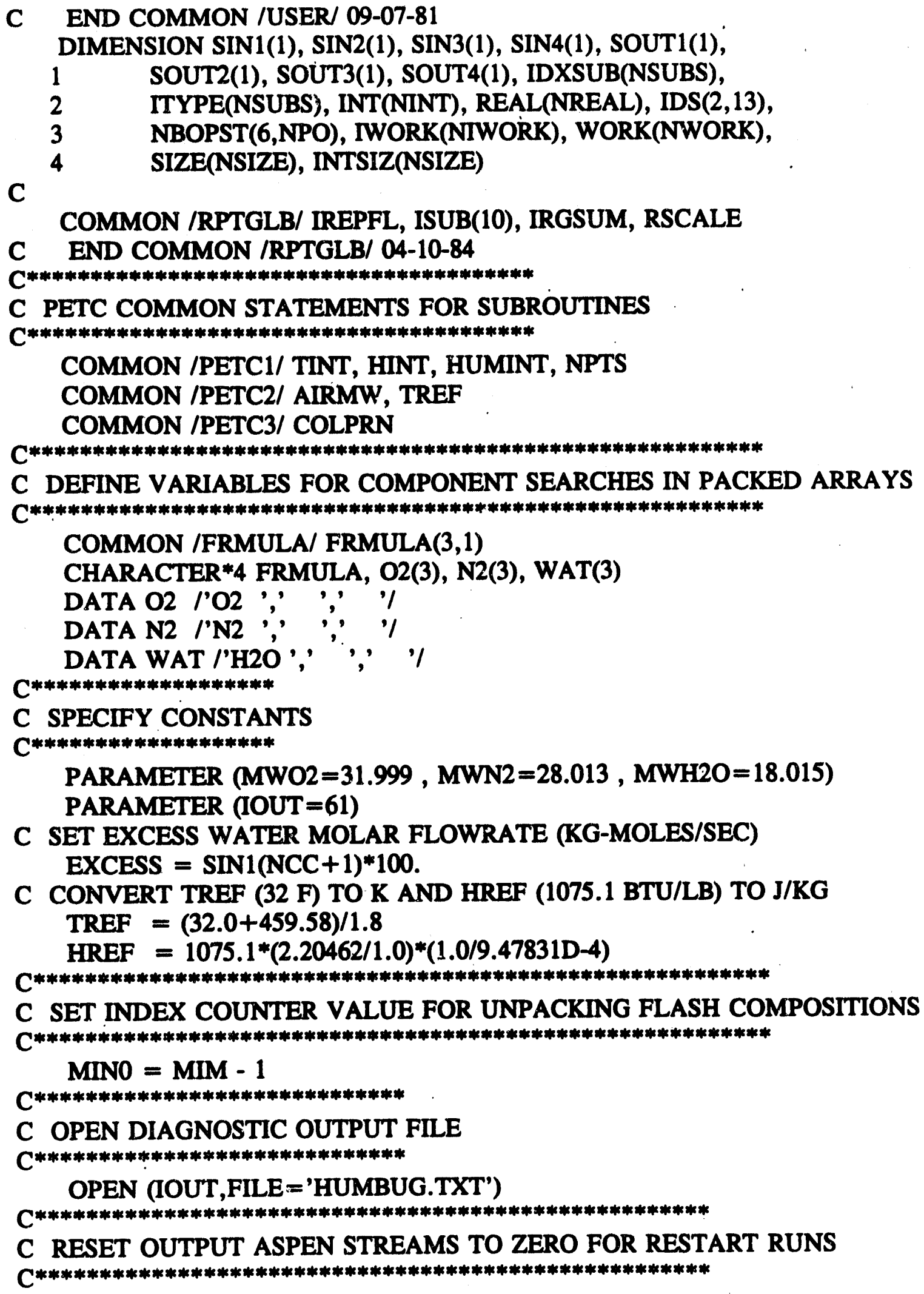




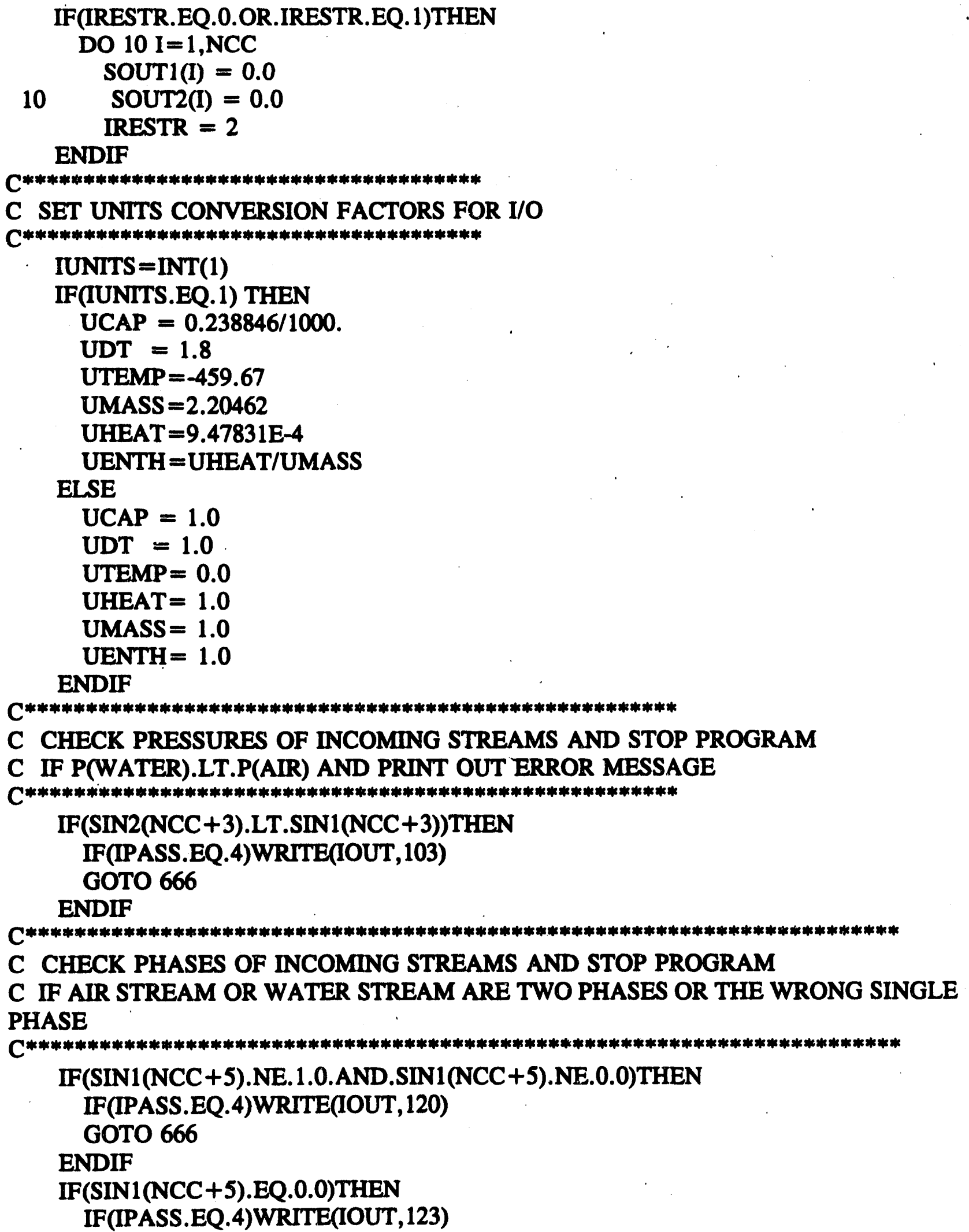


GOTO 666

ENDIF

IF(SIN2(NCC+6).NE.1.0.AND.SIN2(NCC+6).NE.0.0)THEN

IF(IPASS.EQ.4)WRITE(IOUT, 124)

GOTO 666

ENDIF

IF(SIN2(NCC+6).EQ.0.0)THEN

IF(IPASS.EQ.4)WRITE(IOUT,125)

GOTO 666

ENDIF

C

C DETERMINE THE BOILING POINT OF INCOMING WATER STREAM AT GIVEN PRESSURE

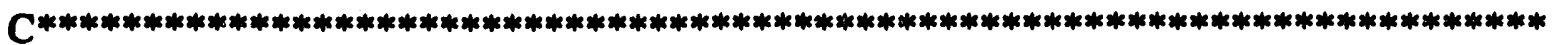

PRES $=$ SIN $1(\mathrm{NCC}+3)^{*} 1.45038 \mathrm{E}-4$

CALL VAPINT (2, TEMP, PRES, HEATVAP)

TBWAT $=($ TEMP+459.58) $/ 1.8$

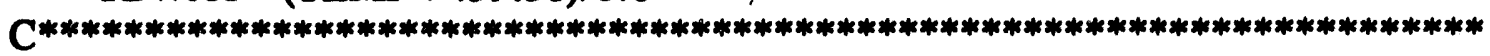

C DEVELOP TABLE OF INTERFACIAL HUMIDITY AND ENTHALPY AS A FUNCTION OF

C TEMPERATURE OVER A TEMPERATURE RANGE OF $($ TLOW + 1) TO TTOP

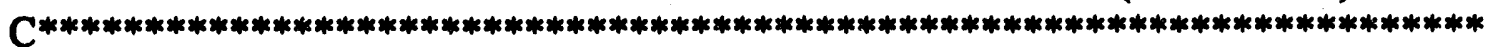

C

C CALCULATE MOLE FRACTIONS OF INCONIING AIR STREAM ON A "DRY" BASIS

C CALCULATE THE AVERAGE MW OF DRY AIR STREAM

C

YO2A $=\operatorname{SIN} 1(1) /(\operatorname{SIN} 1(1)+\operatorname{SIN} 1(2))$

YN2A $=\operatorname{SIN} 1(2) /(\operatorname{SIN} 1(1)+\operatorname{SIN} 1(2))$

AIRMW $=(Y O 2 A * M W O 2)+(Y N 2 A * M W N 2)$

C

C CALCULATE WATER MOLE FRACTION AND HUMIDITY OF INCOMING AIR STREAM

C

YB $=\operatorname{SIN} 1(3) / \operatorname{SIN} 1(\mathrm{NCC}+1)$

HUMYB $=\left(M W H 2 O^{*}\right.$ YB $) /(A I R M W *(1.0-Y B))$

C

C PERFORM WET BULB STEP 1 TO OBTAIN DEW POINT TEMPERATURE OF INCOMING AIR

C

DO $11 \mathrm{UI}=1, \mathrm{NCC}+9$

WORK(III) $=$ SIN1(IJI)

11 CONTINUE

PRES $=$ SIN1 $(\mathrm{NCC}+3)$

$\mathrm{V}=1.0$. 
KODE $=3$

NPKODE $=2$

GUESS $=311.00$

MAXIT $=100$

TOL $=1 \mathrm{D}-04$

CALL FLASH (WORK, NSUBS, IDXSUB, ITYPE, NBOPST, KODE, NPKODE, KPHSE, MAXIT, TOL,

2 PRES, V, GUESS, 4, 4, 0, 1, RESLTS(MRETN),

3 INDEX(MIRETN),LCFLAG)

IF(LCFLAG.NE.0)THEN

IF(IPASS.EQ.4)WRITE(IOUT,101)

ENDIF

C

TDP $=$ TCALC

C CONSTRUCT TABLE FROM THE DEW POINT TEMPERATURE OF THE INCOMING

C AIR STREAM (TDP), OR 273 C, WHICHEVER IS HIGHER,

C TO THE HIGHER TEMPERATURE OF THE INCOMING AIR

C OR WATER STREAMS (TTOP) USING TEMPERATURE INCREMENTS OF TINCR

C

IF(SIN1(NCC +2).GT.SIN2(NCC+2))THEN

TTOP $=$ SIN1 $(N C C+2)$

ELSE

TTOP $=\operatorname{SIN} 2(\mathrm{NCC}+2)$

ENDIF

TINCR $=1.0$

IF(TDP.GT.273.0)THEN

TLOW $=$ TDP

ELSE

TLOW $=273.15$

ENDIF

NPTS $=((T T O P-T L O W) / T I N C R)+2$

IF(IUNITS.EQ.1.AND.IPASS.EQ.4)

1 WRTTE(IOUT, 1130) NPTS,(TINCR*UDT),

1 ((TLOW)*UDT +UTEMP),(TTOP*UDT+UTEMP),

1 (SIN1(NCC+3)*(14.5038/1.0E5))

IF(IUNITS.EQ.0.AND.IPASS.EQ.4)

C

1 WRITE(IOUT,130) NPTS,TINCR,(TLOW),TTOP,SIN1(NCC+3)

DO $523 \mathrm{I}=1$,NPTS

IF(I.EQ.1)THEN

TEMP $=$ TLOW

ELSE

TEMP = TEMP + TINCR

ENDIF 
IF(TEMP.GE.TBWAT)THEN

HUMINT(I) $=1.0 \mathrm{E} 30$

HINT(I) $=1.0 \mathrm{E} 30$

TINT(I) $=$ TEMP

GOTO 716

ENDIF

C

C ADD EXCESS WATER TO SATURATE THE INLET AIR STREAM

C WATER IS COMPONENT 3

C

522

DO $522 \mathrm{II}=1, \mathrm{NCC}+9$

$$
\text { WORK(II) = SIN1(II) }
$$

CONTINUE

WORK(3) $=\operatorname{SIN} 1(3)+$ EXCESS

WORK $($ NCC +1$)=\operatorname{SIN} 1(N C C+1)+$ EXCESS

PRES = SIN1 $($ NCC +3$)$

KODE $=2$

NPKODE $=2$

MAXIT $=100$

TOL $=1 \mathrm{D}-04$

CALL FLASH (WORK, NSUBS, IDXSUB, ITYPE, NBOPST,

1

2

3 KODE, NPKODE, KPHSE, MAXIT, TOL,

TEMP, PRES, GUESS, 4, 4, 0, 1 ,

RESLTS(MRETN),INDEX(MIRETN),LCFLAG)

IF(LCFLAG.NE.0)THEN

IF(IPASS.EQ.4)WRITE(IOUT,101)

ENDIF

IF(VCALC.EQ.1)THEN

IF(IPASS.EQ.4)WRITE(IOUT, 122)

GOTO 666

ENDIF

C

C FIND LOCATION OF "PACKED" WATER MOLE FRACTION FROM FLASH CALCULATION

C

KWAT = KIDVEC(WAT, FRMULA, 3, 1, 3, 1, NCC)

DO $821 \mathrm{~J}=1, \mathrm{NCPM}$

II = INDEX(MIN0+J)

IF(II.EQ.KWAT)THEN

YWAT $=$ RESLTS(MY-1 $+\mathrm{J})$

ENDIF

821 CONTINUE

C

C CALCULATE INTERFACIAL HUMIDITY AND CS IN J/KG-K 
C

HUMID $=($ MWH2O*YWAT)/(AIRMW*(1.0-YWAT))

HUMINT(I) $=$ HUMID

C

CALL CPHEAT (TEMP, HUMID, CPAIR, CPWAT, CS)

C CALCULATE INTERFACIAL ENTHALPY

C

HINT(I) $=$ CS $*($ TEMP-TREF $)+$ HUMINT(I)*HREF

C

$\operatorname{TINT}(\mathrm{I})=$ TEMP

C OUTPUT SATURATION CURVE DATA AT PRINT TIME

C

716 IF(IUNITS.EQ.1.AND.IPASS.EQ.4)

1 WRITE(IOUT, 131)TINT(I)*UDT + UTEMP,HUMINT(I),

1 HINT(I)*UENTH

IF(IUNITS.EQ.0.AND.IPASS.EQ.4)

1 WRITE(IOUT, 131)TINT(I),HUMINT(I),HINT(I)

523 CONTINUE

C

C *** DETERMINE THE WET BULB TEMPERATURE FOR THE INCOMING AIR STREAM ***

C

C APPROACH: (1) DETERMINE THE DEW POINT TEMPERATURE (TDP) OF THE INCOMING

C

C

C

AIR STREAM WHICH WILL BE USED AS A LOWER LIMIT FOR CONVERGENCE ON THE WET BULB TEMPERATURE (TWB), UNLESS TDP IS LESS THAN 273 C, IN WHICH CASE 273 C IS THE LIMIT

C

C (2) PERFORM A FLASH ON THE INCOMING AIR STREAM AND AN

C ARBITRARY INCOMING WATER STREAM. THE WATER STREAM MUST BE LARGE ENOUGH TO SATURATE THE AIR STREAM.

C

C

(3) ITERATE STEP 2 ON TWB UNTIL THE FOLLOWING EQUATION IS SATISFIED: TWB = TYIN - HEATVAP/CS*(HUMWB-HUMB)

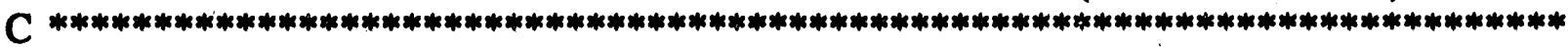

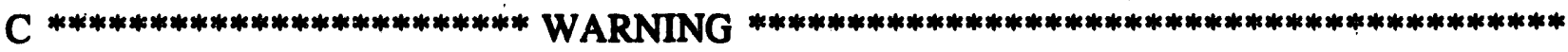

C *** IF THE HUMIDITY OF THE ENTERING AIR IS 0.0000, THE DEW POINT WILL $* * *$

C *** REFER TO THE TEMPERATURE AT WHICH THE AIR BEGINS TO LIQUIFY! $* * * *$

C *** THIS WILL NOT AFFECT THE SOLUTION ALGORITHM. REMEMBER WHAT THESE ***

C *** EXTREMELY LOW TEMPERATURES MEAN, HOWEVER, WHEN THEY APPEAR. ****

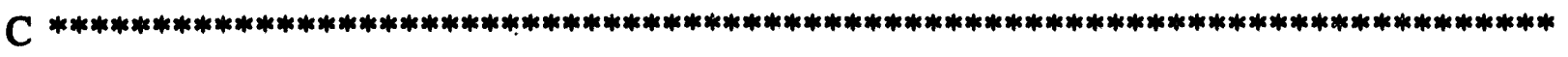

C 
C WRITE HEADER INFORMATION

C

IF(IPASS.EQ.4)WRITE(IOUT,104)

C

C INPUT A CONSTANT CP FOR LIQUID WATER IN J/KG-K AT ANY TEMPERATURE

C

C

$$
\text { CPLIQ }=4183.99538
$$

C

C PERFORM WET BULB STEPS 2 \& 3:

C CALCULATE SATURATION TEMPERATURE USING BOUNDED NEWTON'S

C METHOD; IF OUT OF RANGE, UPDATE USING HALF INTERVAL METHOD.

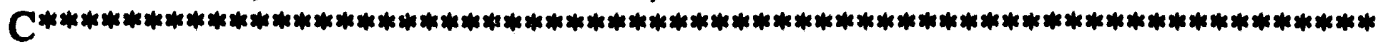

C

TYIN $=$ SIN1 $(\mathrm{NCC}+2)$

TLO $=$ TINT(1)

CALL INTERP (0, IPT, TLO, HI, HUMLO)

TEMP $=\left(T^{2}{ }^{*} 1.8\right)-459.58$

CALL VAPINT (1, TEMP, PRES, HEATVAP)

HEATVAP $=$ HEATVAP $*(2.20462 / 1.0) *(1.0 / 9.47831 D-4)$

FLO $=($ TYIN-TLO) $-($ HEATVAP/1020.)*(HUMLO-HUMYB)

IF(IPASS.EQ.4) WRITE(IOUT, 105) 10000.*UDT +UTEMP,TLO*UDT + UTEMP, \& 10000.*UDT

IF(TTOP.GT.TBWAT)THEN

$$
\text { THI }=\text { TBWAT }
$$

ELSE

THI $=$ TTOP

ENDIF

CALL INTERP (0, IPT, THI, HI, HUMHI)

TEMP $=\left(\mathrm{THI}^{*} 1.8\right)-459.58$

CALL VAPINT (1, TEMP, PRES, HEATVAP)

HEATVAP $=$ HEATVAP*(2.20462/1.0)*(1.0/9.47831D-4)

FHI $=($ TYIN-THI) $-($ HEATVAP/1020.)*(HUMHI-HUMYB)

IF(IPASS.EQ.4) WRITE(IOUT,105) TLO*UDT + UTEMP,THI*UDT + UTEMP, \& (THI-TLO)*UDT

C

TWBB $=0.5 *(T L O+T H I)$

C START ITERATION LOOP FOR WET BULB TEMPERATURE

C

TOLD $=$ TLO

DO $12 \mathrm{I}=3,100$

CALL INTERP (0, IPT, TWBB, HI, HUMWB)

TDIFF = TWBB - TOLD

IF(IPASS.EQ.4) WRITE(IOUT,105) TOLD*UDT+UTEMP,TWBB*UDT+UTEMP, 


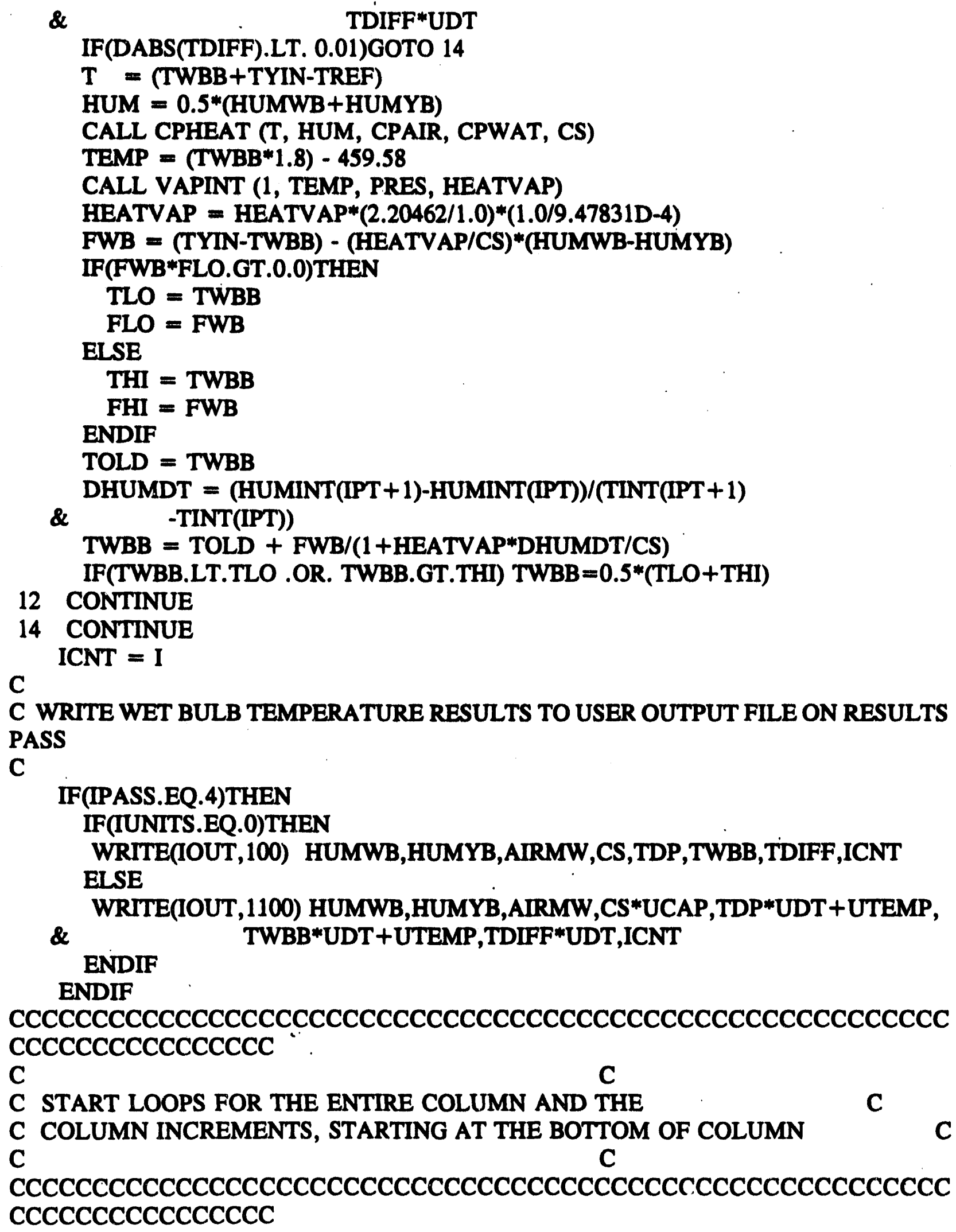

C WRITE WET BULB TEMPERATURE RESULTS TO USER OUTPUT FILE ON RESULTS PASS

C

IF(IPASS.EQ.4)THEN

IF(IUNITS.EQ.0)THEN

WRITE(IOUT,100) HUMWB,HUMYB,AIRMW,CS,TDP,TWBB,TDIFF,ICNT

ELSE

WRITE(IOUT,1100) HUMWB,HUMYB,AIRMW,CS*UCAP,TDP*UDT+UTEMP,

\& TWBB*UDT + UTEMP,TDIFF*UDT,ICNT ENDIF

ENDIF

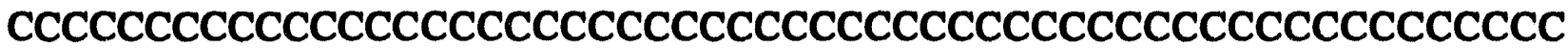
CCCCCCCCCCCCCCCC

C

C START LOOPS FOR THE ENTIRE COLUMN AND THE

C COLUMN INCREMENTS, STARTING AT THE BOTTOM OF COLUMN

C C $\mathrm{C}$

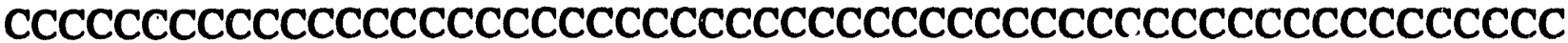
CCCCCCCCCCCCCCCC 


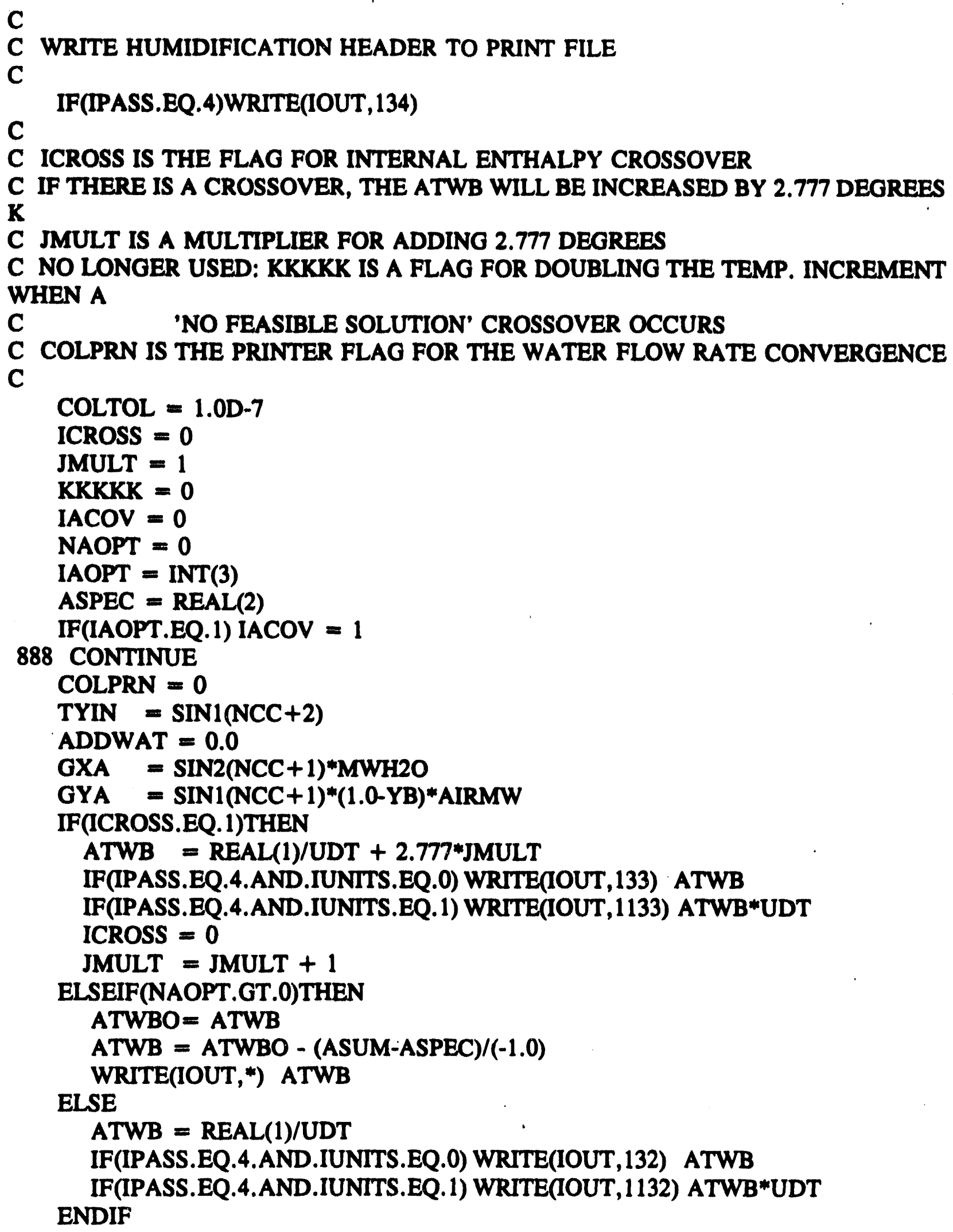


IF(IAOPT.EQ.1)THEN

NAOPT $=$ NAOPT +1

IF(NAOPT.EQ.20) THEN

IACOV $=0$

ENDIF

ENDIF

NINCR $=$ INT(2)

IF(NINCR.EQ.0) NINCR $=($ TXIN-TWBB-ATWB $) / 5 . / 1.8+1$

IF(NINCR.GT.150) NINCR $=150$

C

C START LOOP FOR THE ENTIRE COLUMN, MAX OF 10 LOOPS

C TO CONVERGE ON USER INPUT OF GX

C

DO 622 NCOLUM $=1,100$

ADDWAT $=0.0$

IF(NCOLUM.EQ.1)THEN

GXORIG $=$ GXA

GXORER $=100.0$

ELSE

GXORER = DABS((GXORIG-GXA)/GXORIG)

IF(GXORER.LE.COLTOL)THEN

NCITS $=$ NCOLUM +1

IF(IACOV.EQ.1.AND.IAOPT.EQ.1) GOTO 625

COLPRN $=1$

TINT1 $=0$

TINT2 $=0$

TINT3 $=0$

TINT4 $=0$

TYINT1 $=0$

TYINT2 $=0$

ENDIF

IF(NCOLUM.EQ.50)THEN

WRITE(IOUT, 138)COLTOL,NCOLUM

ENDIF

GXA $=$ GXORIG - (GXA-GXOUT)

TYIN $=$ TYYIN

ENDIF

NINCR2 = NINCR

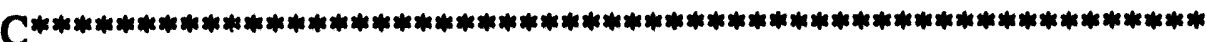

C START LOOP FOR THE COLUMN INCREMENTS OR STAGES (NINCR)

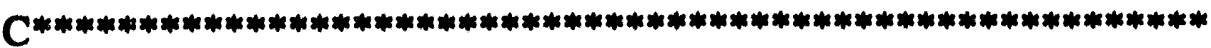

DO $621 \mathrm{NIII}=1, \mathrm{NINCR}$

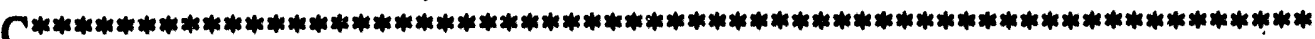

C PROBLEM CLASSIFICATION 
C STEP2 - Determination of TXOUT. Add approach to wet bulb.

C KEEP ACCOUNT OF THE WATER LEAVING AND AIR ENTERING THE

C BOTTOM, OR FIRST, STAGE. THEIR PROPERTIES WILL BE USED

C IN THE COLUMN MATERIAL AND ENERGY BALANCES

C

IF(NIII.EQ.1)THEN

HUMIN = HUMYB

HUMYY $=$ HUMIN

TXOUT $=$ TWBB + ATWB

GXOUT $=$ GXA

TYYIN $=$ TYIN

TXXOUT $=$ TXOUT

ELSE

HUMIN $=$ HUMOUT

TXOUT $=$ TXIN

TYIN $=$ TYOUT

ENDIF

6666 IF(KKKKK.EQ.0)THEN

TXIN $=(($ SIN2(NCC +2)-TWBB-ATWB $) / N I N C R) * N I I+$

1 (TWBB + ATWB)

ELSE

TXIN $=(($ SIN2(NCC +2$)-$ TWBB-ATWB $) / N I N C R) *(N I I I+1)+$

1 (TWBB+ATWB)

KKKKK $=0$

NIII $=$ NIII +1

ENDIF

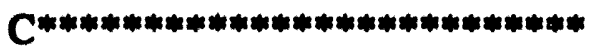

C CHECK FOR LIQUID HEATING

C

IF(TXOUT.GE.TXIN)THEN

IF(IPASS.EQ.4)WRITE(IOUT,121)

GOTO 666

ENDIF

C

C WRITE HEADER FOR STAGE NUMBER AND THE TYPE OF HUMIFICATION

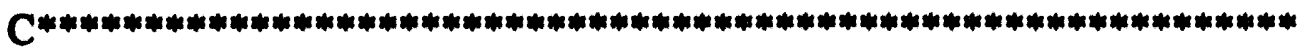

IF(IPASS.EQ.4.AND.COLPRN.EQ.1)THEN

WRITE(IOUT, 111) NIII

IF(TYIN.GE.TXIN)THEN

WRITE(1OUT, 106)

ENDIF

IF((TYIN.LT.TXIN).AND.(TXOUT.LT.TYIN))THEN

WRITE(IOUT, 107)

ENDIF 
IF((TYIN.LT.TXIN).AND.(TXOUT.GT.TYIN))THEN

WRITE(IOUT, 177)

ENDIF

ENDIF

C

C CALCULATION FOR INLET WATER STREAM ENTHALPY IN J/KG

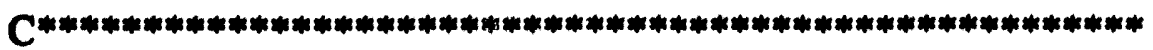

HXIN = CPLIQ*(TXIN-TREF)

C

C CALCULATION FOR INLET AIR STREAM ENTHALPY IN J/KG

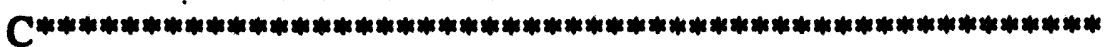

CALL CPHEAT (TYIN, HUMIN, CPAIR, CPWAT, CS)

HYIN $=$ CS $^{*}(T Y I N-T R E F)+$ HUMIN*HREF

IF(NIII.EQ.1)THEN

TYYIN $=$ TYIN

HYYIN $=$ HYIN

ENDIF

C

C DETERMINE WATER ENTHALPY AT BOTTOM OF COLUMN CONDITIONS AT TXOUT

C IN J/KG. THIS ASSUMES THAT GX DOES NOT CHANGE SIGNIFICANTLY

C THROUGHOUT THE STAGE

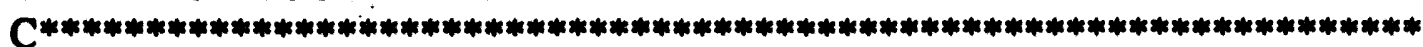

HXOUT $=$ CPLIQ*(TXOUT-TREF)

IF(NIII.EQ.1)THEN

HXXOUT $=$ HXOUT

ENDIF

C

C STEP3 - CALCULATE SLOPE (GXGY) FOR TX, HY LINE

C THIS EQN IS DERIVED BY ASSUMING THAT CHANGES

C IN THE LIQUID FLOW RATE AND ENTHALPY

C FROM THE PREVIOUS ITERATION AROUND THE COLUMN

C CAN BE USED TO ESTIMATE THE DERIVATIVE dGx/dHx

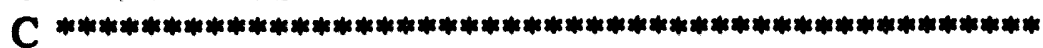

GXGY $=$ CPLIQ*GXA/GYA*(1.+ DGDH(NIII))

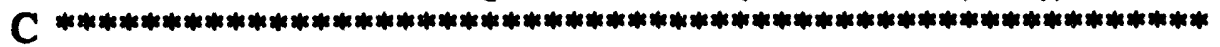

C STEP4 AND STEPS

C CALCULATE AREA OF STAGE USING A LOG MEAN APPROXIMATION

C FOR THE ENTHALPY INTEGRAL

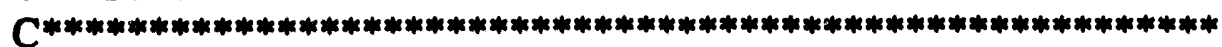

CALL INTERP (0, IPT, TXOUT, HI1, HUMI1)

HY1 = HYIN

$\mathrm{DH} 1=\mathrm{HI} 1-\mathrm{HY} 1$

CALL INTERP (0, IPT, TXIN, HI2; HUMI2) 
HY2 $=$ GXGY*(TXIN-TXOUT) + HYIN

$\mathrm{C} * * * * * * * * * * * * * * * * * * * * * * * * * * * * * * * * * * * * * * * * * * * * * * * * * * * * * * * * * * * * * *$

C CHECK FOR ENTHALPY CROSSOVER A ID HUMIDITY CROSSOVER

C ENTHALPY CROSSOVER IS IDENTICAL TO HUMIDITY CROSSOVER

C THEREFORE, ONLY ONE CHECK IS REQUIRED

$\mathrm{C} * * * * * * * * * * * * * * * * * * * * * * * * * * * * * * * * * * * * * * * * * * * * * * * * * * * * * * * * * * * * * * * *)$

IF(HI2.LE.HY2)THEN

ICROSS $=1$

IF(IPASS.EQ.4)WRITE(IOUT,115)

GOTO 888

ENDIF

DH2 = HI2 - HY2

AREA $=($ HY2-HY1 $) *$ DLOG(DH2/DH1)/(DH2-DH1)

HYOUT $=$ HY2

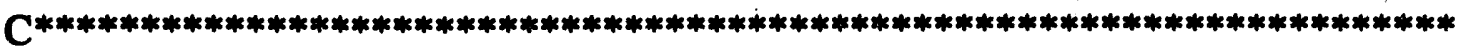

C STEP6 - SOLVE FOR THE TYOUT THAT MATCHES THE AREA CALCULATED ABOVE

C - CHECK FOR 'NO FEASIBLE SOLUTION' CROSSOVER, INCREASE TEMP

C. INCREMENT IF THIS OCCURS

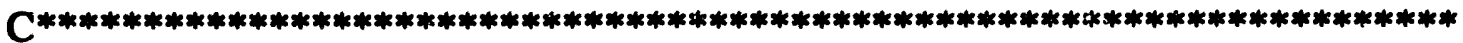

\&

CALL TINTEG (0,ICONV,IDUM,IOUT,IUNITS,AREA,TXIN,TXOUT,TYIN,

\& TYOUT,KKKKK)

IF(KKKKK.EQ.1)GOTO 6666

C******************************************

C STORE CONVERGENCE HISTORY FOR TINTEG

$\mathrm{C} * * * * * * * * * * * * * * * * * * * * * * * * * * * * * * * * * * * * * * * * * * *$

IF(CONV.EQ.-2.AND.COLPRN.EQ.1)TINT1 $=$ TINT1 +1

IF(ICONV.EQ.-1.AND.COLPRN.EQ.1)TINT2 $=$ TINT2 +1

IF(ICONV.EQ. O.AND.COLPRN.EQ.1)TINT3 $=$ TINT3 +1

IF(ICONV.EQ. 1.AND.COLPRN.EQ.1)TINT4 = TINT4+1

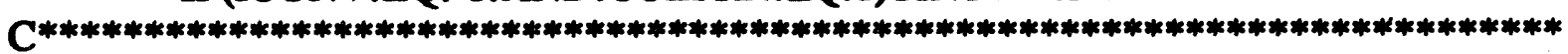

C STEP7 - SOLVE FOR EXIT AIR HUMIDITY BASED ON TYOUT AND HYOUT CALCULATED

C HUMOUT*HREF

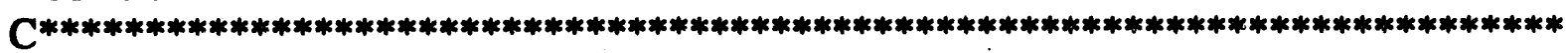

CALL CPHEAT (TYOUT, 0.0, CPAIR, CPWAT, CS)

HUMOUT $=($ HYOUT - CPAIR $*(T Y O U T-T R E F)) /($ HREF + CPWAT $*$

$\&$

(TYOUT-TREF))

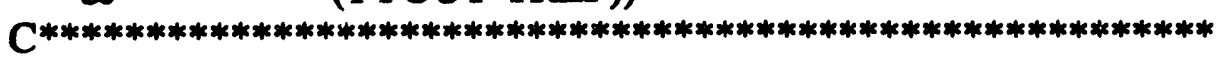

C CALCULATE AREA OF STAGE USING A LOG MEAN APPROXIMATION

C FOR THE HUMIDITY INTEGRAL

$\mathrm{C} * * * * * * * * * * * * * * * * * * * * * * * * * * * * * * * * * * * * * * * * * * * * * * * * * * * * * * * * * * * * * * * * *)$

CALL INTERP (0, IPT, TXOUT, ENTHAL, HUMID) 
HUMD1 = HUMID-HUMIN

CALL INTERP (0, IPT, TXIN, ENTHAL, HUMID)

HUMD2 = HUMID-HUMOUT

AREAH $=$ (HUMOUT-HUMIN)*DLOG(HUMD2/HUMD1)/(HUMD2-HUMD1)

ARERR $=(1.0-$ AREAH/AREA $) * 100$

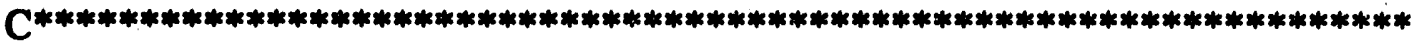

C WRITE INFORMATION FOR AREA CALCULATION FOR EACH HUMIDIFIER STAGE

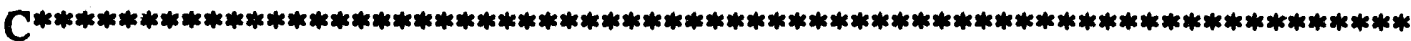

IF(COLPRN.EQ.1.AND.IPASS.EQ.4)THEN

WRTTE(IOUT,110) AREA,AREAH,ARERR

ENDIF

C

C STEP 8 - DETERMINE IF EXITING AIR STREAM FROM THE STAGE IS SATURATED

C

C IF THE EXITING GAS IS A VAPOR LIQUID MIXTURE, THIS SECTION

C OF THE COLUMN ACTS AS A SATURATOR, AND THE CORRECT COMPOSITION

C OF THE EXITING GAS IS THE SATURATED GAS WHICH SATISFIES THE MASS

C AND ENERGY BALANCE

$\mathrm{C} * * * * * * * * * * * * * * * * * * * * * * * * * * * * * * * * * * * * * * * * * * * * * * * * * * * * * * * * * * * * * * * * * * * * * * * * * * * * * * *)$

CALL INTERP (0, IPT, TYOUT, ENTHAL, HUMID)

IF(HUMOUT.GT.HUMID)THEN

IF(IPASS.EQ.4.AND.COLPRN.EQ.1)WRITE(IOUT,126)

C IF(IPASS.EQ.4.AND.COLPRN.EQ.1)WRITE(IOUT,1104)

TYOUT $=$ TYOUT $+15 .{ }^{*}$ (TYOUT-TYIN)

CALL INTERP (0, IPT, TYOUT, ENTHAL, HUMOUT)

FLO $=0.0$

C**********************************************************************

C CALCULATE SATURATION TEMPERATURE USING BOUNDED NEWTON'S

C METHOD; IF OUT OF RANGE, UPDATE USING HALF INTERVAL METHOD.

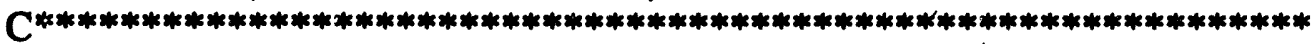

DO $881 \mathrm{JS}=1,200$

TITER $=$ TYOUT

CALL CPHEAT (TITER, HUMOUT, CPAIR, CPWAT, CS)

F = TITER-TREF-(HYIN-HUMOUT *HREF+(HUMOUT-HUMIN)*HXIN

\& + GXB*(HXIN-HXOUT)/GYA)/CS

IF(F*FLO.EQ.0.0)THEN

TLO $=$ TYIN

FLO $=-F$

THI $=$ TITER

$\mathrm{FHI}=\mathrm{F}$

ELSEIF(F*FLO.GT.0.0)THEN

TLO $=$ TTTER

$\mathrm{FLO}=\mathrm{F}$

ELSE 


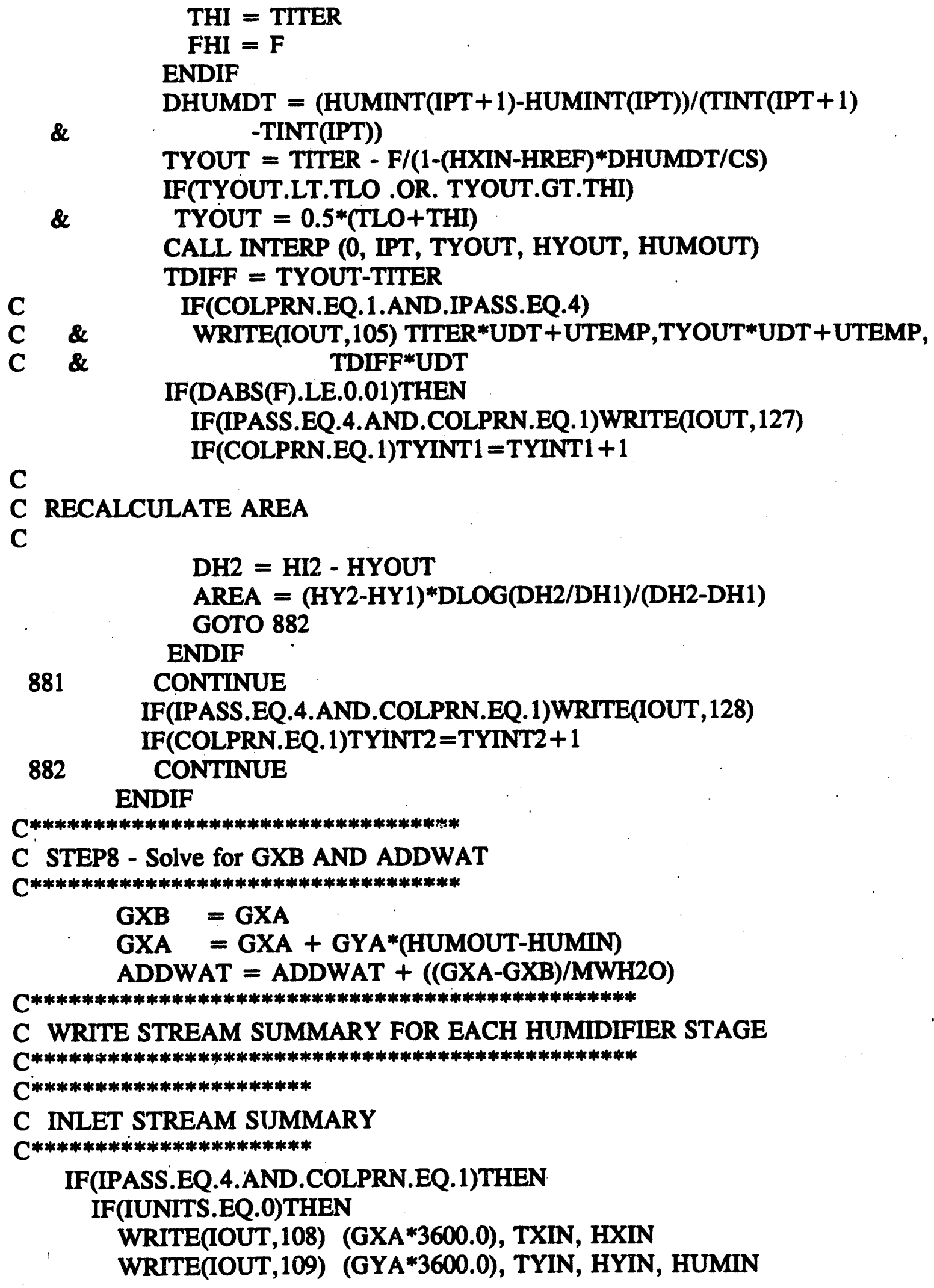




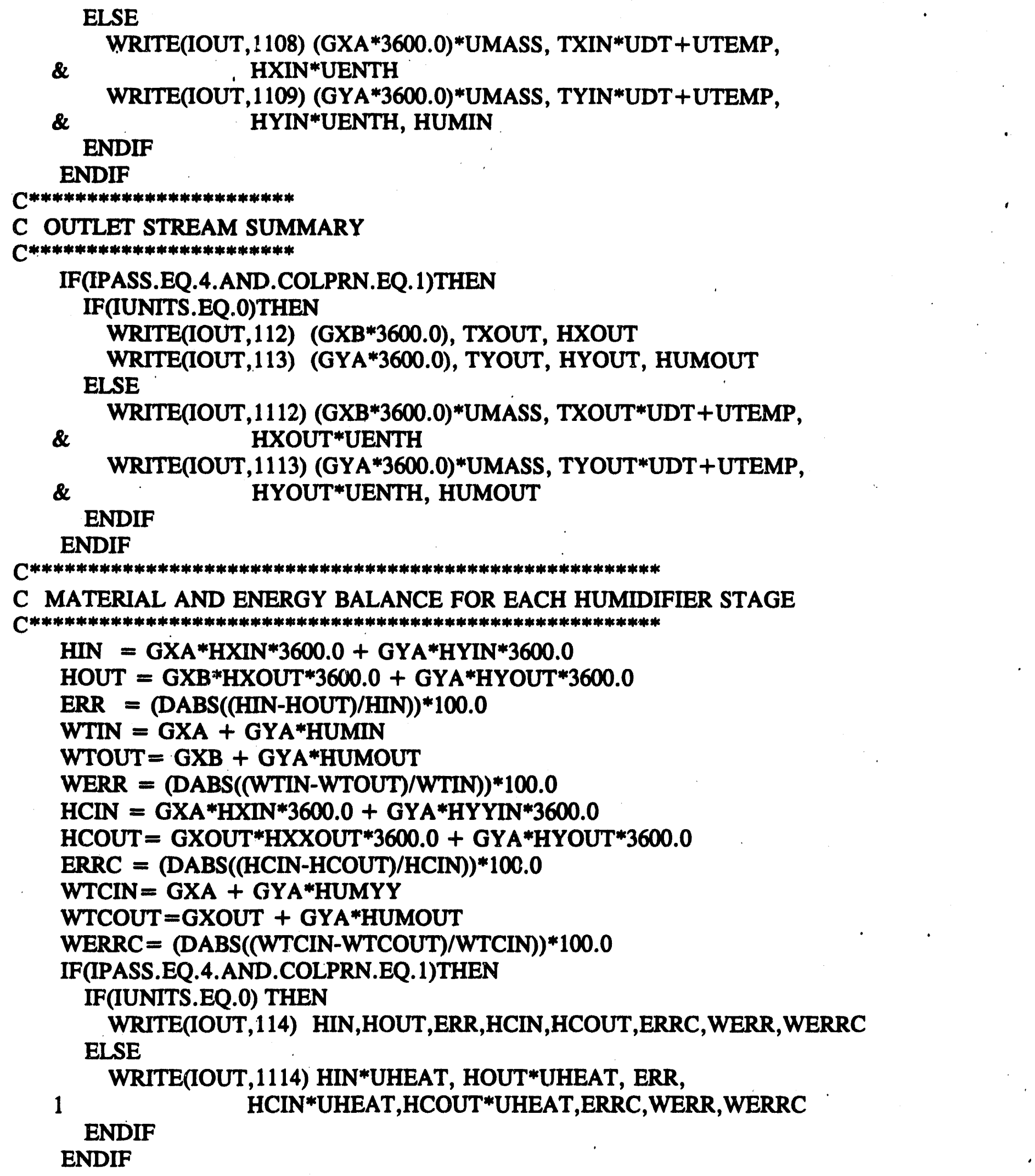




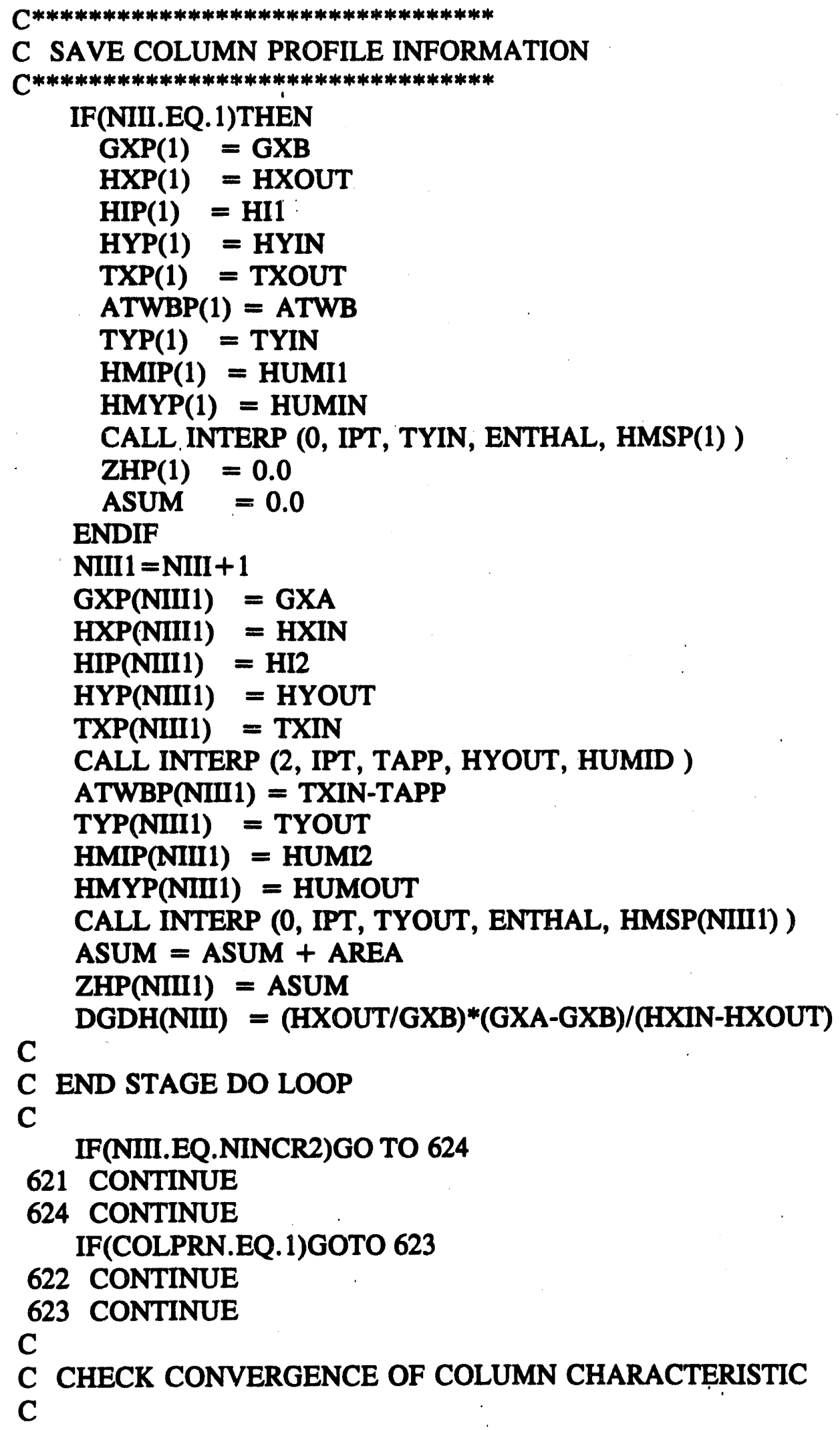




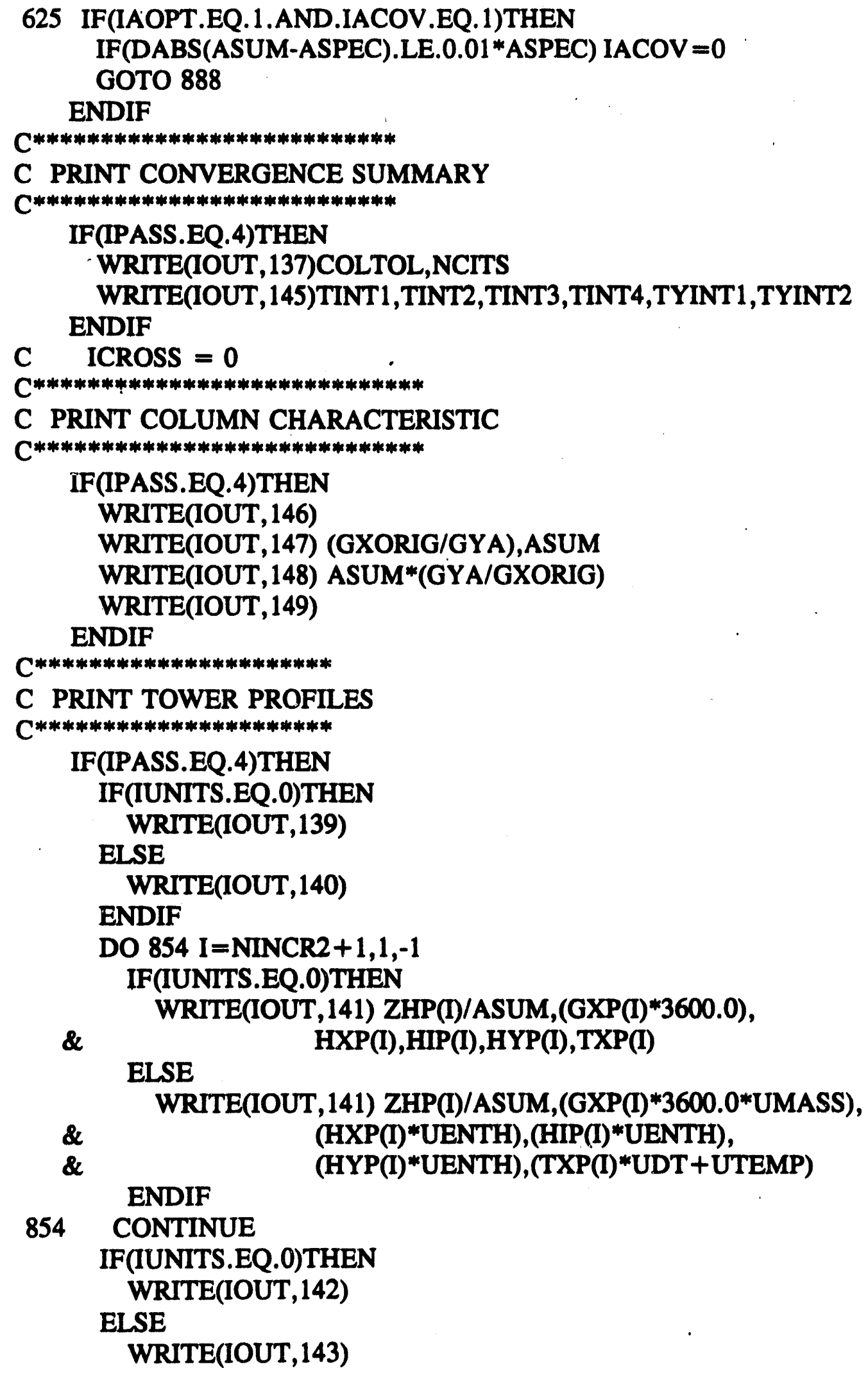




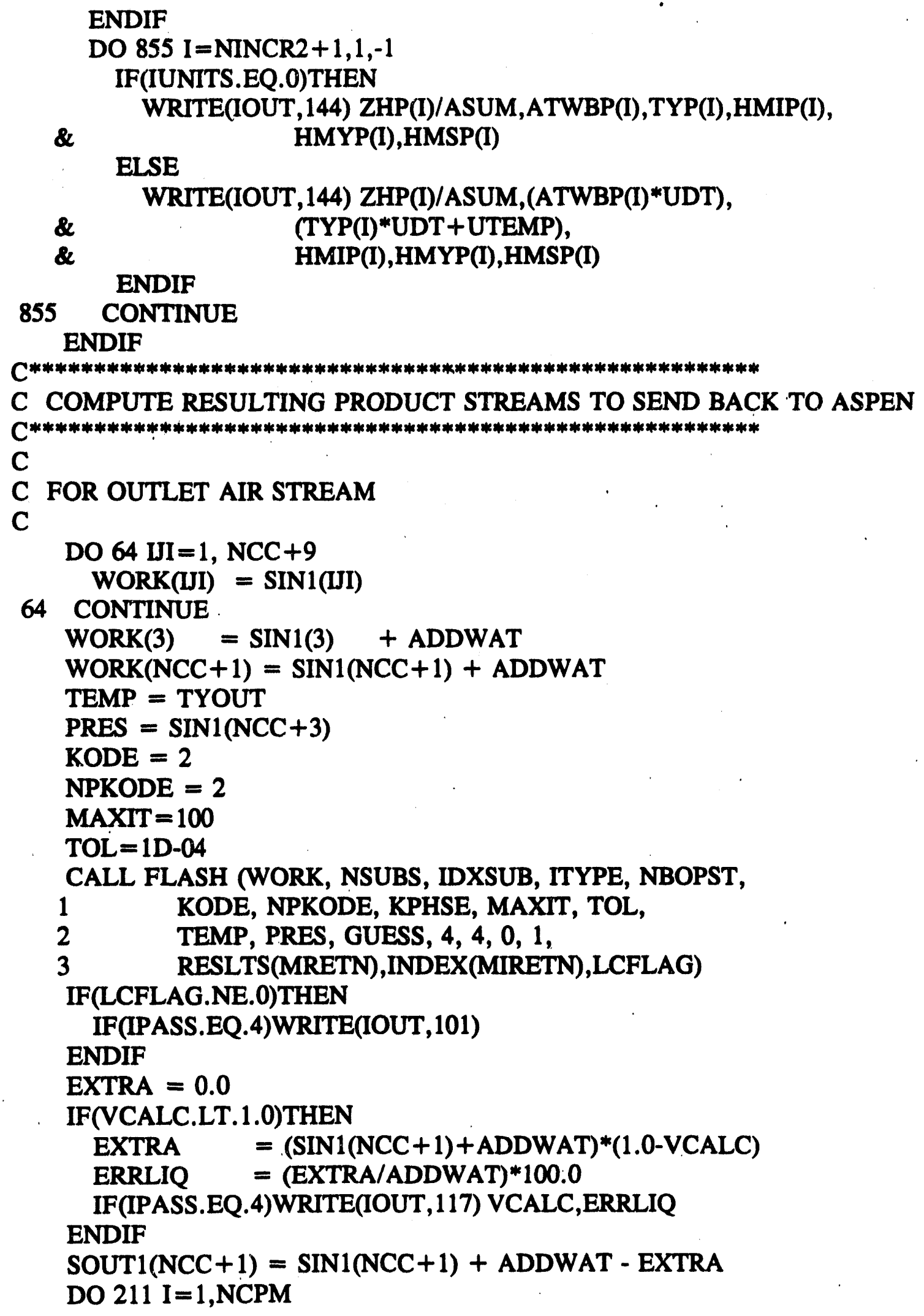




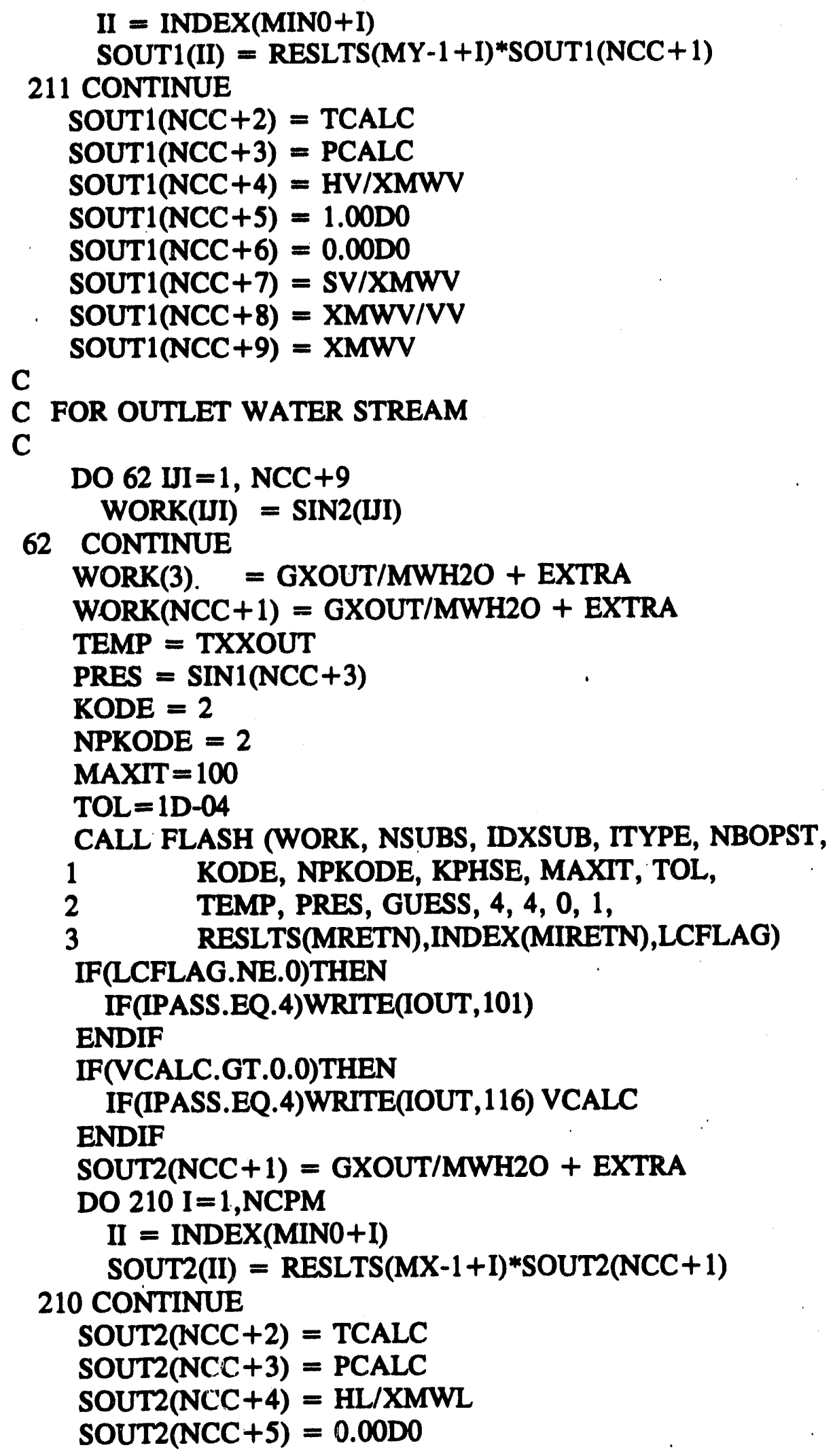




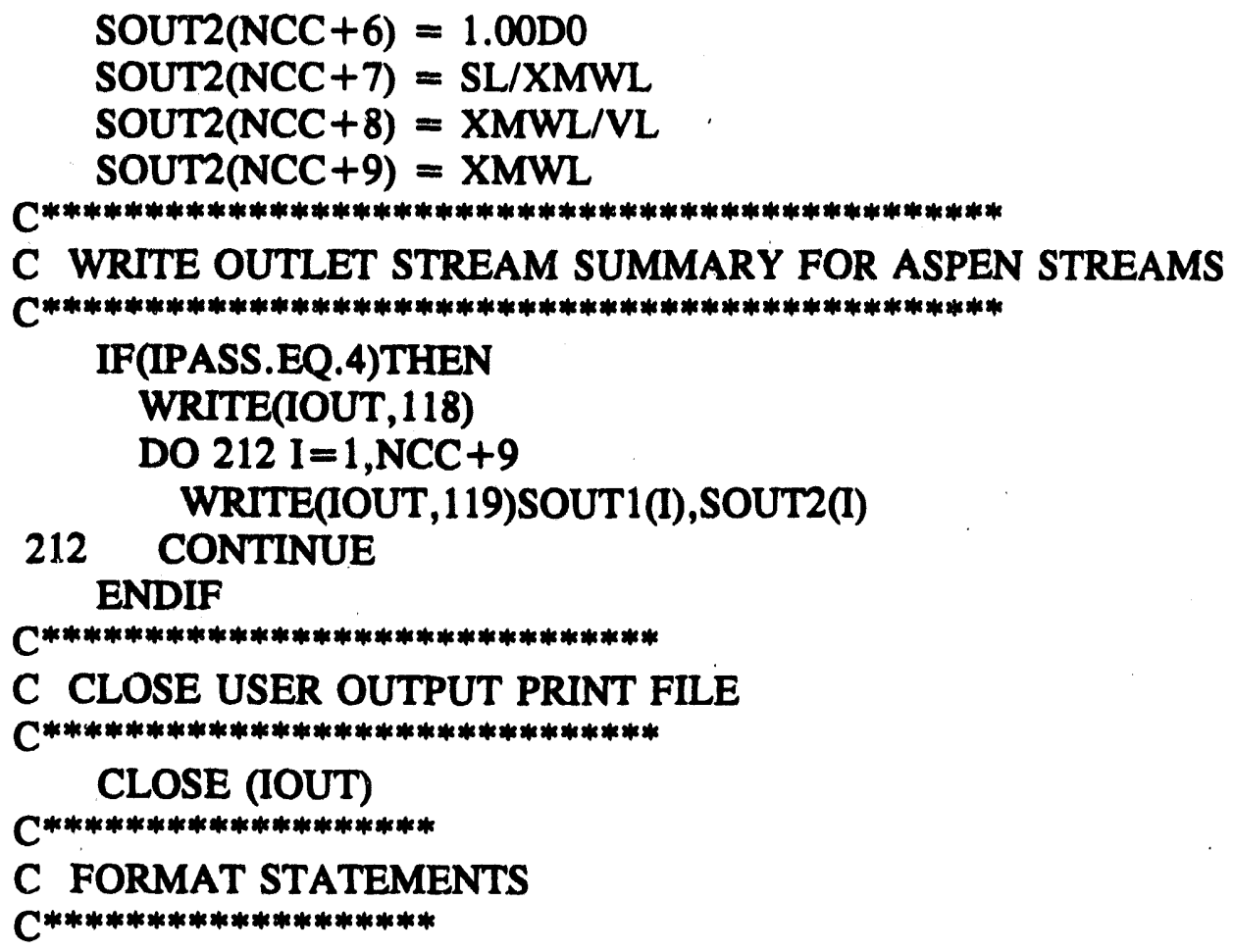




$$
14 \text { 4X, '----',9X,'---',9X,'--'---') }
$$

1104 FORMAT $\left(/, 1 X,{ }^{\prime} * * * * * * * * * * * * * * * * * * * * * * * * * * * * * * * * * * \prime, /\right.$,

1 1X, 'SATURATION TEMPERATURE CONVERGENCE',/,

$1 \quad 1 \mathrm{X},{ }^{\prime * * * * * * * * * * * * * * * * * * * * * * * * * * * * * * * * * * * ', /,}$

1 4X,'TITER',8X,'TYOUT',8X,'TDIFF',/,

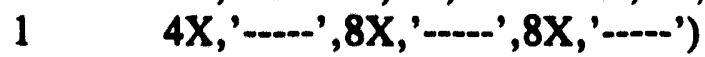

105 FORMAT(1X,F10.5,3X,F10.5,3X,F10.5)

106 FORMAT (/,'GAS COOLING AND HUMIDIFICATION PROBLEM',/)

107 FORMAT (/,'GAS HEATING AND HUMIDIFICATION PROBLEM',/,

1 ' WTTH TEMPERATURE CROSSOVER',/)

177 FORMAT ( $/$,'GAS HEATING AND HUMIDIFICATION PROBLEM',/,

1 ' WITHOUT TEMPERATURE CROSSOVER',/)

108 FORMAT ( $/$,'INLET STREAM SUMMARY',/,

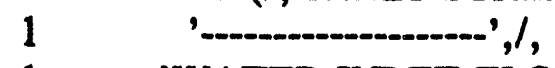

1 'WATER INLET FLOW (GXA) =',E12.5,' KG/HR',/,

\& 'TEMPERATURE (TXIN) =',F12.5,' K',/,

\& 'ENTHALPY (HXIN) $=$ ',E12.5,' J/KG',/)

1108 FORMAT (/,'INLET STREAM SUMMARY',/,

1 'WATER INLET

1 'WATER INLET FLOW (GXA) =',E12.5,' LB/HR',/,

\& 'TEMPERATURE (TXIN) =',F12.5,' F',l,

\& 'ENTHALPY (HXIN) =',E12.5,' BTU/LB',/)

109 FORMAT ('AIR FLOWRATE (GYB) =',E12.5,' KG DRY-AIR/HR',/,

\& 'TEMPERATURE (TYIN) =',F12.5,' $\mathrm{K}$ ',l,

\& 'ENTHALPY (HYIN) $=$ ',E12.5,' J/KG DRY-AIR',/,

\& 'HUMIDITY (HUMIN) =',F12.5,' KG H2O/KG DRY-AIR',/)

1109 FORMAT ('AIR FLOWRATE (GYB) =',E12.5,' LB DRY-AIR/HR',/,

\& 'TEMPERATURE (TYIN) =',F12.5,' F', /,

\& 'ENTHALPY (HYIN) =',E12.5,' BTU/LB DRY-AIR',/,

\& 'HUMIDITY (HUMIN) =',F12.5,' LB H2O/LB DRY-AIR',/)

110 FORMAT (3X, 'AREA-H',5X, 'AREA-HUM',4X, 'ERROR',/,

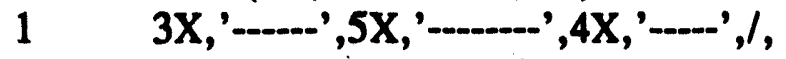

$1 \quad \mathrm{~F} 10.5,2 \mathrm{X}, \mathrm{F} 10.5, \mathrm{F9} .2)$

111 FORMAT $\left(/, 60\left({ }^{\prime *}\right), /\right.$,

1 '***',19X,'STAGE NUMBER ',I3,19X,'***',/,

$\left.160\left({ }^{* * \prime}\right)\right)$

112 FORMAT ('OUTLET STREAM SUMMARY',/,

1 '

1 'WATER OUTLET FLOW (GXB) =',E12.5,' KG/HR',/,

\& . 'TEMPERATURE (TXOUT) =',F12.5,' $\mathrm{K}$ ', $/$,

\& 'ENTHALPY (HXOUT) =',E12.5,' J/KG',/)

1112 FORMAT ('OUTLET STREAM SUMMARY',/,

1 '

1 'WATER OUTLET FLOW (GXB) =',E12.5,' LB/HR',/, 


$\begin{array}{lll}\& & \text { 'TEMPERATURE } & \text { (TXOUT) }=\text { ',F12.5,' F',/, } \\ \& & \text { 'ENTHALPY } & \text { (HXOUT) }=\text { ',E12.5,' BTU/LB',l) }\end{array}$

113 FORMAT ('AIR FLOWRATE (GYA) =',E12.5,' KG DRY-AIR/HR',/, $\&$ 'TEMPERATURE (TYOUT) $=', F 12.5,{ }^{\prime} \mathrm{K},, /$, \& 'ENTHALPY (HYOUT) $=$ ',E12.5,' J/KG DRY-AIR',/, \& 'HUMIDITY (HUMOUT) =',F12.5,' KG H2O/KG DRY:-AIR')

1113 FORMAT ('AIR FLOWRATE (GYA) =',E12.5,' LB DRY-AIR/HR',/, $\begin{array}{lll}\& & \text { 'TEMPERATURE } & \text { (TYOUT) }=', F 12.5, ', /, \\ \& & \text { 'ENTHALPY } & \text { (HYOUT) }=', \text { E12.5,' BTU/LB DRY-AIR', } /, \\ \& & \text { 'HUMIDITY } & \text { (HUMOUT) }=', \text { F12.5,' LB H2O/LB DRY-AIR') }\end{array}$

114 FORMAT (/,'WATER AND ENERGY BALANCE FOR THIS STAGE',/,

1 '- 1 -

1 'TOTAL ENERGY IN =', 1P, E12.5, ' J/HR', /,

\& 'TOTAL ENERGY OUT =', E12.5, ' J/HR', /,

\& 'PERCENT ERROR = ', OP, F8.3, ' \%', !,

1 'CUM . ENERGY IN =', 1P, E12.5, ' J/HR', /,

1 'CUM . ENERGY OUT =', E12.5, ' J/HR', /,

1 'CUM . PERC. ERROR = ', OP, F8.3, ' \%', /l,

1 'WATER MASS BALANCE ERROR=', OP, F12.9, ' \%',l,

1 'CUM . MASS BALANCE ERROR=', OP, F12.9, ' \%',/)

1114 FORMAT (/,'WATER AND ENERGY BALANCE FOR THIS STAGE',/,

1 '- 1 -

1 'TOTAL ENERGY IN =', 1P, E12.5, ' BTU/HR', /,

\& 'TOTAL ENERGY OUT =', E12.5, ' BTU/HR', /,

\& 'PERCENT ERROR $=$ ', OP, F8.3, ' $\%$ ', $/ /$,

1 . 'CUM . ENERGY IN =', 1P, E12.5, ' BTU/HR', /,

1 'CUM. ENERGY OUT =', E12.5, ' BTU/HR', /,

1 'CUM . PERC. ERROR = ', OP, F8.3,' \%', //,

1 'WATER MASS BALANCE ERROR =', OP, F12.9, ' $\%$ ',l,

1 'CUM . MASS BALANCE ERROR=', OP, F12.9,' \%',/)

115 FORMAT (//***** INTERNAL CROSSOVER (GX TOO HIGH/GY TOO LOW/',

\& 'APPROACH TOO SMALL) *****', $/$,

\& '***** THE ATWB WILL BE AUTOMATICALLY INCREASED',

\& 'AND THE PROBLEM WILL BE STARTED OVER *****';//)

116 FORMAT $\left(/ /,{ }^{* * * * *}\right.$ WARNING - OUTLET WATER STREAM CONTAINS 2',

1 ' PHASES *****',/,

$1 \quad$ ' VCALC $=', F 10.5)$

117 FORMAT (//,'***** WARNING - OUTLET AIR STREAM CONTAINS 2',

1 ' PHASES *****',/,

1 ' VCALC =',F10.5,/,

1 ' LIQUID \% DIFFERENCE =',F10.5)

118 FORMAT $(/ /, * * *$ ASPEN OUTLET STREAM SUMMARY ***', /,

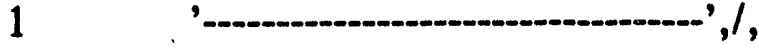

19 9X,'AIR',20X,'WATER',/, 


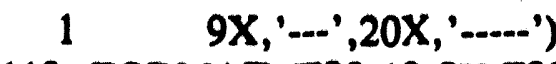

119 FORMAT (F20.10,5X,F20.10)

120 FORMAT $\left(/,,^{* * * *}\right.$ ERROR - PROGRAM TERMINATED ****',/,

$1 \quad 1,{ }^{\prime * * * *}$ INCOMING AIR STREAM CONTAINS 2 PHASES ****')

121 FORMAT (, '**** LIQUID HEATING SPECIFIED - RUN TERMINATED ****')

122 FORMAT $\left(1,{ }^{\prime * * * *}\right.$ INSUFFICIENT EXCESS WATER - RUN TERMINATED ****')

123 FORMAT $\left(/,{ }^{\prime * * * * *}\right.$ ERROR - PROGRAM TERMINATED ****', $/$,

$11,{ }^{\prime * * * *}$ INCOMING AIR STREAM IS LIQUID PHASE ****')

124 FORMAT $(/$, '**** ERROR - PROGRAM TERMINATED ****',/,

1 1,'**** INCOMING WATER STREAM CONTAINS 2 PHASES ****')

125 FORMAT (/,'**** ERROR - PROGRAM TERMINATED ****',I,

$1 \quad I, * * * *$ INCOMING WATER STREAM IS VAPOR PHASE ****')

126 FORMAT ( $/$ 'AIR SATURATED IN THIS STAGE, RECOMPUTE TYOUT')

127 FORMAT (6X,'TYOUT: CONVERGED')

128 FORMAT (6X,'TYOUT: NOT CONVERGED')

129 FORMAT(1X,F10.5,3X,F10.5,3X,F10.5,3X,F10.5,3X,F10.5)

130 FORMAT(78('*'),/,

1'***',16X,'INTERFACIAL ENTHALPY AND HUMIDITY. CURVE', 16X, '***',/,

1. 78('*'),l,

1 1X,'NUMBER OF POINTS =',18, $/$,

1 1X,'TEMPERATURE INCREMENT =',F8.2,' $\mathrm{K}$ ',/,

1 1X,'LOW TEMPERATURE =',F8.2,' $\mathrm{K}, \mathrm{l}$,

1 1X,'HIGH TEMPERATURE =',F8.2,' $\mathrm{K}, \mathrm{l}$,

1 1X,'PRESSURE =',F20.2,' N/M2',/l,

1 1X,'TEMP (K)',17X, 'HUMIDITY',9X,'ENTHALPY (J/KG)',l,

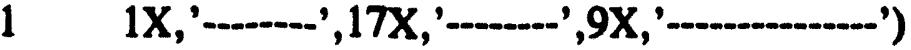

1130 FORMAT(78('*'),/,

$1^{\prime * * * \prime}, 16 \mathrm{X}$, 'INTERFACIAL ENTHALPY AND HUMIDITY CURVE',17X,'***',/,

1 78('*'),/,

1 . 1X,'NUMBER OF POINTS =',18,/,

1 1X,'TEMPERATURE INCREMENT =',F8.2,' F', $/$,

1 1X,'LOW TEMPERATURE =',F8.2,' F',/,

1 1X,'HIGH TEMPERATURE =',F8.2,' $\mathrm{F}^{\prime}, l$,

1 1X,'PRESSURE =',F8.2,' PSIA',//,

$11 \mathrm{X}$, 'TEMP (F)',17X, 'HUMIDITY',7X, 'ENTHALPY (BTU/LB)',/,

$11 \mathrm{X}$, ',17X,' ',7X,'

131 FORMAT(1X,F8.2,5X,F20.6,5X,F13.2)

132 FORMAT(/,'APPROACH TO WET BULB =',F8.2,' $\mathrm{K}$ ')

1132 FORMAT( $/$,'APPROACH TO WET BULB =',F8.2,' F')

133 FORMAT(/,'ADJUSTED APPROACH TO WET BULB =',F8.2,' $\mathrm{K}$ ')

1133 FORMAT(/,'ADJUSTED APPROACH TO WET BULB =',F8.2,' F')

134 FORMAT(/,78('*'),/,

1 '***', 19X, 'BEGIN HUMIDIFICATION CALCULATIONS',20X,'***',,/,

$\left.178\left({ }^{\prime \prime}\right)\right)$ 
137 FORMAT(/,

$178\left('{ }^{\prime \prime}\right), /$,

1 '***', 26X, 'CONVERGENCE HISTORY',27X,'***',, ,

$178\left({ }^{\prime \prime}\right), / /$,

1 'THE INLET WATER FLOW RATE HAS CONVERGED',,

1 , TOLERANCE $=$ ',E10.5,,

1 ' ITERATIONS = ',I10)

138 FORMAT $/$,

1 'THE INLET WATER FLOW RATE HAS NOT CONVERGED **',/,

1 ' TOLERANCE $=$ ',E10.5,, ,

1 ' ITERATIONS $=$ ',110)

139 FORMAT( $/, 78\left({ }^{* \prime \prime}\right), /$,

\& '***',28X,'COLUMN PROPILES',29X,'***',/,

\& 78('*'),/l,

\& 2X, 'Z',6X, 'G (KG/HR)',4X,'HX (J/KG)',3X, 'HI (J/KG)',

\& 3X,'HY (J/KG)',4X,'TX (K)',I,

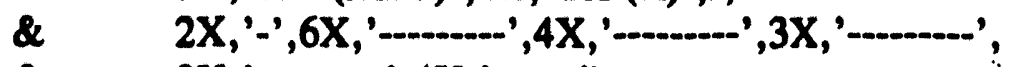

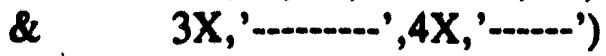

140 FORMAT $\left(/, 78\left({ }^{\prime} * '\right), /\right.$,

\& '***',28X, 'COLUMN PROFILES',29X,'***',/,

\& 78('*'),/l,

\& 2X, 'Z',6X, 'G (LB/HR)',4X,'HX (BTU/LB)',3X,

\& 'HI (BTU/LB)',3X, 'HY (BTU/LB)',4X, 'TX (F)',/,

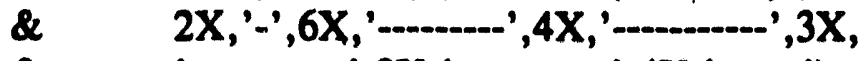

\& '---.-.--',3X,'---.--.-',4X,'--..-')

141 FORMAT(F5.3,4(2X,E12.5),2X,F7.1)

142 FORMAT( $/, 78\left({ }^{\prime *}\right), /$,

\& '***', 28X, 'COLUMN PROFILES',29X,'***',/,

\& 78('*'),/l,

\& $\quad 2 \mathrm{X}, \mathrm{Z}$ ',

\& 6X, 'TAPPR',4X, 'TY (K)',7X, 'HUMI',10X, 'HUMID',

\& 8X,'HUMSAT',/,

\& $2 \mathrm{X}, '-1$

$\& \quad 6 \mathrm{X}$

\& 8X,'---.')

143 FORMAT( $/, 78\left({ }^{\prime} * '\right), /$,

\& '***',28X, 'COLUMN PROFILES',29X,'***', /,

\& 78('*'),/l,

\& $2 \mathrm{X}, \mathrm{Z}$ ',

\& 6X,'TAPPR',4X,'TY (F)',7X, 'HUMI',10X, 'HUMID',

\& 8X,'HUMSAT',/,

\& $2 \mathrm{X}, \mathrm{\prime}^{\prime}$,

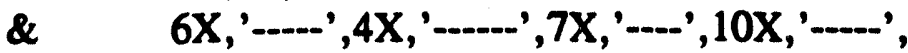

\& $8 \mathrm{X}, \mathbf{\prime}^{\left.-----)^{\prime}\right)}$ 
144 FORMAT(F5.3,2X,F7.1,2X,F7.1,3(2X,F12.5))

145 FORMAT(/,'TINTEG CONVERGENCE SUMMARY',/,

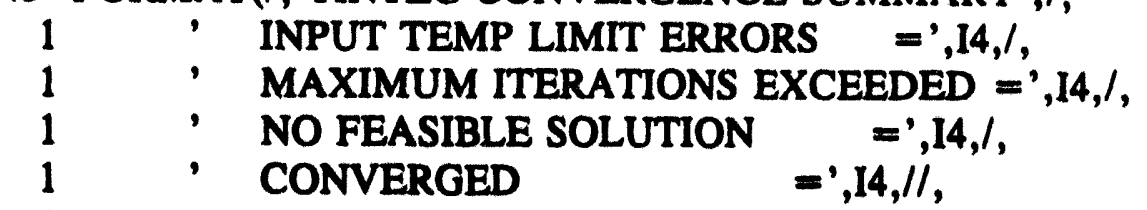

1 'SATURATED TYOUT CONVERGENCE SUMMARY',/,

1 ' CONVERGED =',14,1,

1 NOT CONVERGED $\quad='$, I4)

146 FORMAT( $/, 78\left({ }^{\prime *}\right), /$,

$1^{\prime * * * \prime}, 25 X,{ }^{\prime}$ COLUMN CHARACTERISTICS',25X, ${ }^{* * * *}, l$, 178('*'))

147 FORMAT(/,

1'L/G RATIO =',F20.5,/,

1' ACCORDING TO PERRYS HANDBOOK, L/G FOR MECHANICAL DRAFT', ,,

1' COOLING TOWERS SHOULD BE BETWEEN 0.75 - 1.50 AND',/,

1' THE SECOND COLUMN CHARACTERISTIC LISTED BELOW SHOULD',/,

1' BE BETWEEN 0.50 - 2.50',/l,

1 'COLUMN CHARACTERISTIC =',F20.5,/,

1'THIS COLUMN CHARACTERISTIC IS EQUAL TO THE FOLLOWING',,/,

1' $\left(\mathrm{Ky}^{*} \mathrm{Mb} \mathbf{A m}^{*} \mathrm{AT}\right) / \mathrm{Gy}$ or $\left(\mathrm{Ky}^{*} \mathrm{Mb}^{*} \mathrm{Am} \mathrm{m}^{*} \mathrm{VT}\right) / \mathrm{My} \mathbf{y}^{\prime}, /$,

1' (hy*Ah*ZT)/(Cs*Gy) or (hy*Ah*VT)/(Cs*My)',/l,

1'or')

148 FORMAT(/,

1'COLUMN CHARACTERISTIC =',F20.5,/,

1'THIS COLUMN CHARACTERISTIC IS EQUAL TO THE FOLLOWING',/,

1' $\left(\mathrm{Ky}^{*} \mathrm{Mb}^{*} \mathrm{Am} * \mathrm{ZT}\right) / \mathrm{Gx},\left(\mathrm{Ky}^{*} \mathrm{Mb}^{*} \mathrm{Am}{ }^{*} \mathrm{VT}\right) / \mathrm{Mx}$, IF Cl IS ABOUT UNITY')

149 FORMAT $($,

1' where: $\mathrm{Ky}=$ gas mass transfer coefficient (lb-mol/ft2-h)',/,

1. $\quad \mathrm{Mb}=$ dry-air molecular weight $(\mathrm{lb} / \mathrm{lb} \mathrm{mol}),, /$,

1' $\quad \mathrm{Am}=$ transfer area for mass transfer $(\mathrm{ft} 2 / \mathrm{ft} 3)^{\prime}, 1$,

1' $\quad$ ZT $=$ total column height $(\mathrm{ft})^{\prime}, /$,

1' $\quad$ Gy = dry-air flux (lb/ft2-h)',/,

1' hy = gas heat transfer coefficient (Btu/ft2-h-F)',/,

1. $\quad A h=$ transfer area for heat transfer (ft2/ft3)',, ,

1' $\quad$ Cs $=$ humid heat (Btu/lb-F)',/,

1' $\mathrm{hx}=$ liquid heat transfer coefficient $(B t u / f t 2-h-F)$,

$1 /$,

1' $\quad \mathrm{Cl}=$ specific heat of liquid (Btu/lb-F)',/,

1' $\quad \mathrm{Gx}=$ liquid mass flux (b/ft2-h)',l,

1' VT = total contact volume (ft3)', /,

1' $\quad$ My $=$ dry-air flowrate $(\mathrm{lb} / \mathrm{h})^{\prime}, /$,

C

1' $\quad \mathrm{Mx}=$ liquid mass flowrate $\left.(\mathrm{lb} / \mathrm{h})^{\prime}, \mathrm{l}\right)$ 


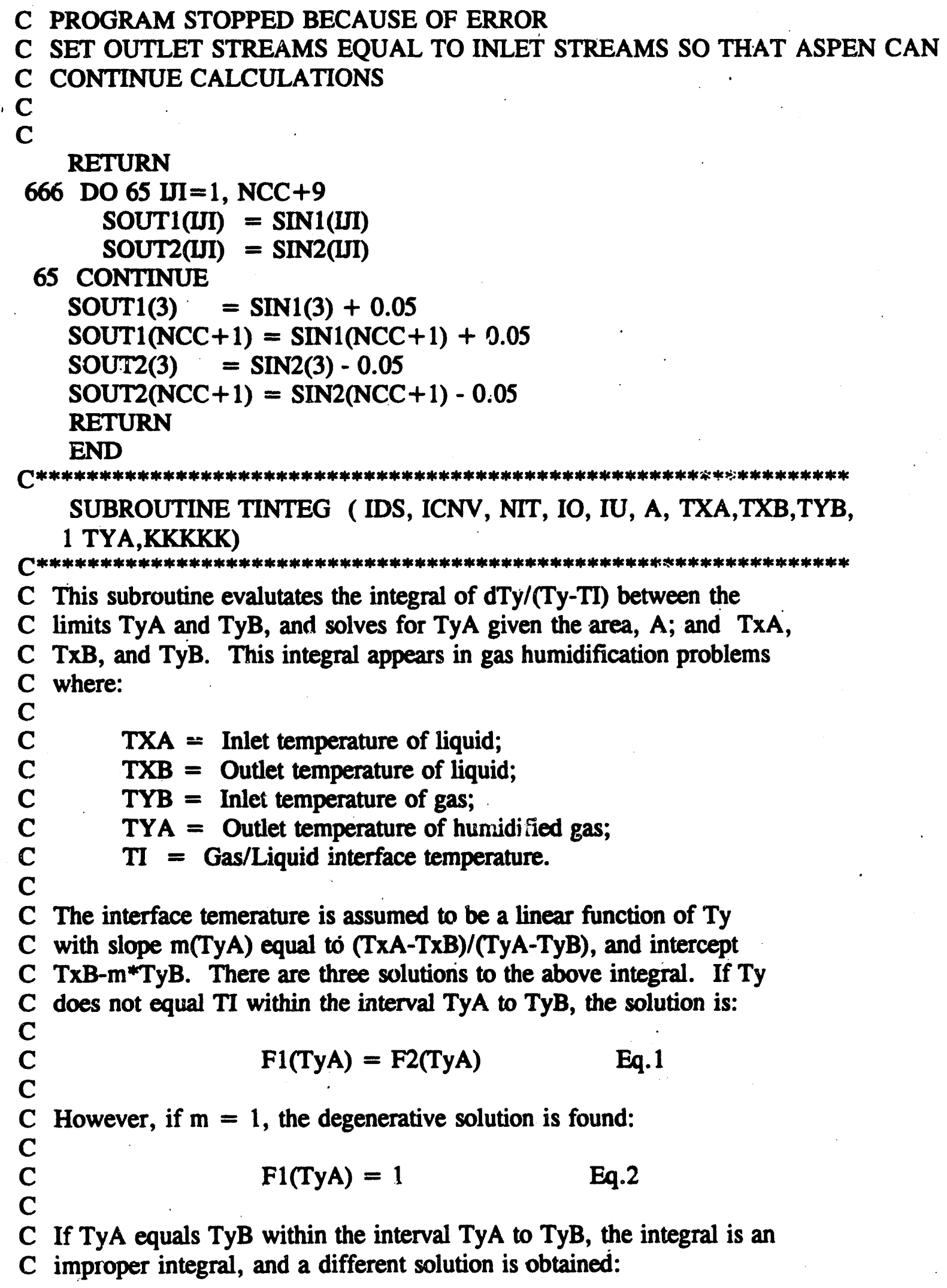

C This subroutine evalutates the integral of $\mathrm{dTy} /(\mathrm{Ty}-\mathrm{TI})$ between the

C limits TyA and TyB, and solves for TyA given the area, A; and TxA,

C TxB, and TyB. This integral appears in gas humidification problems

C where:

C

C $\quad$ TXA $=$ Inlet temperature of liquid;

C $\quad$ TXB = Outlet temperature of liquid;

C $\quad$ TYB $=$ Inlet temperature of gas;

C $\quad$ TYA $=$ Outlet temperature of humidified gas;

C $\quad$ TI $=$ Gas/Liquid interface temperature.

C

C The interface temerature is assumed to be a linear function of Ty

C with slope m(TyA) equal to (TxA-TxB)/(TyA-TyB), and intercept

C TxB- $m *$ TyB. There are three solutions to the above integral. If Ty

C does not equal TI within the interval TyA to TyB, the solution is:

C

C

$$
\mathrm{F} 1(\mathrm{TyA})=\mathrm{F} 2(\mathrm{TyA}) \quad \text { Eq. } 1
$$

C

C However, if $m=1$, the degenerative solution is found:

C

C$$
\mathrm{F} 1(\mathrm{TyA})=1
$$

Eq.2

C

C If TyA equals TyB within the interval TyA to TyB, the integral is an

C improper integral, and a different solution is obtained: 


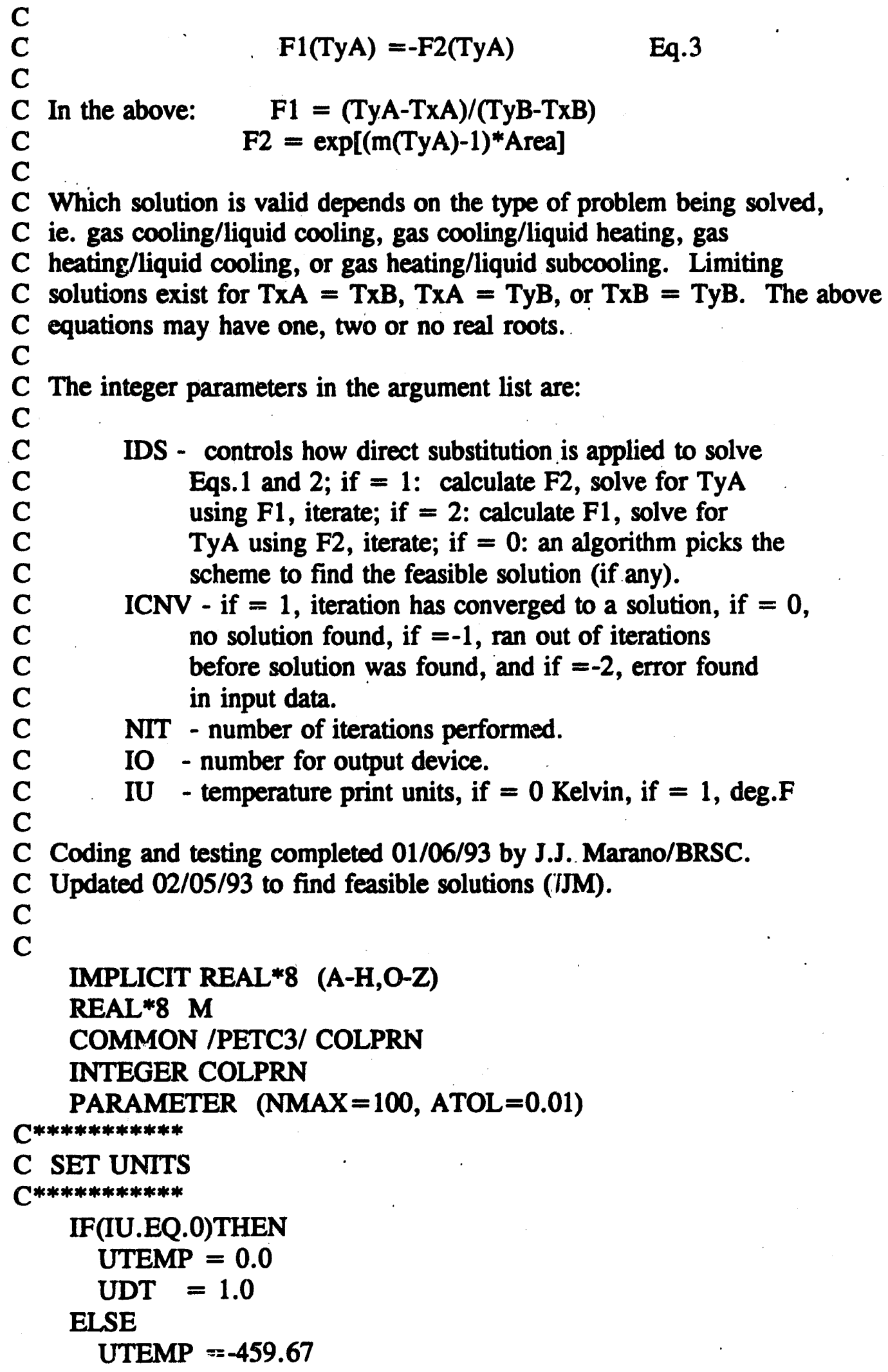




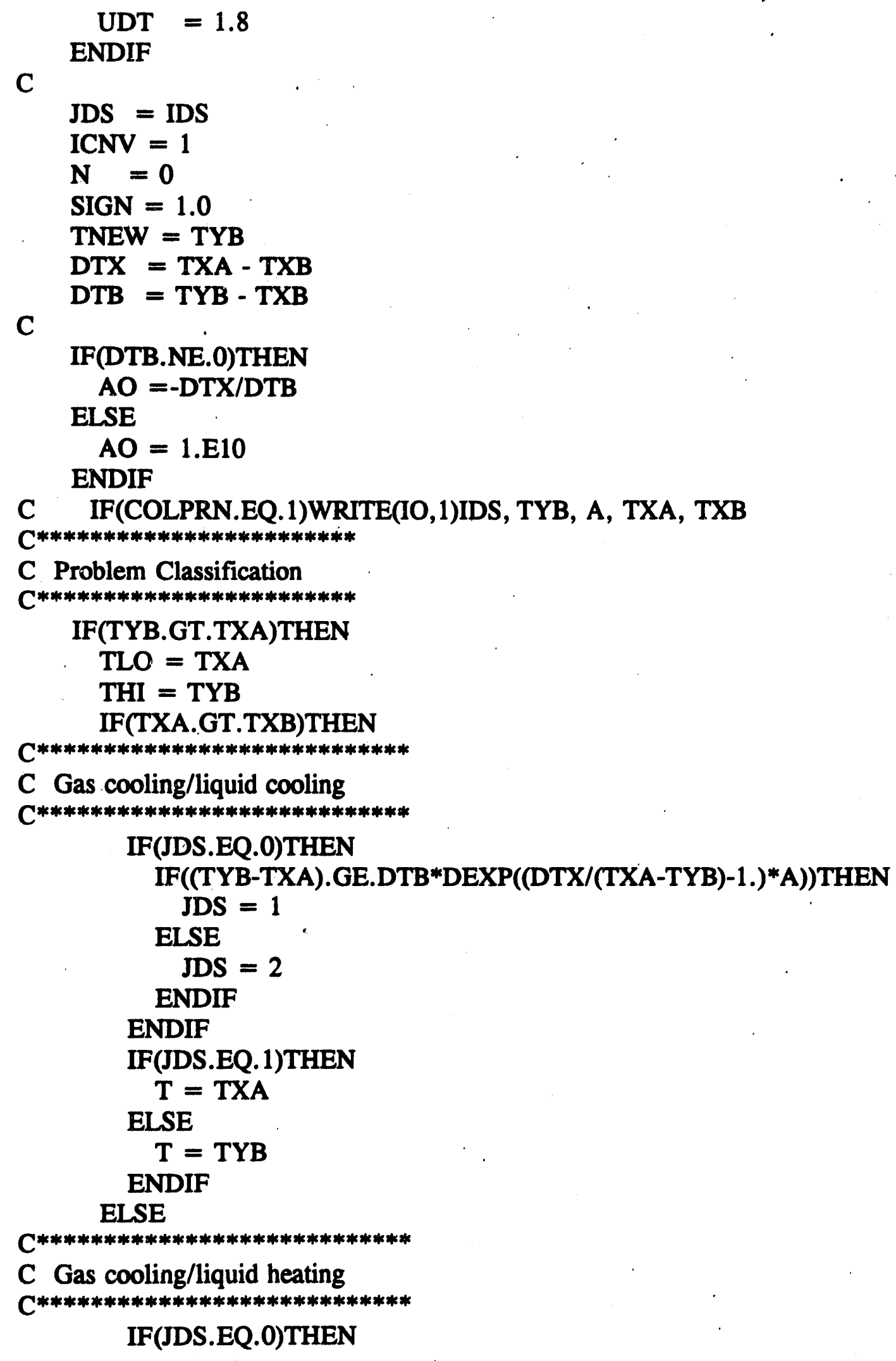

IF(JDS.EQ.0)THEN IF((TYB-TXA).GE.DTB*DEXP((DTX/(TXA-TYB)-1.)*A))THEN JDS $=1$$$
T=T Y B
$$

ENDIF

\section{ELSE}

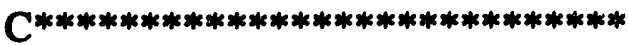

C Gas cooling/liquid heating

$\mathrm{C} * * * * * * * * * * * * * * * * * * * * * * * * * * * * * * * * * *$

IF(JDS.EQ.0)THEN 


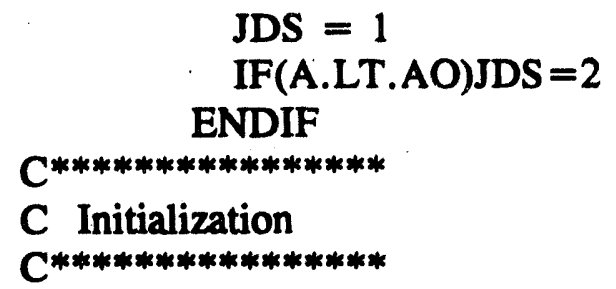

C Gas heating/liquid subcooling

C***********************************

IF(JDS.EQ.0)JDS $=2$

SIGN $=-1.0$

ELSEIF(TYB.LT.TXB)THEN

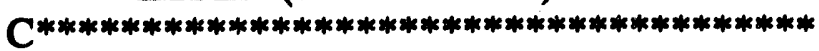

C Gas heating/"normal" liquid cooling

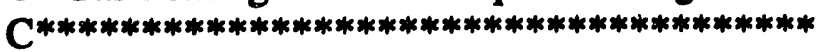




$$
\begin{aligned}
& \text { IF(JDS.EQ.0)THEN } \\
& \text { JDS }=1 \\
& \text { IF(A.LT.AO)JDS = } 2 \\
& \text { ENDIF }
\end{aligned}
$$

\section{ENDIF}

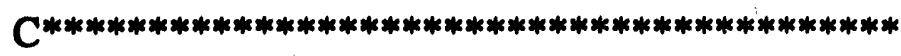

C Check for input temperature limit error

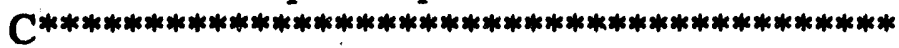

$$
\begin{aligned}
& \text { IF(TXB.GT.TXA)THEN } \\
& \text { ICNV }=-2 \\
& \text { GOTO } 100
\end{aligned}
$$

ENDIF

\section{ELSE}

$\mathrm{C}^{* * * * * * * * * * * * * * * * * * * * * * * * * * * * * * * * * * * * * * *}$

C Gas heating/TXB equal to TYB

$\mathrm{C} * * * * * * * * * * * * * * * * * * * * * * * * * * * * * * * * *$

$$
\text { IF(JDS.EQ.0)THEN }
$$

$\mathrm{JDS}=2$

IF(COLPRN.EQ.1)THEN

C WRITE (IO,2) JDS, TLO*UDT+UTEMP, THI*UDT+UTEMP, AO

C WRITE $(I 0,5) \mathrm{N}$, TNEW*UDT+UTEMP, 100000., 100000.

ENDIF

GOTO 100

\section{ENDIF}

END IF

C*******************

C Initialization

C********************

IF (JDS.EQ.1) THEN

$$
T=\text { TXA }+ \text { SIGN*DTB*DEXP(-A) }
$$

ELSE

$$
T=T Y B
$$

\section{ENDIF}

C

\section{ELSE}

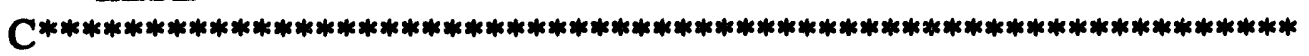

C Gas isothermal/liquid cooling; check for input temperature

C limit error

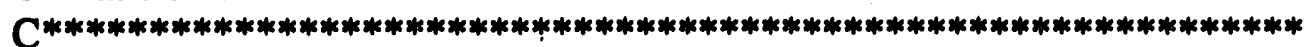

$$
\text { IF(TXB.GT.TXA)THEN }
$$

ICNV $=-2$

\section{ELSE}

$$
\text { IF(COLPRN.EQ.1)THEN }
$$

C WRITE(IO,2) JDS, TNEW*UDT+UTEMP, TNEW*UDT+UTEMP, AO

C WRITE(IO,5) N, TNEW*UDT +UTEMP, 100000., 100000. 


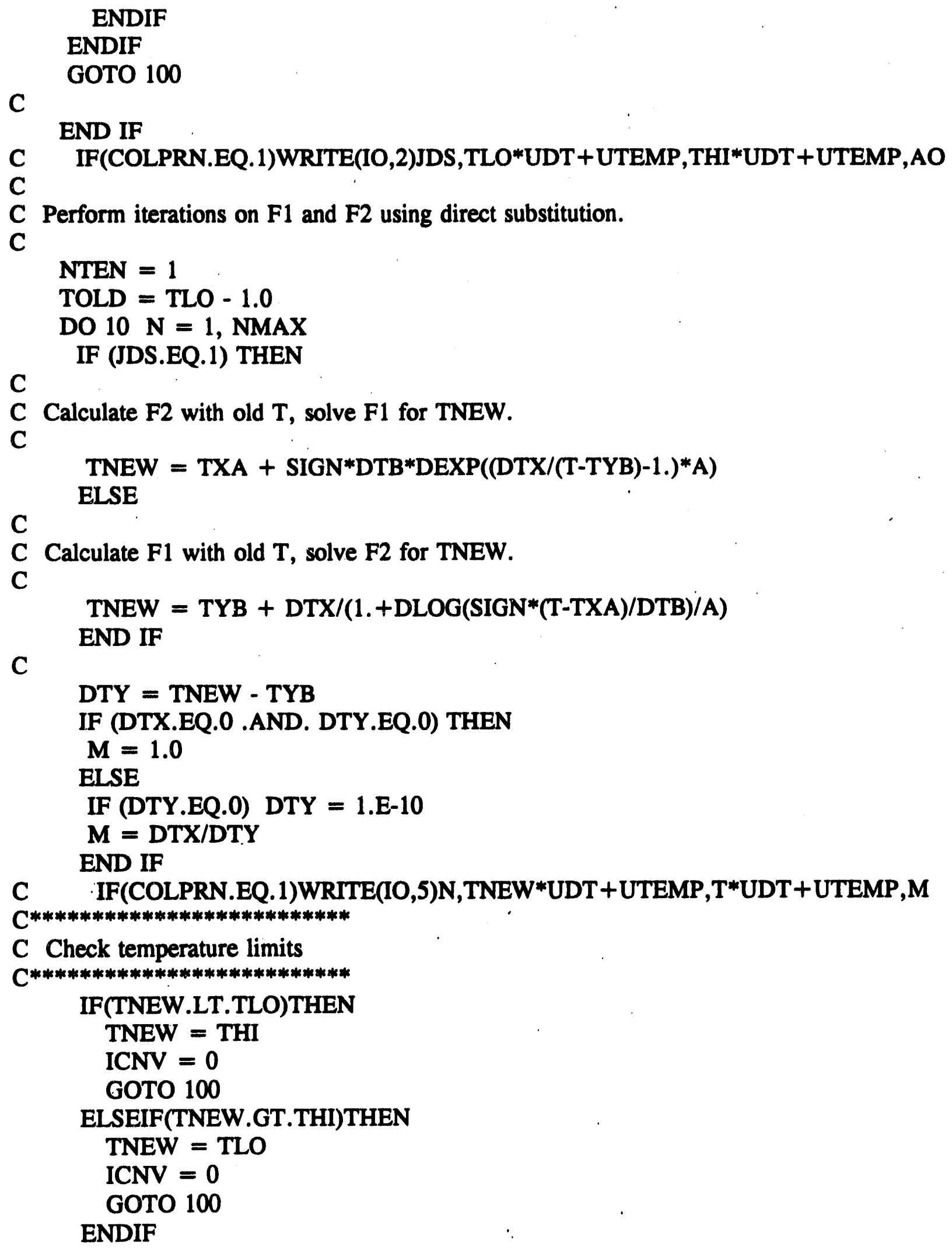




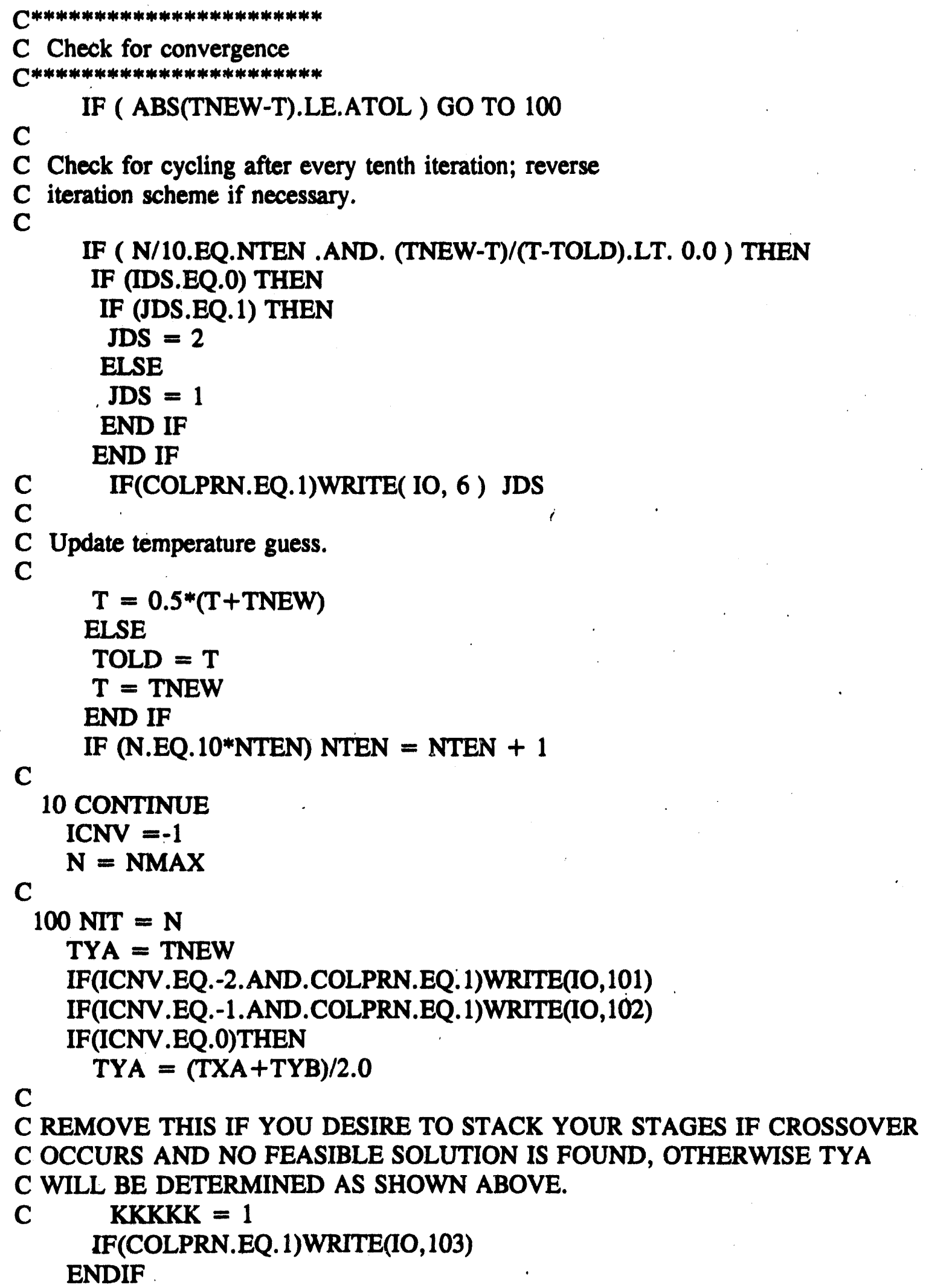

C REMOVE THIS IF YOU DESIRE TO STACK YOUR STAGES IF CROSSOVER C OCCURS AND NO FEASIBLE SOLUTION IS FOUND, OTHERWISE TYA 
IF(ICNV.EQ.1.AND.COLPRN.EQ.1)WRITE(IO,104)

$\mathrm{C} * * * * * * * * * * * * * * * * * * * * *$

C FORMAT STATEMENTS

$\mathrm{C} * * * * * * * * * * * * * * * * * * * * * *$

1 FORMAT $\left(/ / /^{* * *}\right.$ SOLVING FOR THE OUTLET GAS TEMPERATURE ***',/, \&'TINTEG: IDS =', I3,' TYB =', F8.3, 16X,

\& AREA $=$ ', F8.4,

\& I,'TINTEG: ', ' TXA =', F8.3,' TXB =', F8.3)

2 FORMAT ('TINTEG: JDS =', 13,' TLO =', F8.3,' THI =', F8.3,

\& ' AM1 =', F8.4)

5 FORMAT ('TINTEG: ITER =', 13,' TNEW =', F8.3,' TOLD =', F8.3,

\& $, M=', F 8.4$ )

6 FORMAT ('TINTEG: JDS =', I3)

101 FORMAT ('TINTEG: INPUT TEMP LIMIT ERROR',/)

102 FORMAT ('TINTEG: MAX ITERATIONS EXCEEDED',/)

103 FORMAT ('TINTEG: NO FEASIBLE SOLUTION FOUND',/,

1

AVERAGE TEMPERATURE WILL BE USED',/)

104 FORMAT ('TINTEG: CONVERGED',/)

RETURN

END

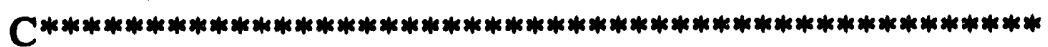

SUBROUTINE INTERP (INT, IPT, TS, HI, HUMID)

$\mathrm{C} * * * * * * * * * * * * * * * * * * * * * * * * * * * * * * * * * * * * * * * * * * * * * * * * * * * * * *$

C

C INT $=0$ :

C Given a temperature, this subroutine performs a table look up

C for interfacial enthalpy and humidity for the air/water system.

C

C INT $=1$ :

C Given a humidity, look up temperature and enthalpy.

C

C INT $=2$ :

C Given a enthalpy, look up temperature.

C

C Linear interpolation for $T$ vs. $H$, and $1 / T$ vs. $\ln (\mathrm{Hum})$.

C

IMPLICIT REAL*8 (A-H,O-Z)

COMMON /PETC1/ TINT, HINT, HUMINT, NPTS

DIMENSION TINT(1000), HINT(1000),HUMINT(1000)

PARAMETER $($ IOUT $=61)$

C

C TS known, find HI AND HUMID

C

IF (INT.EQ.0) THEN 


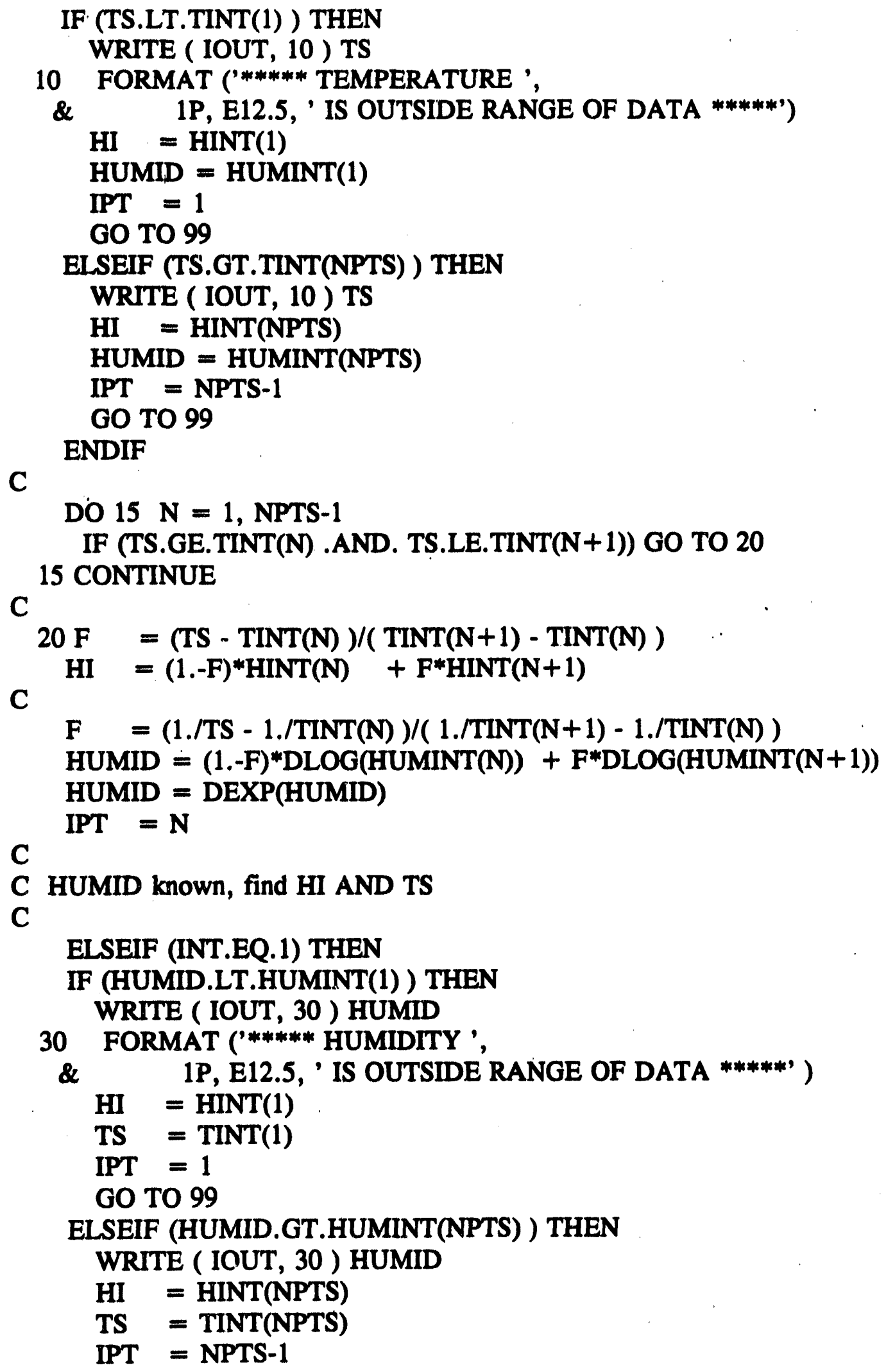




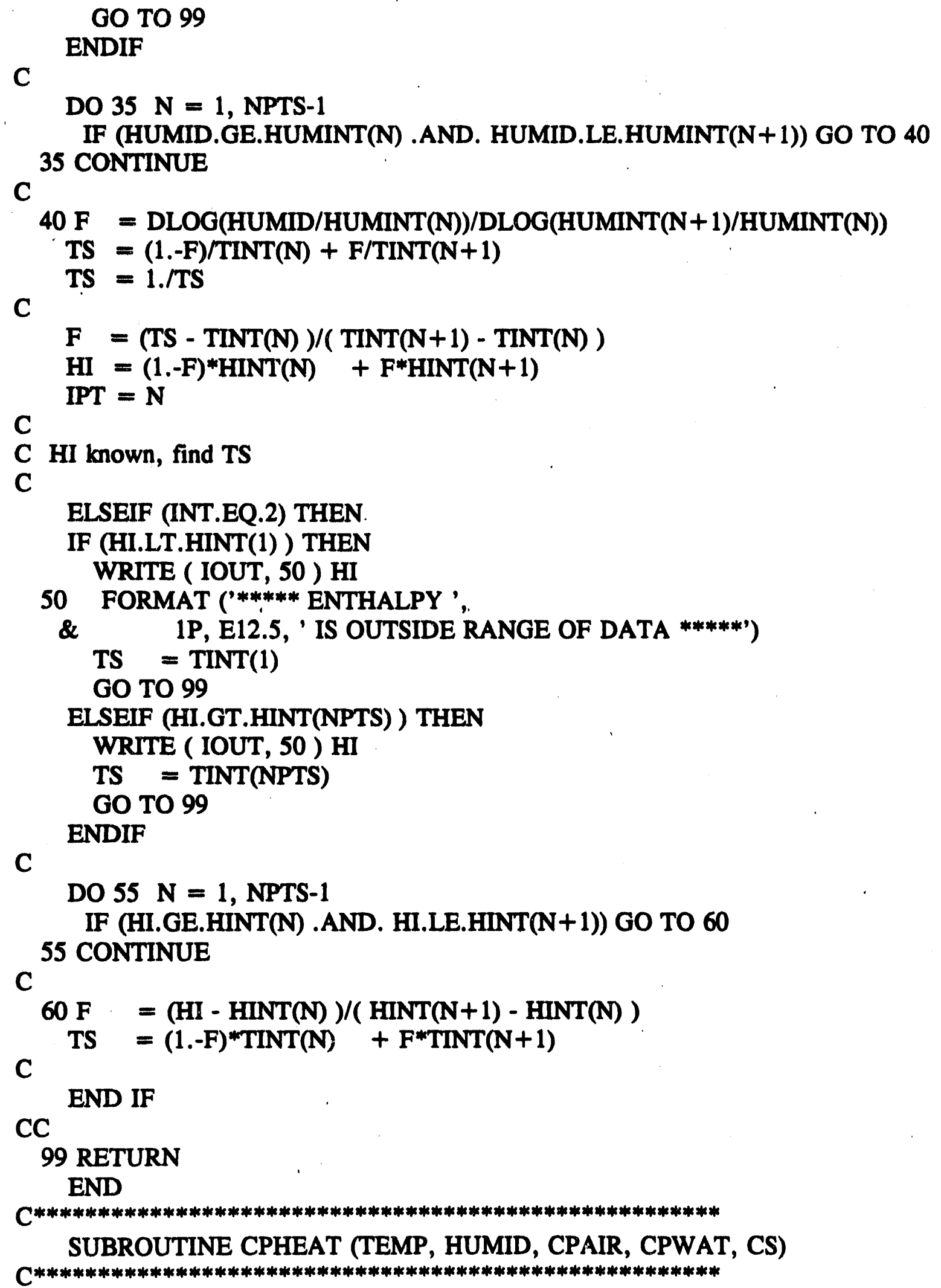


C

C GIVEN A TEMPERATURE, THIS SUBROUTINE CALCULATES THE HEAT CAPACITY

C FOR DRY AIR AND WATER VAPOR. GIVEN A TEMPERATURE AND HUMIDITY, THIS

C SUBROUTINE ALSO CALCULATES CS.

C CORRELATIONS FOR AIR AND WATER VAPOR CP FROM "BASIC PRINCIPLES AND

C CALCULATIONS IN CHEMICAL ENGINEERING", HIMMELBLAU,

C THIRD EDITION, PG. 495-497

C

IMPLICIT REAL*8 (A-H,O-Z)

REAL *8 MWH2O

COMMON /PETC2/ AIRMW, TREF

CPAIR $=0$. DO

CPWAT $=0 . \mathrm{DO}$

$\mathrm{CS}=0 . \mathrm{DO}$

C

$\mathrm{T}=(\mathrm{TEMP}+\mathrm{TREF}) / 2.0$

C DRY AIR CP IN J/KG-K

C

CPAIR $=6.713+0.04697 \mathrm{E}-2 * \mathrm{~T}+0.1147 \mathrm{E}-5 * \mathrm{~T} * \mathrm{~T}-0.4696 \mathrm{E}-9 * \mathrm{~T}^{*} \mathrm{~T} * \mathrm{~T}$

C

CPAIR $=($ CPAIR*1.0E3)/(0.239*AIRMW)

C WATER VAPOR CP IN J/KG-K

C

CPWAT $=6.970+0.3464 \mathrm{E}-2 * \mathrm{~T}-0.0483 \mathrm{E}-5 * \mathrm{~T} * \mathrm{~T}$

CPWAT $=($ CPWAT $* 1.0 \mathrm{E} 3) /(0.239 * 18.015)$

C

C CALCULATE CS IN J/KG-K

C

CS = CPAIR + CPWAT*HUMID

RETURN

END

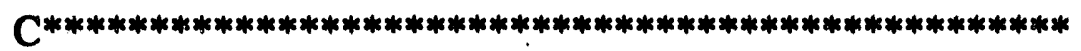

SUBROUTINE VAPINT (INT, TEMP, PRES, HEATVAP)

$\mathrm{C} * * * * * * * * * * * * * * * * * * * * * * * * * * * * * * * * * * * * * * * * * * * * * * * * * * * * * * * * * *)$

C

C THIS SUBROUTINE INTERPOLATES THE HEAT OF VAPORIZATION FOR WATER

C AS A FUNCTION OF TEMPERATURE AND PRESSURE

C IF INT $=1$, GIVEN A TEMPERATURE, THE SUBROUTINE RETURNS THE CORRESPONDING

C HEAT OF VAPORIZATION

C IF INT =2, GIVEN A PRESSURE, THE SUBROUTINE RETURNS THE 


\section{CORRESPONDING}

C BOILING POINT FOR WATER

C

IMPLICIT REAL*8 (A-H,O-Z)

DIMENSION TV(190),HV(190),PV(190)

PARAMETER (IOUT $=61$ )

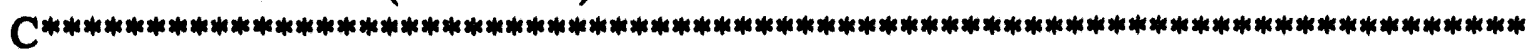

C HEAT OF VAPORIZATION DATA FOR WATER/STEAM TAKEN FROM SMITH \& VAN NESS

C STEAM TABLES,

C TV = TEMPERATURE IN F

C HV = HEAT OF VAPORIZATION IN BTU/LB

C PV . = PRESSURE IN PSI

C NPTS $=$ TOTAL NUMBER OF DATA POINTS IN ARRAYS

C

DATA NPTS $/ 190 /$

DATA TV / 32, 34, 36, 38, 40, 42, 44, 46, 48, 50, 52, 54, 56,

$1 \quad 58,60,62,64,66,68,70,72,74,76,78,80,82$,

$2 \quad 84,86,88,90,92,94,96,98,100,102,104,106,108$,

$3110,112,114,116,118,120,122,124,126,128,130,132,134$,

$4136,138,140,142,144,146,148,150,152,154,156,158,160$,

$5 \quad 162,164,166,168,170,172,174,176,178,180,182,184,186$,

$6188,190,192,194,196,198,200,202,204,206,208,210,212$,

$7 \quad 215,220,225,230,235,240,245,250,255,260,265,270,275$,

$8280,285,290,295,300,305,310,315,320,325,330,335,340$,

$9 \quad 345,350,355,360,365,370,375,380,385,390,395,400,405$,

$14410,415,420,425,430,435,440,445,450,455,460,465,470$,

$2475,480,485,490,495,500,505,510,515,520,525,530,535$,

$3 \quad 540,545,550,555,560,565,570,575,580,585,590,595,600$,

$4 \quad 605,610,615,620,625,630,635,640,645,650,655,660,665$,

$5670,675,680,685,690,695,700,705$ I

DATA HV / 1075.1,1074.0,1072.9,1071.7,1070.5,1069.3,1068.2,

1 $1067.1,1065.9,1064.8,1063.6,1062.5,1061.4,1060.2$, $1059.1,1057.9,1056.8,1055.7,1054.5,1053.4,1052.3$, $1051.2,1050.1,1048.9,1047.8,1046.6,1045.5,1044.4$, 1043.2,1042.1,1040.9,1039.8,1038.7,1037.5,1036.4, 1035.2,1034.1,1033.0,1032.0,1030.9,1029.7,1028.6, $1027.5,1026.4,1025.3,1024.1,1023.0,1021.8,1020.7$, 1019.5,1018.3,1017.2,1016.0,1014.9,1013.7,1012.5, 1011.3,1010.2,1009.0,1007.8,1006.7,1005.5,1004.4, 1003.2,1002.0,1000.8, 999.7, 998.5, 997.3, 996.1, 995.0, 993.8, 992.6, 991.4, 990.2, 989.0, 987.8, 986.6, 985.3, 984.1, 982.8, 981.5, 980.3, 979.0, 977.8, 976.6, 975.3, 974.1, 972.8, 971.5, 970.3, 
968.3, 965.2, 961.9, 958.7, 955.3, 952.1, 948.7, 945.3, 942.0, 938.6, 935.3, 931.8, 928.2, 924.6, 921.0, 917.4, 913.7, 910.1, 906.3, 902.6, 898.8, 895.0, 891.1, 887.1, 883.2, 879.2, 875.1, 871.0, 866.8, 862.5, 858.2, 853.8, 849.4, 844.9, 840.4, 835.7, 831.0, 826.2, 821.4, 816.6, 811.7, 806.7, 801.6, 796.5, 791.2, 785.9, 780.4, 774.9, 769.3, $763.6,757.8,751.9,745.9,739.8,733.6,727.3$, $720.8,714.2,707.5,700.6,693.6,686.5,679.2$, $671.9,664.4,656.7,648.9,640.9,632.6,624.1$, 615.4, 606.5, 597.4, 588.1, 578.6, 568.8, 558.7, $548.4,537.7,526.6,515.3,503.7,491.5,478.8$, $465.5,452.0,437.6,422.7,407.0,390.5,372.1$, $353.3,332.8,310.0,284.5,254.9,219.1,171.7$, 77.61

DATA PV / 0.0886,0.0961,0.1041,0.1126,0.1217,0.1315,0.1420,

$0.1532,0.1652,0.1780,0.1918,0.2063,0.2219,0.2384$, $0.2561,0.2749,0.2949,0.3162,0.3388,0.3628,0.3883$, $0.4153,0.4440,0.4744,0.5067,0.5409,0.5772,0.6153$, $0.6555,0.6980,0.7429,0.7902,0.8403,0.8930,0.9487$, $1.0072,1.0689,1.1338,1.2020,1.2740,1.3500,1.4290$, $1.5120,1.6000,1.6920,1.7880,1.8890,1.9950,2.1050$, 2.2210,2.3430,2.4700,2.6030,2.7420,2.8870,3.0390, 3.1980,3.3630,3.5360,3.7160,3.9040,4.1000,4.3050, 4.5180,4.7390,4.9700,5.2100,5.4600,5.7200,5.9900, 6.2720,6.5650,6.8690,7.1840,7.5100,7.8490,8.2010, 8.5660,8.9440,9.3360,9.7440,10.168,10.605,11.057, $11.525,12.010,12.512,13.031,13.568,14.123,14.696$, $15.591,17.188,18.915,20.780,22.800,24.970,27.310$, 29.820,32.530,35.430,38.540,41.850,45.400,49.200, $53.250,57.550,62.130,67.010,72.180,77.680,83.500$, 89.650,96.160,103.03,110.31,117.99,126.10,134.62, $143.58,153.01,162.93,173.33,184.23,195.70,207.71$, 220.29,233.47,247.25,261.67,276.72,292.44,308.82, $325.91,343.71,362.27,381.59,401.70,422.61,444.35$, $466.97,490.43,514.70,539.90,566.12,593.28,621.44$, $650.59,680.80,712.19,744.55,777.96,812.68,848.37$, $885.20,923.45,962.80,1003.6,1045.6,1088.8,1133.4$, $1179.3,1226.7,1275.7,1326.1,1378.1,1431.5,1486.5$, 1543.2,1601.5.1661.6,1723.4,1787.0,1852.4,1919.8, 1989.0,2060.3,2133.5,2208.8,2286.4,2366.2,2448.0, $2532.4,2619.2,2708.4,2800.4,2895.0,2992.7,3094.1$, $3199.1 /$ 
C FOR INT $=1$, GIVEN $\triangle$ TEMPERATURE, FIND THE CORRESPONDING HEAT OF

C VAPORIZATION

C

IF(INT.EQ.1)THEN

IF (TEMP.LT.TV(1)) THEN

WRITE (IOUT, 10) TEMP

HEATVAP $=$ HV $(1)$

GOTO 99

ENDIF

IF (TEMP.GT.TV(NPTS)) THEN

WRITE (IOUT, 10) TEMP

HEATVAP $=$ HV(NPTS)

GOTO 99

ENDIF

DO $15 \mathrm{~N}=1, \mathrm{NPTS}-1$

IF (TEMP.GE.TV(N) .AND. TEMP.LE.TV(N+1)) GO TO 20

15 CONTINUE

$20 \mathrm{~F}=(\operatorname{TEMP}-\mathrm{TV}(\mathrm{N})) /(\mathrm{TV}(\mathrm{N}+1)-\mathrm{TV}(\mathrm{N}))$

HEATVAP $=(1 .-\mathrm{F})^{*} \mathrm{HV}(\mathrm{N})+\mathrm{F}^{*} \mathrm{HV}(\mathrm{N}+1)$

GOTO 99

ENDIF

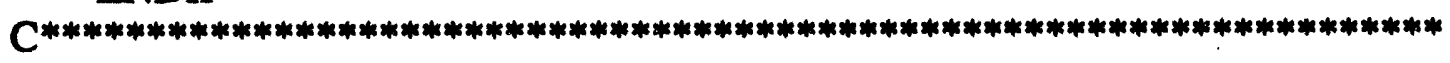

C FOR INT $=2$, GIVEN A PRESSURE, FIND THE CORRESPONDING BOILING POINT

C TEMPERATURE FOR WATER

C

IF(INT.EQ.2)THEN

IF (PRES.LT.PV(1)) THEN

WRITE (IOUT, 11) PRES

TEMP $=$ TV(1)

GOTO 99

ENDIF

IF (PRES.GT.PV(NPTS)) THEN

WRITE (IOUT, 11) PRES

TEMP $=$ TV(NPTS)

GOTO 99

ENDIF

DO $16 \mathrm{~N}=1$,NPTS-1

IF (PRES.GE.PV(N) .AND. PRES.LE.PV(N+1)) GO TO 21

16 CONTINUE

$21 \mathrm{~F}=(\mathrm{PRES}-\mathrm{PV}(\mathrm{N})) /(\mathrm{PV}(\mathrm{N}+1)-\mathrm{PV}(\mathrm{N}))$

TEMP $=(1 .-\mathrm{F})^{*} \mathrm{TV}(\mathrm{N})+\mathrm{F}^{*} \mathrm{TV}(\mathrm{N}+1)$

GOTO 99

ENDIF

$\mathrm{C} * * * * * * * * * * * * * * * * * * * * * * * *$ 

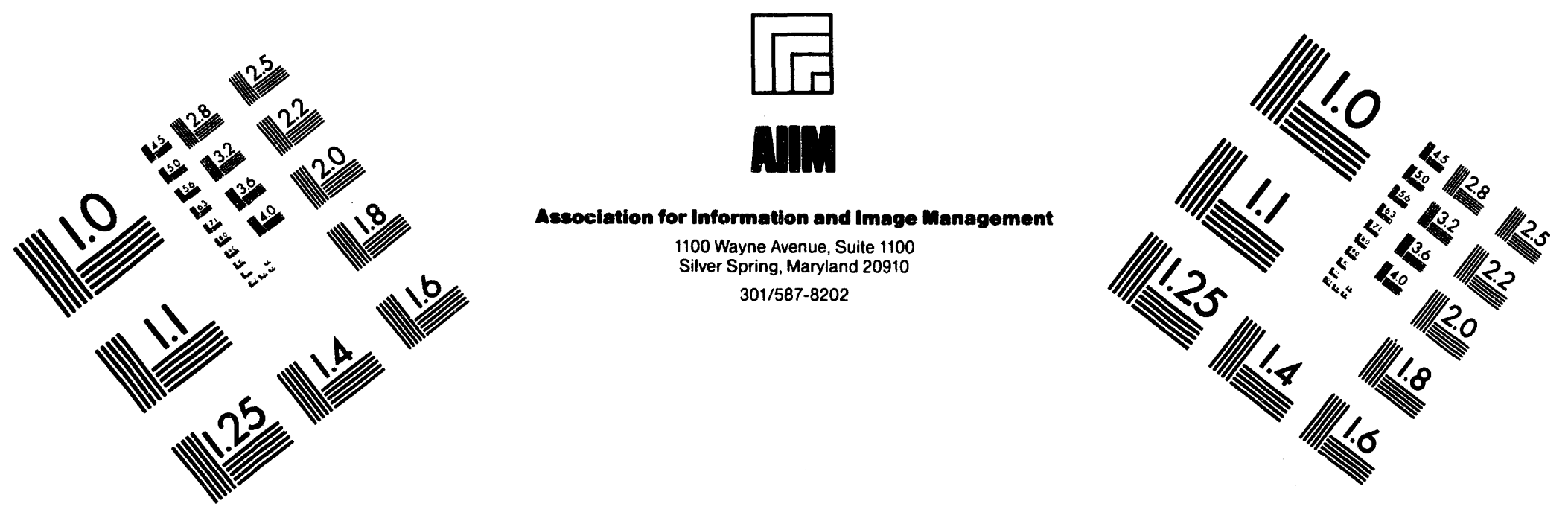

\section{Centimeter}

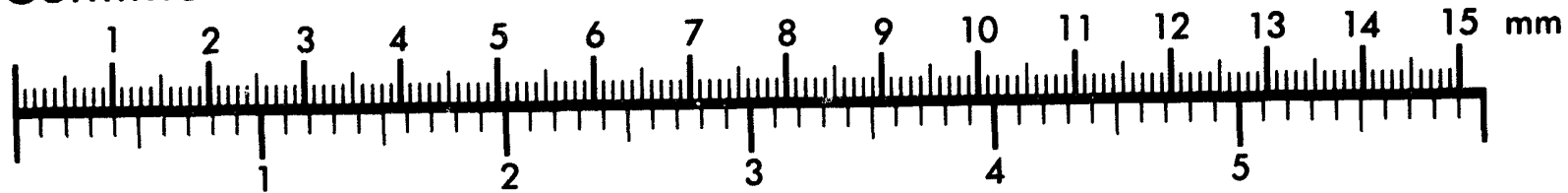

Inches
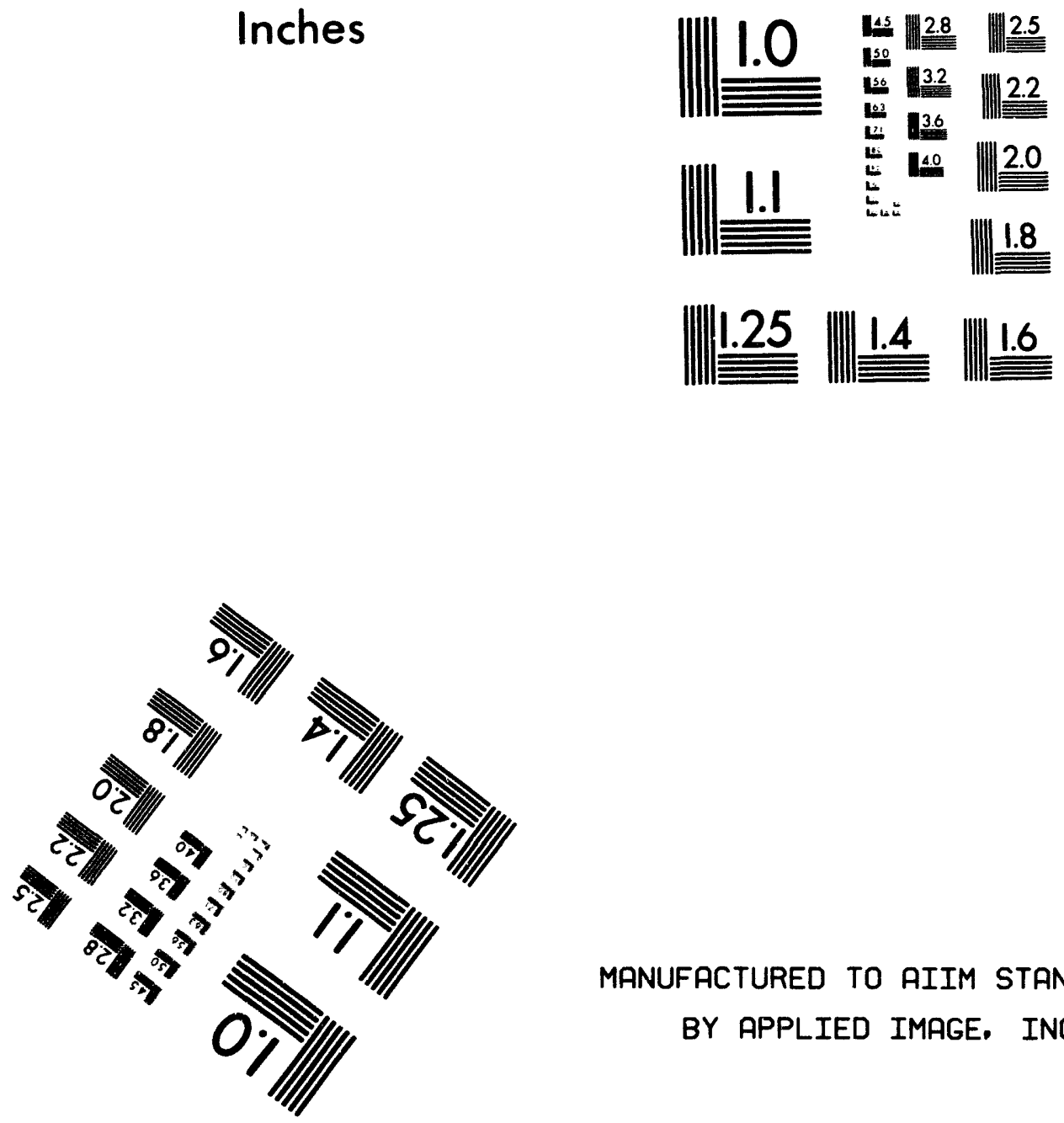

MANUFACTURED TO AIIM STANDARDS

BY APPLIED IMAGE, INC.

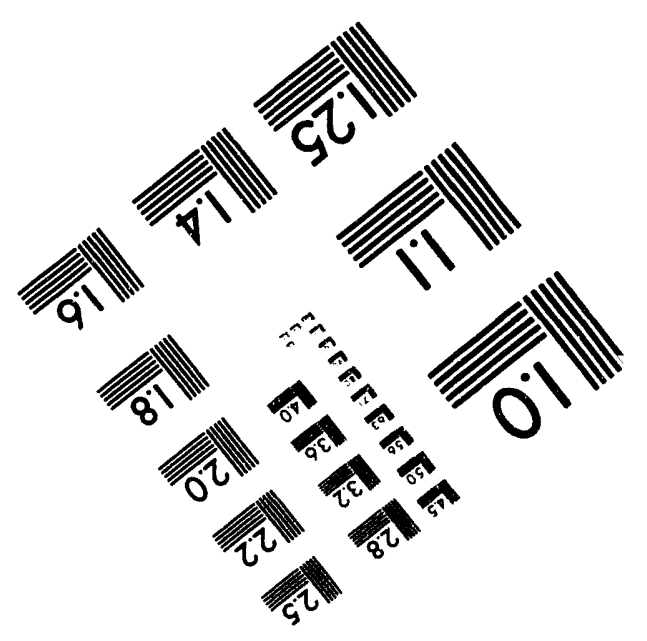



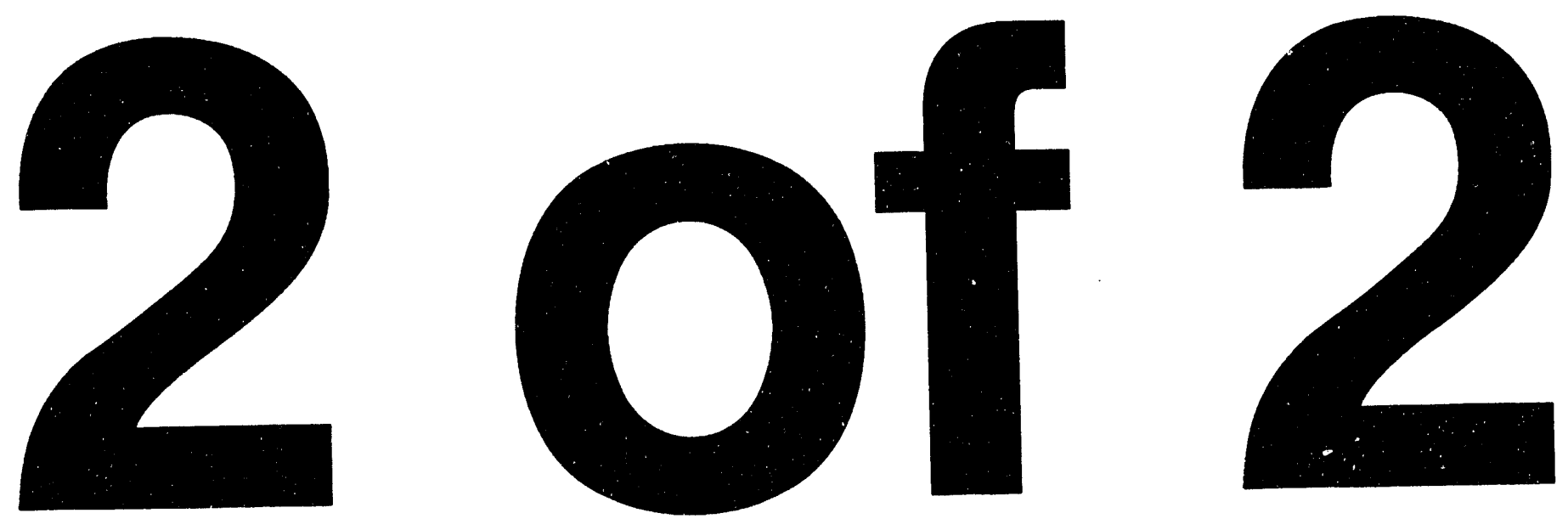
C FORMAT STATEMENTS

$\mathrm{C} * * * * * * * * * * * * * * * * * * *$

10 FORMAT ('***** TEMPERATURE IS OUTSIDE RANGE OF DATA *****', $1 \quad 1, * * * * * \quad$ IN SUBROUTINE VAPINT

$1 \quad 1,{ }^{* * * * *} \quad$ TEMP $=$ ',F10.5,'

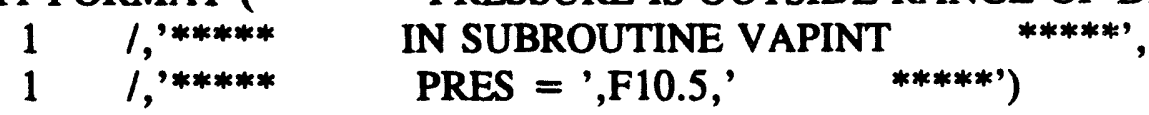

99 RETURN

END 

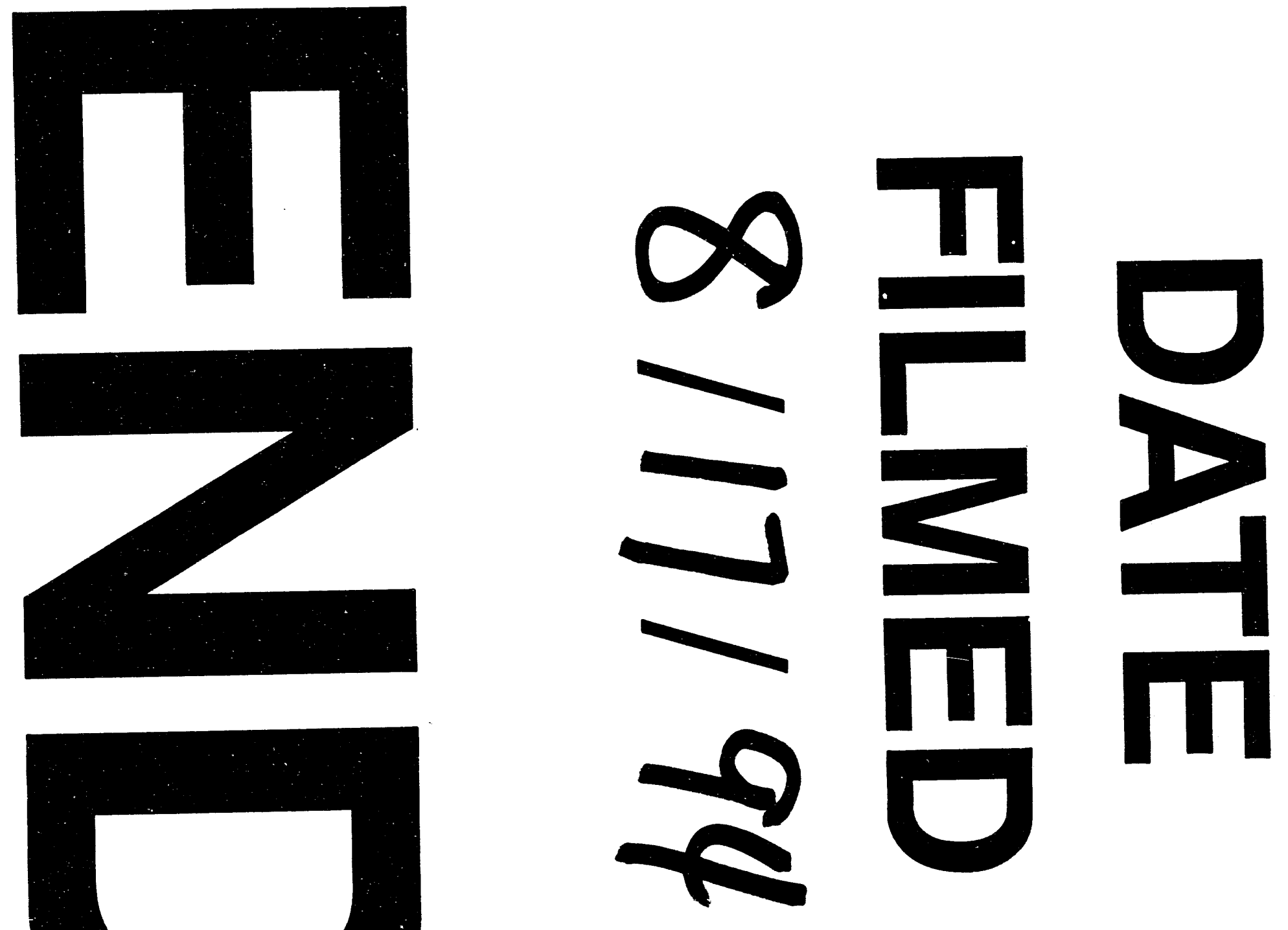


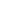

